Portland State University

PDXScholar

$1-1-2012$

\title{
Biological Treatment of Leachates of Microaerobic Fermentation
}

Manar Arica Alattar

Portland State University

Follow this and additional works at: https://pdxscholar.library.pdx.edu/open_access_etds Let us know how access to this document benefits you.

Recommended Citation

Alattar, Manar Arica, "Biological Treatment of Leachates of Microaerobic Fermentation" (2012).

Dissertations and Theses. Paper 905.

https://doi.org/10.15760/etd.905

This Thesis is brought to you for free and open access. It has been accepted for inclusion in Dissertations and Theses by an authorized administrator of PDXScholar. Please contact us if we can make this document more accessible: pdxscholar@pdx.edu. 
Biological Treatment of Leachates of Microaerobic Fermentation

\title{
by
}

Manar Arica Alattar

A thesis submitted in partial fulfillment of the requirements for the degree of

\author{
Master of Science \\ in \\ Biology
}

\section{Thesis Committee: \\ Radu Popa, Chair \\ Pamela Yeh \\ Elise Granek \\ Terrance Green}

\section{Portland State University}

(C)2012 


\begin{abstract}
Microaerobic fermentation (MF) is a process of controlled degradation of organic waste material that occurs in enclosed fermentors under micro-aerobic conditions at near-room temperature. MF processing of vegetal materials progresses to endpoints in about 2-5 weeks. During MF processing, an acidic leachate rich in organic acids and alcohols is produced. The research presented in this thesis focuses on the efficiency of MF preprocessing of feedstock containing fibrous lignocellulosic (FLC) materials; efficiency of microbial and insect larvae-based treatments of MF leachate; tolerance of the Black Soldier fly larvae (BSFL) to various biological inhibitors common in leachate; and effectiveness of using MF and BSFL solid and liquid processing products as agricultural fertilizers. Results indicate that MF is unsuitable for pre-processing of FLC materials. Enhanced MF leachate treatment may increase efficiency of FLC processing though. Leachate can be efficiently treated using BSFL which decrease overall leachate toxicity. BSFL are able to tolerate increased levels of many of the biological inhibitors within the leachate including ethanol, acetate, $\mathrm{pH}$ extremes and temperature. MF solid residues increased corn plant growth when amended into soil, but residues resulting from BSFL processing of solid organics stunted corn plant growth. Short-term phytotoxicity of MF leachate was eliminated by diluting it 10 - 10,000 times or through BSFL processing. It can be concluded that MF processing of organics is beneficial for producing solid soil amendments from non-FLC materials and that dilution or BSFL treatment of MF leachate leads to a beneficial liquid fertilizer.
\end{abstract}




\section{Dedication}

$\sim$ O Allah, teach me that which is beneficial to me and benefit me and others with that which you teach me. Ameen.

I dedicate this work to my loving parents:

Amy Benfield and Osama Alattar.

You were my best advisors, counselors, mentors, and friends during every moment of my journey. May Allah bless you with many years of love, happiness and success. 


\section{Acknowledgements}

I would like to thank Dr. Radu Popa, Dr. Terrence Green, the three graduate students in my lab and my friends, professors, colleagues and students for their constant support on the presented projects and research endeavors.

This work was supported financially by a sustainability initiative grant from the Miller Foundation at Portland State University (PSU), by a grant from the PSU Graduate School's Office of Research and Sponsored Projects, by a grant from the PSU Institute for Sustainable Solutions, by Terrence Green Corporations, LLC and by Bokashicycle LLC. 


\section{Table of Contents}

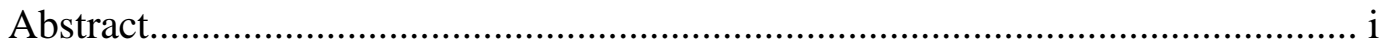

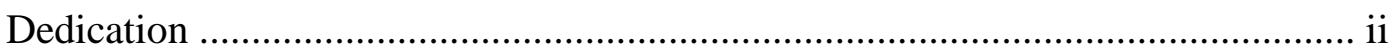

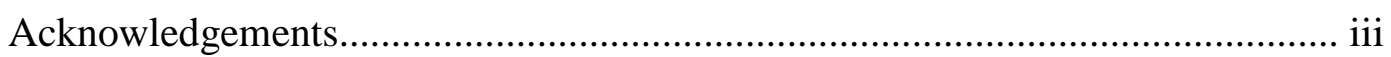

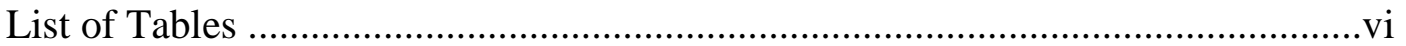

List of Figures ......................................................................................... vii

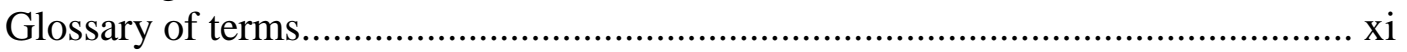

\section{Chapter 1}

Introduction.

Overview of composting

- Societal and global importance of recycling of organic waste

- Define, reasons, most common techniques and performances

Micro-aerobic fermentation (MF)

- Benefits and limitations of traditional composting

- MF description

Integrated Micro-aerobic Fermentation (IF)

- Limitations to MF

- Integration of leachate processing with MF ( $\rightarrow$ IF)

- IF description

The place of Black Soldier fly larvae (BSFL) in IF

- Description of BSFL

- Merits of use

- Uses in organic waste reduction, biofuel production and livestock feed

- Preliminary BSFL leachate processing data

Goals and Objectives

- Analyze performance of MF pre-processing of FLC materials

- Analyze Hermetia module of IF

○ Leachate treatment

- Competition between fungi and BSFL

- Effects of acids, alcohols, $\mathrm{pH}$ and temperature on BSFL growth

- Effects of MF and BSFL solid residue and leachate on plant growth

\section{Chapter 2}

The efficiency of processing fibrous lignocellulosic materials to the endpoint of microaerobic fermentation for the purpose of soil amendment.

(Journal article; accepted)

\section{Chapter 3}

Treatment of MF leachate and fungal competition during processing .25 
Overview of leachate microbial community

- Benefits of microbial activity to leachate processing

- Effects of microbial activity to BSFL growth

Methods and Results

- Microbial treatment of MF leachate

- BSFL processing of leachate

Conclusions

- Competition between BSFL and fungi in MF leachate

\section{Chapter 4}

Tolerance of BSFL (Hermetia illucens) to ethanol, acetic acid, $\mathrm{pH}$ and

temperature....

(Journal article; writing)

\section{Chapter 5}

Effects of various compost residues and leachates on growth of corn and winter wheat.....

Overview of benefits of compost fertilizers on soil and plant growth

- Specific benefits of various types of composting

Methods

- Effects of solid residue on corn plants

- Effects of leachate on winter wheat

Results

- Effects of compost products on corn plant growth

$\circ$ Height/leaf growth

$\circ$ Soil $\mathrm{pH}$ and ammonium

- Effects of leachate on winter wheat

○ Total leaf biomass

Conclusions

\section{Chapter 6}

Overall conclusions

References. 


\section{List of Tables}

Table 2.1. Setup of MF fermentors based on starting abundance of produce relative to FLC and treatment of leachate.

Table 3.1. Leachate VOA and alcohol concentrations before and after 2 days of BSFL treatment. 


\section{List of Figures}

\section{Chapter 1}

Figure 1.1. The basic layout and functioning of an MF fermentor. Organic residues are held in the main incubation reservoir and leachate is continuously drained. Liquid (water or treated leachate) is periodically added to maintain high moisture levels and reintroduce mineral nutrients. Conditions inside the fermentor are micro-aerobic, moist, acidic, and near room temperature.

Figure 1.2. Diagram of the integrated micro-aerobic fermentation (IF) system which collects the MF leachate from the MF fermentor and directs it through a series of modules for insect-based, microbial/chemical- and phyto- processing. The processed liquid is then re-circulated into the original MF fermentor.

Figure 1.3. BSF egg clutch on the underside of a compost container (A); BSFL in earlier stage (white) and final pupating stage (black) of development (B); adult BSF (C).

\section{Chapter 2}

Figure 2.1. The basic scheme and functioning of an MF fermentor. Compost leachate is continuously drained. Liquid (water or treated leachate) is periodically added to maintain a high moisture level and reintroduce mineral nutrients. Conditions inside the fermentor are micro-aerobic, moist, and acidic.

Figure 2.2. The effect of fermentate composition and leachate treatment on $\mathrm{pH}$ of the leachate. Evolution of the $\mathrm{pH}$ in the fermentors: A) leachate continuously eliminated; B) leachate returned un-aerated to the fermentors; and $\mathrm{C}$ ) leachate aerated for three days then returned to the fermentor. The labels (A1, A2, A3; B1, B2 ... etc.) are explained in Table 1.

Figure 2.3. The change in $\mathrm{O}_{2}$ concentration in the headspace of the MF fermentors based on: A) fermentate composition; and B) leachate treatment.

Figure 2.4. The evolution of $\mathrm{CO}_{2}$ in the headspace of the MF fermentors based on: A) fermentate composition; and B) leachate treatment.

Figure 2.5. The fermentation: respiration ratios (F: R) for: A) leachate treatments; and B) produce amendments. The values given are based on total amounts of $\mathrm{O}_{2}$ consumed and $\mathrm{CO}_{2}$ produced during five weeks of experiment and are averages of the three fermentors from each series. Error bars represent \pm 1 standard deviation. 
Figure 2.6. Evolution of: ethanol ( $\bullet$ ); acetic acid ( $\boldsymbol{\Delta})$; and butyric acid ( $\mathbf{\square})$ in all fermentors.

Figure 2.7. PS content in the leachate in relation to: A) produce amendment; and B) leachate treatment. The labels (Leachate el, Leachate an, and Leachate ar) are explained in Table 1.

Figure 2.8. Evolution of BOD in leachate relative to: A) produce amendments; and B) leachate treatment.

Figure 2.9. PS degradation in soil in relation to: A) produce amendment; and B) leachate treatment with FLC material relative to unfermented FLC material (Wood C) and control soil (Soil C). PS evolution in soil was similar in all treatments.

\section{Chapter 3}

Figure 3.1. Evolution of pH (A), COD (B) and BOD (C) in oxic, anoxic and 12 hour alternate (oxic/anoxic) microbial treatments of MF leachate.

Figure 3.2. Compared to unprocessed MF leachate (A), BSFL treatment results in a darker, more thoroughly processed leachate (B). (Aerial view).

Figure 3.3. Evolution of $\mathrm{pH}(\mathrm{A}), \mathrm{COD}(\mathrm{B})$ and $\mathrm{BOD}(\mathrm{C})$ in relation to concentration of larvae in leachate treatments. (Treatments represented in legend had 0 larvae $(\mathbf{A})$, $0.005 \mathrm{~g} / \mathrm{ml}(\mathbf{B}), 0.05 \mathrm{~g} / \mathrm{ml}(\mathbf{C}), 0.25 \mathrm{~g} / \mathrm{ml}(\mathbf{D})$, or $0.5 \mathrm{~g} / \mathrm{ml}$ (E) of larval concentrations.)

Figure 3.4. Larvae excrete partially digested plant waste (A; top left area) and compacted beaded materials (B, cracked ovoid object), or frass, into the leachate as they process it. (1000x magnification)

Figure 3.5. Acids and alcohols removed by BSFL (Popa and Green, 2012). "Et" = ethanol; "nP"=n-Propanol; "Ac" = acetic acid; "Pr" = Propanoic acid; "Bu" = Butyric acid; "Is" = Isovaleric acid.

Figure 3.6. Changes in protein (A) and carbohydrate (B) content in MF leachate due to larval processing. (Green, 2011 unpublished)

Figure 3.7: $E$. coli growth in various concentrations of BSFL excreta (in shades of blue) and MF leachate (in shades of green) compared to E. coli grown in sterile water $(-)$ ) and a TSB/saline control $(\rightarrow)$.

Figure 3.8. Effects of fungal biomass (FB) and fungal leachate (FL) on percent larval growth compared to controls with only MF leachate $(\mathbf{M F})$ and water $\left(\mathbf{H}_{2} \mathbf{O}\right)$. Data significant within \pm 1 standard deviation. 
Figure 3.9: Effects of fungal leachate (FL), MF leachate (MF), or fungal biomass (FB) with either water $(\mathbf{H 2 O})$ or nutrient media $(\mathbf{M})$ on percent larval growth.

\section{Chapter 4}

Figure 4.1. Tilted tube set-up exposes larvae to chemical or condition of interest as they feed on nutrients in the liquid, while allowing them to crawl in and out of the solution to breathe.

Figure 4.2: Percent larval wet weight (WW) growth after two days of incubation in up to $5 \%$ ethanol. WW growth is not significantly affected until $3.75 \%$. Error bars represent \pm 1 standard deviation.

Figure 4.3: Larval growth and death rates after two days of incubation in solutions of varying acetate concentrations.

Figure 4.4: Larval growth and death rates after two days of incubation in solutions of LB with amended $\mathrm{pHs}$.

Figure 4.5: Larval growth and death rates after two days of incubation at various temperatures.

Figure 4.6: Larval developmental categories based on color and density relative to water. Small (A; 8-18 mm) and large $(\mathrm{B} ; 20-25 \mathrm{~mm})$ white/grey floaters developed and grew, but brown floaters (C) and white/grey sinkers (D) were near pupating stage and no longer grew.

\section{Chapter 5}

Figure 5.1: Aerobic compost bin (A), MF fermentor (B), BSFL processing bin (same container type used for earthworm vermicompost) $(\mathrm{C})$.

Figure 5.2: Evolution of growth of height over time (A) and as a percentage over the duration of the experiment (B) in compost treatments: Aerobic (A), MF and BSFL residue (BSFL) compared to control dirt (D) and Cedar Grove compost (CG).

Figure 5.3: Evolution of leaf growth (A) and percent overall growth of leaves (B) over the duration of the experiment in compost treatments: Aerobic (A), MF and BSFL residue (BSFL) compared to control dirt (D) and Cedar Grove compost (CG).

Figure 5.4: Ammonium concentrations in unmixed compost (compost), initial compost/dirt mixtures (Mixture initial) and final compost/dirt mixtures (Mixture final) from different treatments and controls: Aerobic (A), MF and BSFL residue (BSFL) compared to control dirt (D) and Cedar Grove compost (CG). 
Figure 5.5: Winter wheat growth in water controls compared to dilution series of MF leachate (A) and dilution series of BSFL processed leachate (B) (Photo by Terrence Green, 2012).

Figure 5.6: Average total winter wheat plant weight in relation to leachate treatment. (Bars are color-coded by the color of the original liquid used for fertilizing: water - blue; MF leachate - tan; BSFL leachate - dark brown.) 


\section{Glossary of Scientific Abbreviations}

\begin{tabular}{|c|c|}
\hline $\mathrm{ADH}$ & Alcohol dehydrogenase \\
\hline An & Anaerobic \\
\hline Ar & Aerobic \\
\hline BSF & Black Soldier fly \\
\hline BSFL & Black Soldier fly larvae \\
\hline BOD & Biological oxygen demand \\
\hline $\mathrm{C}$ & Carbon \\
\hline CG & Cedar Grove (compost) \\
\hline $\mathrm{CO}_{2}$ & Carbon dioxide \\
\hline COD & Chemical oxygen demand \\
\hline $\mathrm{D}$ & Dirt \\
\hline $\mathrm{El}$ & Eliminated \\
\hline EPF & End-point fragmentation \\
\hline $\mathrm{F}$ & Fermentation \\
\hline FB & Fungal biomass \\
\hline FL & Fungal leachate \\
\hline FLC & Fibrous lignocellulosic \\
\hline GC & Gas chromatography \\
\hline GHG & Greenhouse gas \\
\hline ha & Hectare \\
\hline IF & Integrated micro-aerobic fermentation \\
\hline $\mathrm{Kg}$ & Kilogram \\
\hline LB & Luria broth \\
\hline M & Media (1 g/100ml yeast, $10 \mathrm{~g} / 100 \mathrm{ml}$ glucose $)$ \\
\hline $\mathrm{MF}$ & Micro-aerobic fermentation \\
\hline MSW & Municipal solid waste \\
\hline $\mathrm{N}$ & Nitrogen \\
\hline $\mathrm{N}_{2} \mathrm{O}$ & Nitrous oxide \\
\hline $\mathrm{P}$ & Phosphorous \\
\hline PS & Polysaccharide \\
\hline PSU & Portland State University \\
\hline $\mathrm{R}$ & Respiration \\
\hline TSA & Trypticase soy agar \\
\hline TSB & Trypticase soy broth \\
\hline VOA & Volatile organic acid \\
\hline WW & Wet weight \\
\hline
\end{tabular}




\section{Chapter 1:}

\section{Introduction}

Processes of controlled degradation of organic waste matter, often referred to as composting, are important contributors to the recycling of nutrients, waste processing, soil structure, and carbon sequestration. Recyclable organic waste from municipal solid waste (MSW) represents approximately $65 \%$ or 250 million tons of the annual waste stream in the United States (EPA, 2011). Therefore, processes that allow for the collection and reuse (often as fertilizer) of this material can decrease the emissions of greenhouse gases (GHG) and the need for increased landfills and increase efficiency of organic matter reuse (Eitzer, 1995). Compost can be used to sequester carbon (C) and other essential nutrients into soil and improve soil fertility in the long and short term, thus increasing agricultural productivity (Diacono et al. 2010; Ros et al., 2006; Meier-Ploeger et al., 1989; Marchesini et al. 1988).

A variety of composting techniques exist. They include forced-aeration composting, vermicomposting, and anaerobic digestion. Of these, forced-aeration composting is the most prevalent (in its various forms) and used in about $85 \%$ of all composting facilities in the United States (BioCycle, 2008). Forced-aeration processing techniques tend to require minimal matter displacement and low energy input, and produce fiber- and nutrient-rich compost fertilizer. Drawbacks of aerate composting include loss of about $30 \%$ to $50 \%$ of $\mathrm{C}$ into the atmosphere in the form of carbon dioxide $\left(\mathrm{CO}_{2}\right)$; lengthy processing time (6-12 months); and odor and dust issues (Breitenbeck and Schellinger, 2004; Brown et al., 1998). It also has a large GHG 
footprint due to substantial emissions of methane $\left(\mathrm{CH}_{4}\right)$ and nitrous oxide $\left(\mathrm{N}_{2} \mathrm{O}\right)$, GHGs more potent than $\mathrm{CO}_{2}$ (Hellmann, 1997; Eitzer, 1995).

A process called micro-aerobic fermentation $(\mathrm{MF})$, has been proposed as an alternative to aerated composting (Maso and Blasi, 2008; Bhattarai, 2006; Pontin et al., 2002). MF is a vegetal degradation biotechnology analogous to silage, occurring in enclosed fermentors at near room temperature under low oxygen conditions $(0.5-2 \%)$ (Fig 1.1). MF has shorter incubation time, lower GHG emissions, higher $\mathrm{C}$ recycling and better $\mathrm{N}$ management potential compared to aerated composting (Maso and Blasi, 2008; Bhattarai, 2006; Pontin et al., 2002). When fermenting vegetal material and food waste, MF processing occurs in about 2-5 weeks (Maso and Blasi, 2008; Bhattarai, 2006; MataAlvarez, 2000). Relative to aerobic composting, $\mathrm{MF}$ has $25-67 \%$ lower $\mathrm{CO}_{2}$ emission, depending on the feedstock used and specifics of the technique (Mata-Alvarez, 2000). Overall, MF has also been reported as user friendly, especially for small-scale waste processing operations (Pontin, et al., 2002). MF treated vegetal products have the appearance and odor of pickled vegetables (Green, 2009). Whether the short duration of MF is sufficient to degrade fibrous lignocellulosic (FLC) to an adequate level has not yet been studied.

The degree of degradation of MF materials after fermentation is not as advanced as traditional compost, which is sufficiently mineralized to be stored and spread atop the soil. Therefore, MF materials must be immediately buried in the soil, where a second stage of processing (and stabilization) occurs. This stabilization stage is an essential part of the process, because it allows for further degradation and incorporation of nutrients 
into the soil. The fact that MF products are used as underground fertilizers allows increased moisture and nutrient retention, minimizes risk of attracting rodent pests, discourages fungal growth and keeps aerobic decomposition low. Research indicates that amendment of soil with MF increases soil quality and plant productivity, although such data remains limited in the scientific literature (Perez et al., 2008; Rezende et al., 2008; Bhattarai, 2006; Nishio, 1996).

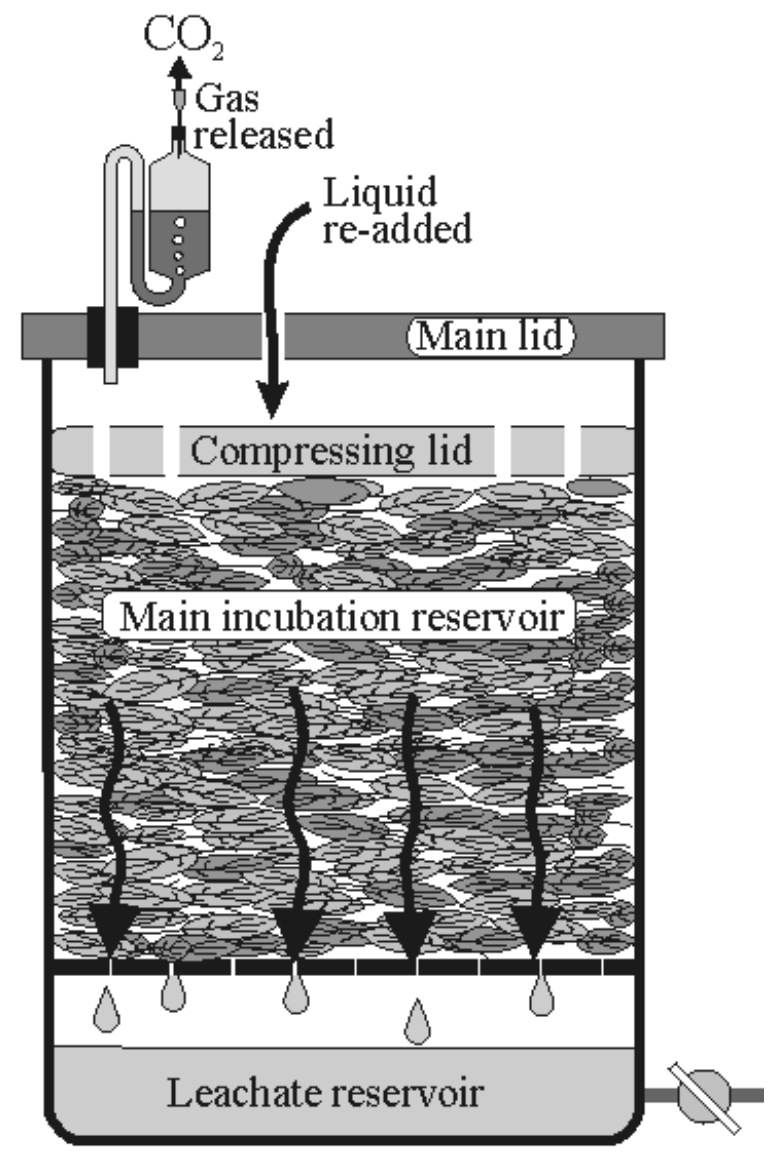

Figure 1.1. The basic layout and functioning of an MF fermentor. Organic residues are held in the main incubation reservoir and leachate is continuously drained. Liquid (water or treated leachate) is periodically added to maintain high moisture levels and reintroduce mineral nutrients. Conditions inside the fermentor are micro-aerobic, moist, acidic, and near room temperature.

MF is dominated by fermentation processes which release organic alcohols, acids and other small metabolites, resulting in leachates characterized by low $\mathrm{pH}$. The 
accumulation of such organics eventually leads to inhibition of microbial activity. Common fermentation byproducts such as ethanol, butyric acid and acetic acid inhibit microbial activity at about $1-2 \%, 2.2-2.3 \%$ and $0.1-0.2 \%$ respectively (Najafpour and Lim, 2002; Savarda et al., 2002; Maddox, 2000; Osman and Ingram, 1985; Aiba et al., 1968). Thus, one drawback of MF is the production of fermentation leachate, which must be drained from fermentors. Processed leachate or freshwater are re-added to fermentors to reestablish moisture levels, introduce mineral nutrients and allow the flow of some $\mathrm{O}_{2}$ through the system. As easily degradable organic materials become depleted, fermentation eventually slows down and a fermentation endpoint is reached. This is interpreted as an endpoint of the fermentor-based stage. This research focuses on the treatment and utilization of fermentation leachates.

Leachates are traditionally processed through a variety of treatments methods. In small-scale garden and farm operations leachates are diluted (10-10,000 times) and used as liquid fertilizers, because they have high organic content, and are particularly rich in organic acids and alcohols, nitrate and other metabolites (Cumar and Nagaraja, 2011). At a larger scale, leachate is traditionally collected in aeration lagoons for stabilization before further treatment or use (CED, 2010; Mehmood, 2009). In some cases, untreated leachate is collected and recirculated into the organic waste processors (CED 2010), but this often leads to increased concentration of toxins and further microbial inhibition. 


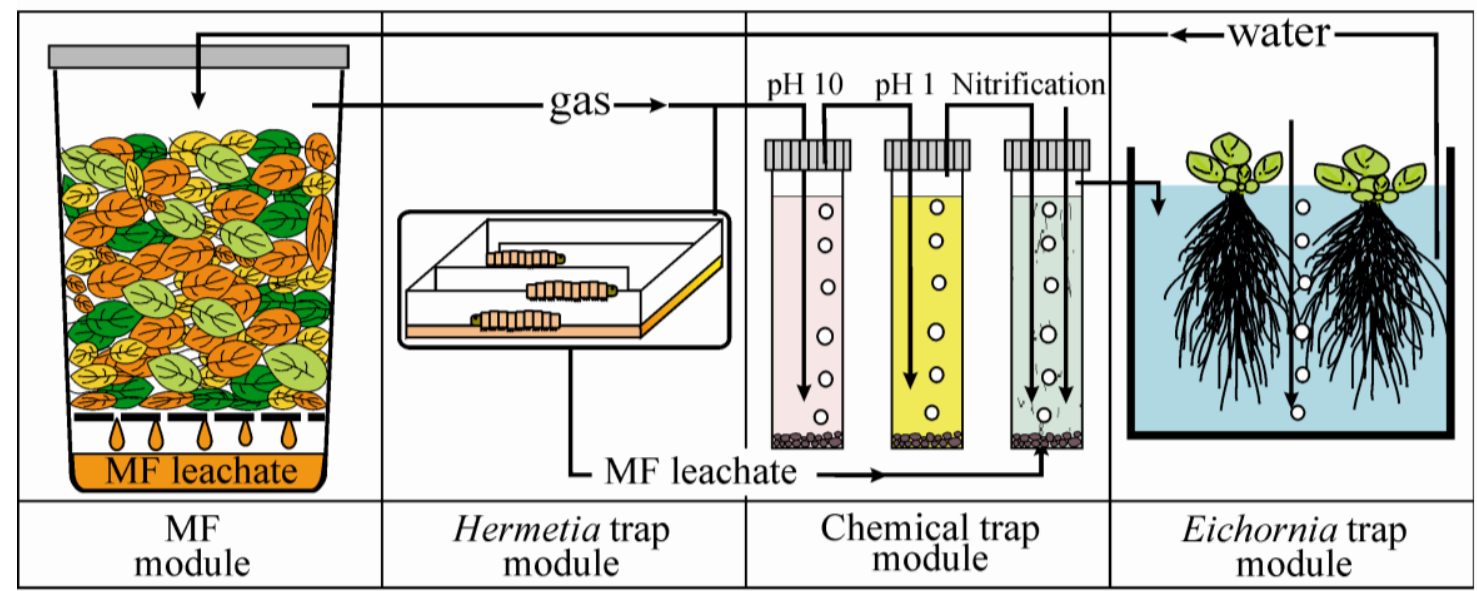

Figure 1.2. Diagram of the integrated micro-aerobic fermentation (IF) system which collects the MF leachate from the MF fermentor and directs it through a series of modules for insect-based, microbial/chemical- and phyto- processing. The processed liquid is then re-circulated into the original MF fermentor.

Most work presented in this thesis is based on a modified MF process called integrated micro-aerobic fermentation (IF), developed at Portland State University (PSU). The IF process combines biological and chemical treatments in a series of leachate processing modules (Fig 1.2). Leachate produced in the MF fermentor first enters into an insect-processing module. The IF from PSU uses Black Soldier fly larvae (BSFL; Hermetia illucens). In the Hermetia module a significant amount of small metabolites (amines, alcohols and carboxylic acids) are removed from the leachate and its acidic $\mathrm{pH}$ is neutralized (Popa and Green, 2012). The second module includes a series of microbial and chemical gas traps, which scrub leachate and headspace of the GHGs $\mathrm{CO}_{2}$ and $\mathrm{N}_{2} \mathrm{O}$, and remove odoriferous organic amines. The partially treated liquid then moves to a final phyto-processing module, a water-plant based macrocosm using Eichornia plants, where processing of leachates continues. The chemical oxygen demand (COD), biological oxygen demand (BOD) and nitrogen $(\mathrm{N})$ content are decreased. The research presented here focuses on MF fermentation and the efficiency of the Hermetia module. 
Black Soldier flies (BSF) are Diptera from the family Stratiomyidae, common in temperate and tropical habitats (Tomberlin, 2009; Beckemeyer, 2008). BSFs are most common in the southeastern United States, but can be found throughout the country (Diclaro and Kaufman, 2009; Newton et al., 2005; Sheppard et al., 2002). BSFs spend their larval stage eating and growing on decaying organic materials, which they digest with the assistance of their diverse microbial gut communities (Jeon et al., 2011; Diclaro and Kaufman, 2009). Larvae progress through six developmental stages (instars) in about $14-40$ days depending on food abundance and growth conditions, but this process may be prolonged to up to 4 months if food is scarce (Myers et al., 2008; Hall and Gerhardt, 2002). In the final instar, larvae cease to eat, and they move out of the organic matter to drier areas to pupate (Hall and Gerhardt, 2002). BSFL remain in the pupae stage for about two weeks before emerging as adults to mate (Diclaro and Kaufman, 2009; Hall and Gerhardt, 2002). Adult BSFs live approximately 9 - 13 days, depending on the amount and quality of food ingested during the larval stage (Myers et al. 2008). Adults, who do not have functional digestive systems, drink water but do not eat and are therefore not known to transmit communicable diseases to humans (Diclaro and Kaufman, 2009; Sheppard et al., 2002). Mating behavior (lekking) occurs when adults are given area to disperse from the pupating site, access to sunlight, and temperatures around $22{ }^{\circ} \mathrm{C}$ to $27{ }^{\circ} \mathrm{C}$ (Sheppard et al., 2002; Tomberlin and Sheppard, 2002). Optimal conditions for oviposition include temperatures between $24{ }^{\circ} \mathrm{C}$ to $27{ }^{\circ} \mathrm{C}$ and humidity above $60 \%$ (Tomberlin and Sheppard, 2002). A female BSF will lay a clutch of 100-500 eggs which hatch in 4 - 9 days (Diclaro and Kaufman, 2009; Sheppard et al., 2002). 

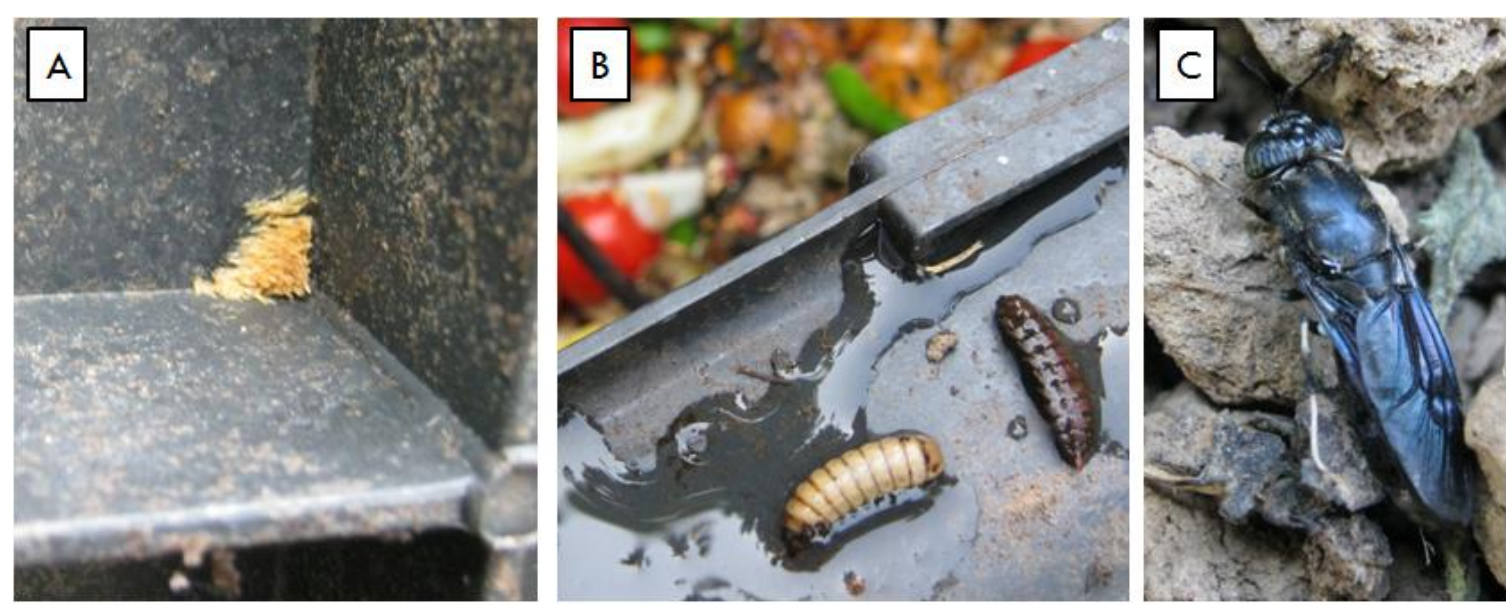

Figure 1.3. BSF egg clutch on the underside of a compost container (A); BSFL in earlier stage (white) and final pupating stage (black) of development (B); adult BSF (C).

Due to their high protein $(\sim 40 \%)$ and fat $(\sim 30 \%)$ content BSFL are used as feed or feed supplement for fish, poultry, reptiles, swine and other pets and livestock (Jeon et al., 2011; Sealey et al., 2011; St-Hilaire et al., 2007). They have also been used for bioconversion of organic matter into biofuel (Li et al., 2010; EcoSystem Corp., 2009). Studies show that BSFL biofuel is comparable to biofuel produced from rapeseeds (Li et $a l, 2010)$.

BSFs are common natural or artificially-introduced inhabitants of vegetal waste and manure piles (Morales and Wolff, 2010; Sheppard et al., 2002). Their activity reduces manure's dry weight (by $42-56 \%$ ) and unpleasant odor (Jeon et al., 2011; Sheppard et al., 2002). BSFL growth suppresses housefly (Musca domestica L.) populations and the populations of some bacterial pathogens (E. coli and Salmonela) in manure and composts piles (Liu et al., 2008; St-Hilaire et al., 2007; Erickson et al., 2004; Bradley and Sheppard, 1984). Due to their unique characteristics and uses in waste 
management BSFL were selected for further analysis of MF leachate detoxification in the IF system developed at PSU.

Preliminary data show that BSFL are capable of significantly decreasing concentrations of organic alcohols, acids, and proteins while processing MF leachate (Green and Popa, 2012). The larvae are also able to alter the $\mathrm{pH}, \mathrm{COD}$ and BOD of the MF leachate.

\section{Objectives}

The work presented in this thesis has four main goals. First, the research described the biochemical evolution of MF during processing of FLC-rich feedstocks. Secondly, the efficiency of microbial and BSFL leachate treatments on the evolution of $\mathrm{pH}, \mathrm{COD}$ and BOD in MF leachate was analyzed. Thirdly, the tolerance of BSFL to biological inhibitors common in leachate was determined. Finally, BSFL and MF solid residues and liquid leachates were amended into soil and effects on corn and winter wheat plants were monitored. 


\section{Chapter 2:}

The efficiency of processing fibrous lignocellulosic materials to the endpoint of microaerobic fermentation for the purpose of soil amendment

Short title: Microaerobic fermentation of fibrous lignocellulosic material

Authors: Manar Arica Alattar ${ }^{1}$, Terrence R. Green ${ }^{2}$, Jordan Henry ${ }^{1}$, Vitalie Gulca ${ }^{3}$, Mikias Tizazu ${ }^{1}$, Robby Bergstrom ${ }^{1}$, Radu Popa ${ }^{1}$

${ }^{1}$ Biology Department, Portland State University, Portland, OR, USA.

${ }^{2}$ TGA LLC, 13851 Verte Court, Lake Oswego, OR, 97034,USA. greent@spiretech.com

${ }^{3}$ State Agricultural University, Moldova. vitalie.gulca@ gmail.com

Correspondence author: Radu Popa, P.O. Box 751, Biology Department, Portland State University, Portland, OR, 97207, USA. Phone: (503) 725-9503. Email: rpopa@pdx.edu.

Submitted (Dec 2011) to: Journal of Applied Biochemistry and Biotechnology

Accepted for publication February 2012 


\begin{abstract}
Amending soil with organic matter is common in agricultural and logging practices. Such amendments have benefits to soil fertility and crop yields. These benefits may be increased if material is pre-processed before introduction into soil. We analyzed the efficiency of microaerobic fermentation (MF), also referred to as Bokashi, in preprocessing fibrous lignocellulosic (FLC) organic materials with varying produce amendments and leachate treatments. Adding produce amendments increased leachate production and fermentation rates, and decreased the biological oxygen demand (BOD) of the leachate. Continuously draining leachate without returning it to the fermentors led to acidification and decreased concentrations of polysaccharides (PS) in leachates. PS fragmentation and production of soluble metabolites and gases stabilized in fermentors in about 2 - 4 weeks. About $2 \%$ of the carbon content was lost as $\mathrm{CO}_{2}$. PS degradation rates, upon introduction of processed materials into soil, were similar to unfermented FLC. Our results indicate that MF is insufficient for adequate pre-processing of FLC material.
\end{abstract}

Keywords: lignocellulose; microaerobic fermentation; Bokashi; polysaccharides; carbon recycling; soil fertilizers. 


\section{Introduction}

Adding fibrous lignocellulosic (FLC) materials into soil improves carbon (C) sequestration and the recycling of macro- and micro-nutrients. It also improves soil properties, increases biomass and diversity of soil biota, suppresses weed growth and stabilizes pH (Butterly et al., 2011; Campiglia et al., 2011; Holye and Murphy, 2011; Kumar et al., 2011; Albers et al., 2006). The most thorough method of FLC preprocessing is composting, which recycles about $50 \%$ of the initial organic $\mathrm{C}$, decreases the risk of reintroducing plant pathogens and may take between six and twelve months (Hubbe et al., 2011; Zanón, 2011). The most common C sequestration and nutrientrecycling practices are tilling FLCs directly into soil or leaving them to decay on the surface, i.e. no-till practices (Holye and Murphy, 2011; Kumar et al., 2011; Tyree et al., 2011; Lee et al., 2010; Blanco-Canqui, 2004).

Lee et al. (2010) compared greenhouse gas (GHG) emissions of composting and notill disposal of logging residues, and found that composting has lower GHG emissions. On the other hand, till/no-till practices are less energy intensive (USDA, 2011), but have lesser integration of FLC into soil (Hubbe et al., 2011; Tyree et al., 2011). FLC from logging debris, can especially impede the incorporation of organics into the soil ecosystem (Hoyle and Murphy, 2011; Hubbe et al., 2011; Tyree et al., 2011). Furthermore, the lack of FLC pre-processing in till/no-till practices increases the risk of spreading plant pathogens (Zanon, 2011). 
FLC can be pre-processed by fermentation before tilling into soil, which is a common method used in non-intensive farming (Perez et al., 2008; Rezende et al., 2008; Nishio, 1996). Research indicates that the resulting product may increase the availability of FLC nutrients in soil by initiating the hydrolysis of polysaccharidic polymers prior to their introduction into soil (Green and Popa, 2011; Yan and Xu, 2002; Hussain et al., 1995). This process is a form of microaerobic fermentation (MF), sometimes referred to as Bokashi (Mayer et al., 2010; Yan and Xu, 2002). Many aspects and consequences of MF (in general), and of adding FLC into MF (in particular), are unclear, such as the degree of processing at the fermentation's endpoint, the extent of C sequestration and cellulose hydrolysis, GHG emissions and nutrient recycling potential.

MF occurs in enclosed fermentors which remain under microaerobic conditions (about $0.5-2.0 \% \mathrm{O}_{2}$ ). With vegetal materials, such as food waste, leaves and wheat bran, MF takes about 2-5 weeks (Maso and Blasi, 2008; Bhattarai, 2006). The fermentation period required for FLC has not been reported. During fermentation, a compost leachate rich in carboxylic acids, alcohols and amines, is produced and continuously drained. Liquid, in the form of water or treated leachate, must be added to the system periodically to maintain moisture levels. Qi et al. (2005) and Sans et al. (1995) reported that recirculation of leachate increased degradation of both FLC and non-FLC materials in anaerobic fermentation. We report here an analysis of various FLC:vegetal ratios and leachate treatment methods on fermentation endpoints, respiration:fermentation ratio, $\mathrm{pH}$ change, biological oxygen demand (BOD), C loss, polysaccharide (PS) hydrolysis and PS degradation rate after introduction of fermented materials into soil. 


\section{Materials and Methods}

MF treatments were set up in nine 20 liter fermentors (Bokashicycle, LLC) as in Figure

2.1. FLC consisted of shredded poplar wood twigs. Produce amendments were

composed of 50:50 wet weight mixtures of Fuji apples and cabbage. Each fermentor was started with a $4 \mathrm{~kg}$ mixture of FLC and produce, $0.8 \mathrm{~kg}$ finely ground limestone ([particle size $=10$ mesh 90\%, 100 mesh 49\%], [composition = 20\% Ca; $11 \% \mathrm{Mg} ; 50 \% \mathrm{CaCO}_{3}$; $\left.40 \% \mathrm{MgCO}_{3}\right] ;[$ Ca carbonate Eq. = 102\%]; [Oregon Lime scale = 80]) $($ Greenacres Gypsum and Lime Co.), and 1.9 L tap water. All organic materials were shredded twice with a wood chipper prior to MF.

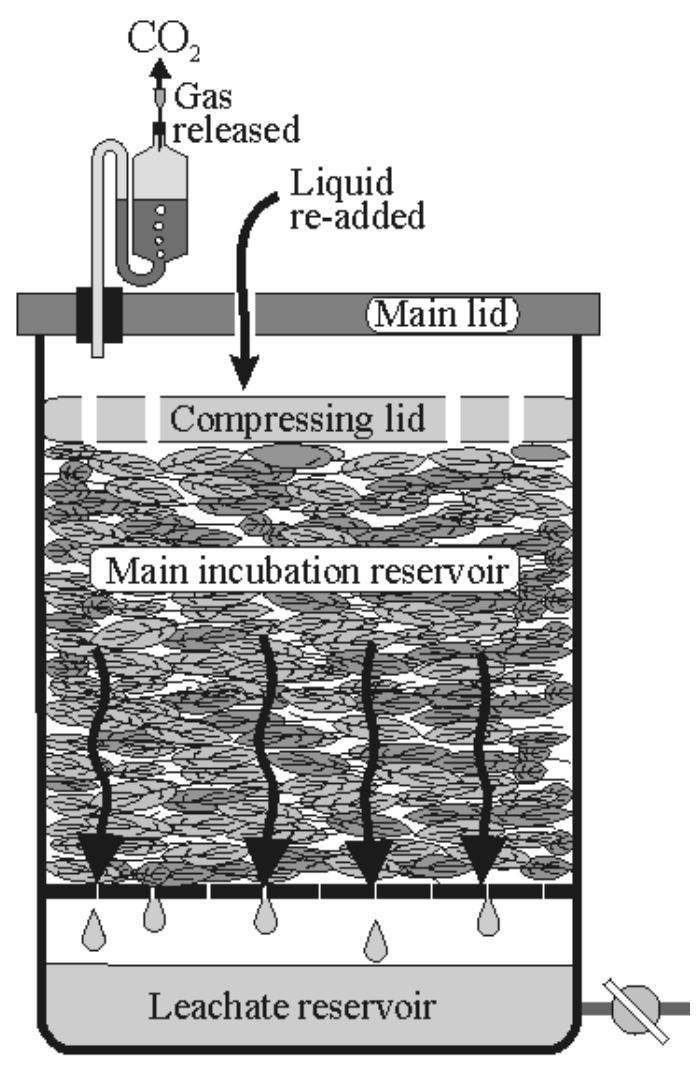

Figure 2.1. The basic scheme and functioning of an MF fermentor. Compost leachate is continuously drained. Liquid (water or treated leachate) is periodically added to maintain a high moisture level and reintroduce mineral nutrients. Conditions inside the fermentor are micro-aerobic, moist, and acidic. 
The overall experimental design was as in Table 2.1. Fermentors A1, A2, and A3 contained $4 \mathrm{~kg}$ wood chips and $0 \mathrm{~kg}$ produce $(0 \% \mathrm{w} / \mathrm{w}) ; \mathrm{B} 1, \mathrm{~B} 2$, and $\mathrm{B} 3$ contained $3.6 \mathrm{~kg}$ wood chips and $0.4 \mathrm{~kg}$ produce $(10 \% \mathrm{w} / \mathrm{w})$; and $\mathrm{C} 1, \mathrm{C} 2$, and $\mathrm{C} 3$ contained $2 \mathrm{~kg}$ wood chips and $2 \mathrm{~kg}$ produce $(50 \% \mathrm{w} / \mathrm{w})$.

\begin{tabular}{|c|c|c|c|}
\hline$\%$ produce & Leachate el & Leachate an & Leachate ar \\
\hline $0 \%$ & A1 & A2 & A3 \\
\hline $10 \%$ & B1 & B2 & B3 \\
\hline $50 \%$ & $\mathrm{C} 1$ & $\mathrm{C} 2$ & C3 \\
\hline $\begin{array}{l}\text { "Leachate el", } \\
\text { conditions for th } \\
\text { for three days, th }\end{array}$ & $\begin{array}{l}\text { then reintrodu } \\
\text { roduced into fe }\end{array}$ & $\begin{array}{l}\text { achate an", le } \\
\text { fermentor; "I } \\
\text { rs. }\end{array}$ & $\begin{array}{l}\text { ed in anaero } \\
\text { r", leachate }\end{array}$ \\
\hline
\end{tabular}

Compost leachate was collected weekly. To each fermentor series amended with 0 $\%, 10 \%$ and $50 \%$ produce, one of three leachate treatments was applied. In "Leachate el" treatments (A1, B1, C1), leachates drawn from the fermentors were used for measurements, and discarded. In "Leachate an" treatments (A2, B2, C2), leachates were stored for three days under anaerobic conditions $\left(\sim 95 \% \mathrm{~N}_{2} ; \sim 5 \% \mathrm{H}_{2}\right)$, then returned to their original fermentors. In "Leachate ar" treatments (A3, B3, C3), leachates were aerated continuously for three days with an air pump and sparger, and returned to their fermentors. Fermentors were kept at room temperature. Their lids were opened weekly for sampling and measurements. The variables followed were temperature in the room and in the fermentor, atmospheric gases in the headspace of the fermentor, water content 
of the top $2-5 \mathrm{~cm}$ of the solid residue, BOD of the solid residue and leachate, volatile organic acids (VOAs), alcohols, ketones, $\mathrm{pH}$ and leachate production. Microbial activity was monitored based on the relationship between $\mathrm{O}_{2}$ and $\mathrm{CO}_{2}$ content in the headspace of fermentors, and by tracking the formation of VOAs (acetic, propanoic, butyric, isovaleric, caproic and valeric), alcohols (ethanol, i-propanol, n-propanol, i-butanol, n-butanol and ipentanol), acetone and acetylacetone in the leachate.

For analysis of atmospheric gasses $\left(\mathrm{O}_{2}, \mathrm{~N}_{2} \mathrm{CH}_{4}, \mathrm{CO}_{2}\right)$, headspace gas was drawn through a stopper installed in each fermentor's lid using a needle guidance sampler, and injected in an SRI 310C gas chromatograph (GC) analyzer (SRI Instruments, CA, USA) equipped with Thermal Conductivity Detector (TCD) and two GC columns (3'-silica and a 6'-13X molecular sieve columns). VOAs, alcohols and ketones were monitored by GC analysis of $10 \mu \mathrm{l}$ aliquots (with 50:1 split) using a Shimadzu GC-2010 with Flame Ionization Detector (FID) on a Stabilwax-DA column (Restek, PA, USA) under the following conditions: $1.5 \mathrm{ml} \mathrm{min}{ }^{-1}$ flow rate; $250^{\circ} \mathrm{C}$ injector temperature; gradient temperature starting at $60^{\circ} \mathrm{C}, 2 \mathrm{~min}$ iso, $10{ }^{\circ} \mathrm{C}$ per minute to $240{ }^{\circ} \mathrm{C}$; and detector temperature of $260^{\circ} \mathrm{C}$. Calibrations and identifications were done by comparing retention times and peak areas against standards using PeakSimple software (ver. 3.87).

Microbial respiration (R) was estimated based on changes in $\mathrm{O}_{2}$ concentration relative to an initial concentration of $21 \% \mathrm{O}_{2}\left(\mathrm{R}=\mathrm{O}_{2 \mathrm{i}}-\mathrm{O}_{2 \mathrm{f}}\right.$ where: $\mathrm{O}_{2 \mathrm{i}}=$ percent initial $\mathrm{O}_{2}$; and $\mathrm{O}_{2 \mathrm{f}}=$ percent final $\mathrm{O}_{2}$ ). Fermentation $(\mathrm{F})$ was estimated based on the amount of $\mathrm{CO}_{2}$ not accounted for by aerobic respiration and assuming a stoichiometry of 1:1 between $\mathrm{O}_{2}$ respired and $\mathrm{CO}_{2}$ produced, consistent with aerobic respiration of carbohydrates $(\mathrm{F}=$ 
$\Delta_{\text {total }} \mathrm{CO}_{2}-\Delta_{\mathrm{R}} \mathrm{CO}_{2}$; where $\Delta_{\text {total }} \mathrm{CO}_{2}=$ change in $\mathrm{CO}_{2}$ between initial and final measurements, and $\Delta_{\mathrm{R}} \mathrm{CO}_{2}=\mathrm{CO}_{2}$ production attributed to $\mathrm{R}$ ).

PS (expressed in glucose equivalents) was measured using the phenol-sulfuric acid carbohydrate assay (Safarik and Santruckova, 1992; DuBois et al., 1956). Changes in the fragmentation state of water-insoluble acid-soluble PS were tracked using the End-point Fragmentation (EPF) index assay (Green and Popa, 2010).

The $\mathrm{pH}$ of the leachate was measured with a Thermo Orion $\mathrm{pH}$ meter model 410. The BOD of MF leachate and residue was measured using BOD bottles (Wheaton, Milville, NJ) filled with air-saturated water at $20{ }^{\circ} \mathrm{C}$. One hundred milligrams of dried and ground compost residue, or $20 \mu 1$ of compost leachate, were inserted into each bottle. The bottles were capped and incubated at room temperature for five days. The soluble $\mathrm{O}_{2}$ content was measured with an Accumet Excel XL60 dual channel pH/ion/conductivity DO meter. BOD measurements were corrected based on $\mathrm{O}_{2}$ saturated controls, temperature and atmospheric pressure. The same instrument was used to measure the temperature and salinity of the solutions. Atmospheric pressure was measured with a Traceable pressure instrument (Fisher Scientific).

MF treated feedstock was amended into soil at a greenhouse facility located at Portland State University (PSU). Soil had the general properties of a Helvetia silt loam (Green, 1982). Soil samples ( 100 g per plot) from the top $\sim 10 \mathrm{~cm}$ layer, were dried for 48 hours at $60{ }^{\circ} \mathrm{C}$, and then ground to uniformity before weighing and analysis. Soil samples were amended with MF treatment materials in a 1:1 ratio in the upper $15 \mathrm{~cm}$ 
layer and tracked for PS content and EPF index (Green and Popa, 2010). Soil pH was measured in aqueous slurries prepared from dried soil samples in a ratio of 1:25 weight/deionized water.

\section{Results and Discussion}

The temperature of our fermentors remained between $20^{\circ} \mathrm{C}$ and $24{ }^{\circ} \mathrm{C}$ for the duration of the experiment. Acidification occurred within the first three days; thereafter leachates shifted toward neutral $\mathrm{pH}$ (Fig. 2.2). Increased abundance of produce relative to FLC resulted in more acidic leachates. Elimination of leachates from the fermentors led to less acidic leachates. The trends in $\mathrm{pH}$ evolution indicate that sugars in many fermenters (Fig. 2.2) were not fully fermented after 35 days. Aeration of leachates shifted the $\mathrm{pH}$ toward more neutral values (most likely due to turnover of carboxylic acids). A similar drop in $\mathrm{pH}$ in all samples in the first week indicates that $\mathrm{pH}$ inhibition is likely an important controller of microbial activity. We infer from these results that recycling leachates through MF fermentors, and concomitant degradation of organic acids accumulating in the leachate, would enhance MF - mediated decomposition of organics. 


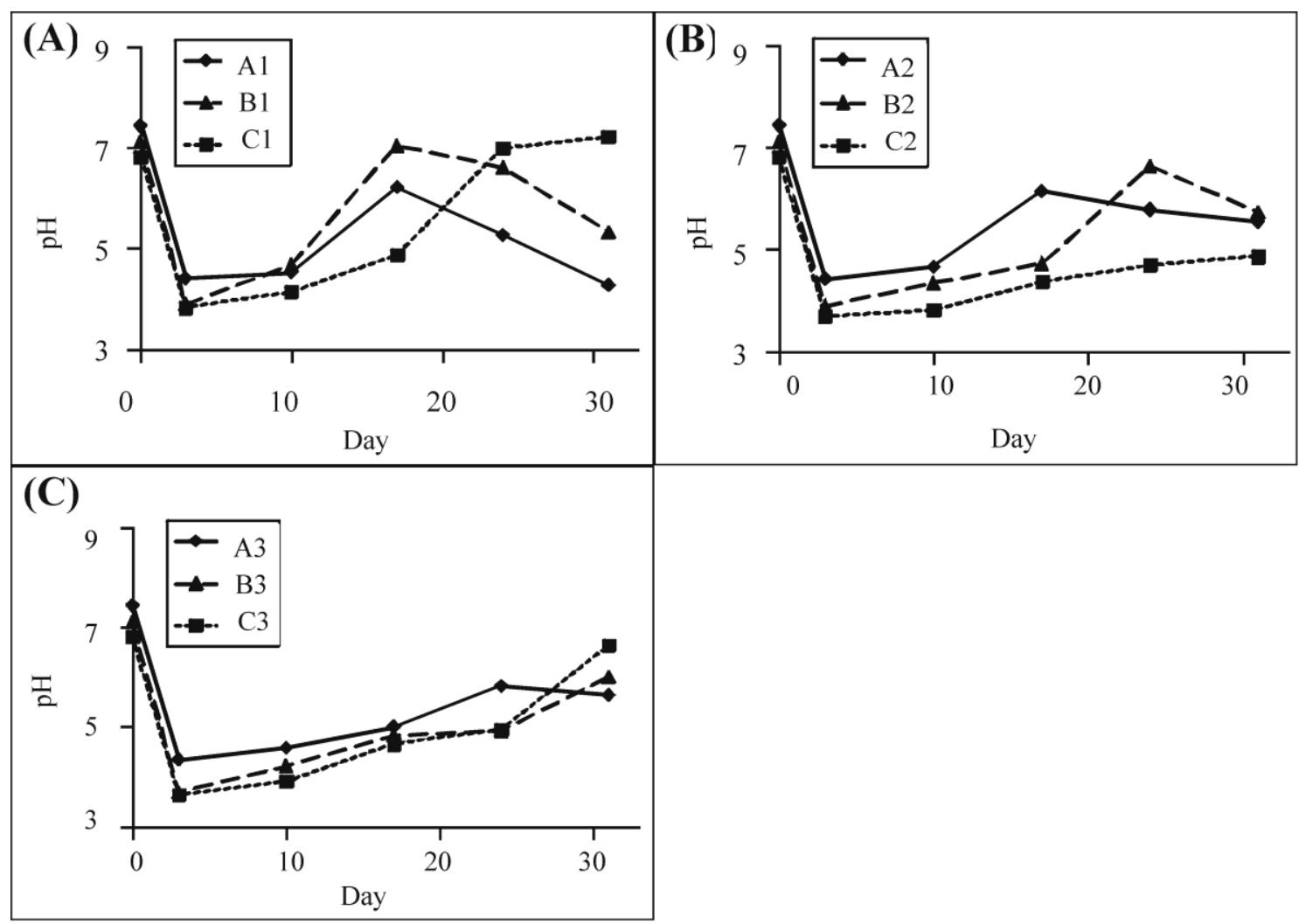

Figure 2.2. The effect of fermentate composition and leachate treatment on $\mathrm{pH}$ of the leachate. Evolution of the $\mathrm{pH}$ in the fermentors: A) leachate continuously eliminated; B) leachate returned un-aerated to the fermentors; and C) leachate aerated for three days then returned to the fermentor. The labels (A1, A2, A3; B1, B2 ... etc.) are explained in Table 1.

We observed no $\mathrm{CH}_{4}$ production. In the first week, $\mathrm{N}_{2}$ in the headspace of the MF fermentors was inversely correlated with the amount of produce amendment, but by the third week there was no significant difference. $\mathrm{N}_{2}$ in the headspace was unaffected by leachate treatments. $\mathrm{O}_{2}$ consumption decreased, leveling out at about 2 to 3 weeks (Fig. 2.3), whereas $\mathrm{CO}_{2}$ increased, reaching a plateau by the second week of fermentation (Fig. 2.4). In the first week, the $\mathrm{O}_{2}$ concentration in all of the fermentors fell to microaerobic conditions regardless of treatment. More $\mathrm{CO}_{2}$ was produced in fermentors with larger produce:FLC ratios. Based on the $\mathrm{O}_{2}$ and $\mathrm{CO}_{2}$ results, considerable amounts of biodegradable materials were still present after five weeks. Little variation occurred in 
fermentation associated with different leachate treatments, whereas the amount of produce amended with FLC material was positively correlated with the level of fermentation (Fig. 2.5).

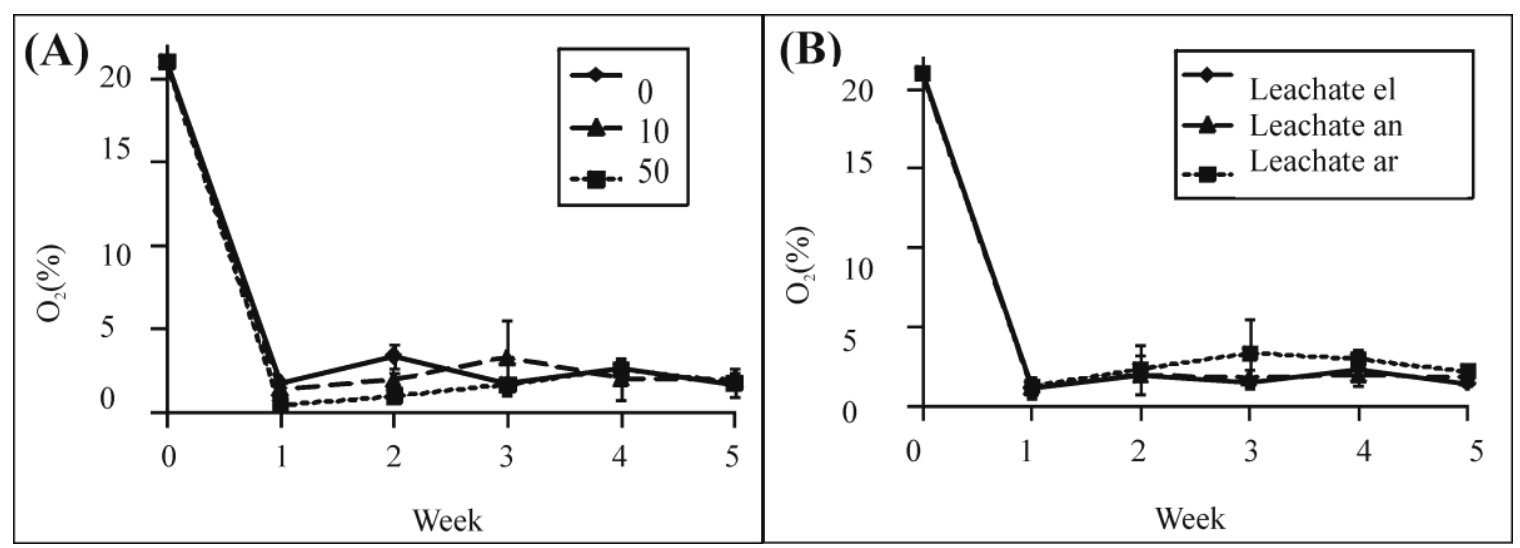

Figure 2.3. The change in $\mathrm{O}_{2}$ concentration in the headspace of the MF fermentors based on: A) fermentate composition; and B) leachate treatment.
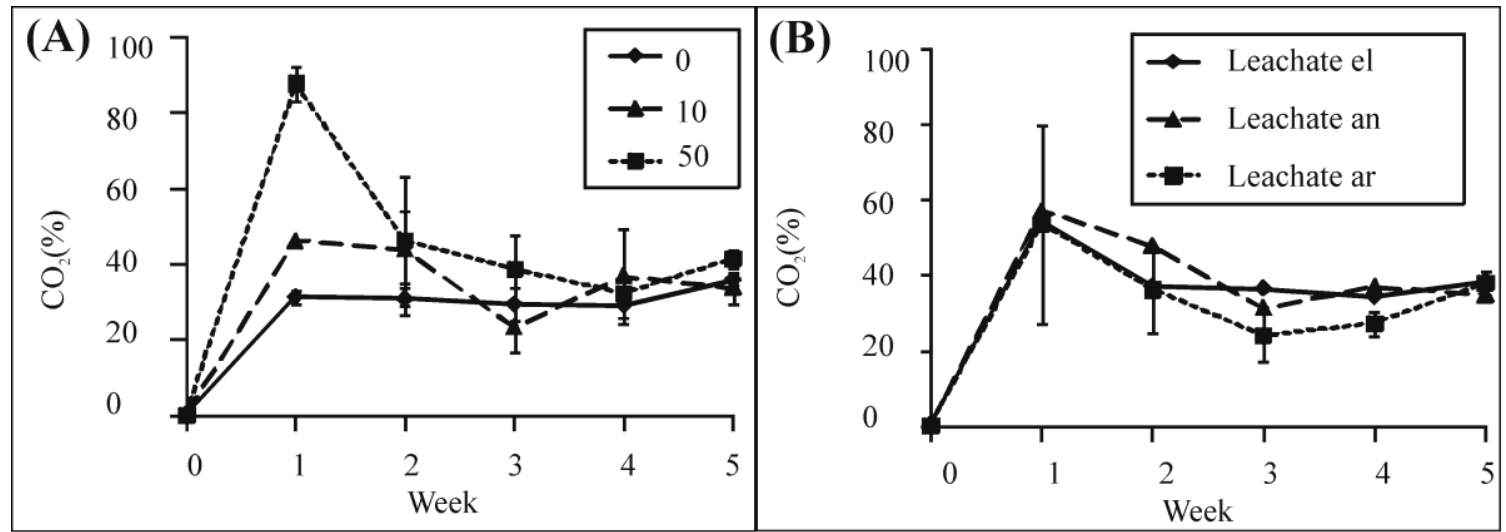

Figure 2.4. The evolution of $\mathrm{CO}_{2}$ in the headspace of the MF fermentors based on: A) fermentate composition; and B) leachate treatment. 


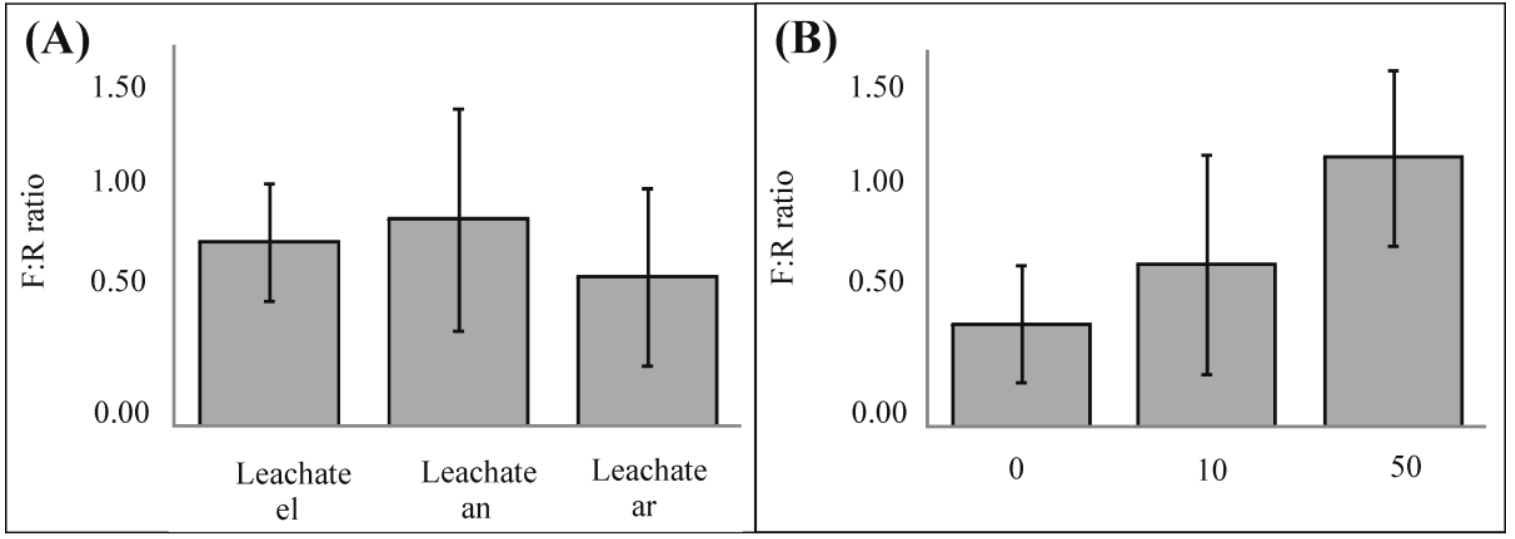

Figure 2.5. The fermentation:respiration ratios (F:R) for: A) leachate treatments; and B) produce amendments. The values given are based on total amounts of $\mathrm{O}_{2}$ consumed and $\mathrm{CO}_{2}$ produced during five weeks of experiment and are averages of the three fermentors from each series. Error bars represent \pm 1 standard deviation.

The fermentation:respiration(F:R) ratio comparing the $50 \%$ and $10 \%$ produce treatments of FLC was about 3:1, markedly skewed from an expected ratio of 5:1, assuming fermentation was unimpaired with increasing proportions of produce. This is consistent with earlier observations related to $\mathrm{pH}$ trends that suggest incomplete fermentation of produce, and shows that produce amendments did not help accelerate the fermentation of FLC materials.

Of the VOAs measured, only acetic, propanoic and butyric acid were produced in significant amounts. No significant differences were seen between produce treatments in the case of propanoic and butyric acid. Acetic acid production increased initially, and then decreased after week 1 (Fig. 2.6). Total acid production (measured as the sum of all VOAs detected) increased over time, but never above $0.01 \%$ (data not shown). Ethanol and lesser amounts of n-propanol were also produced in the fermentors. Ethanol production was highest in FLC material amended with $50 \%$ produce (Fig. 2.6). For any 
given produce abundance, the leachate treatment did not appear to influence alcohol production.

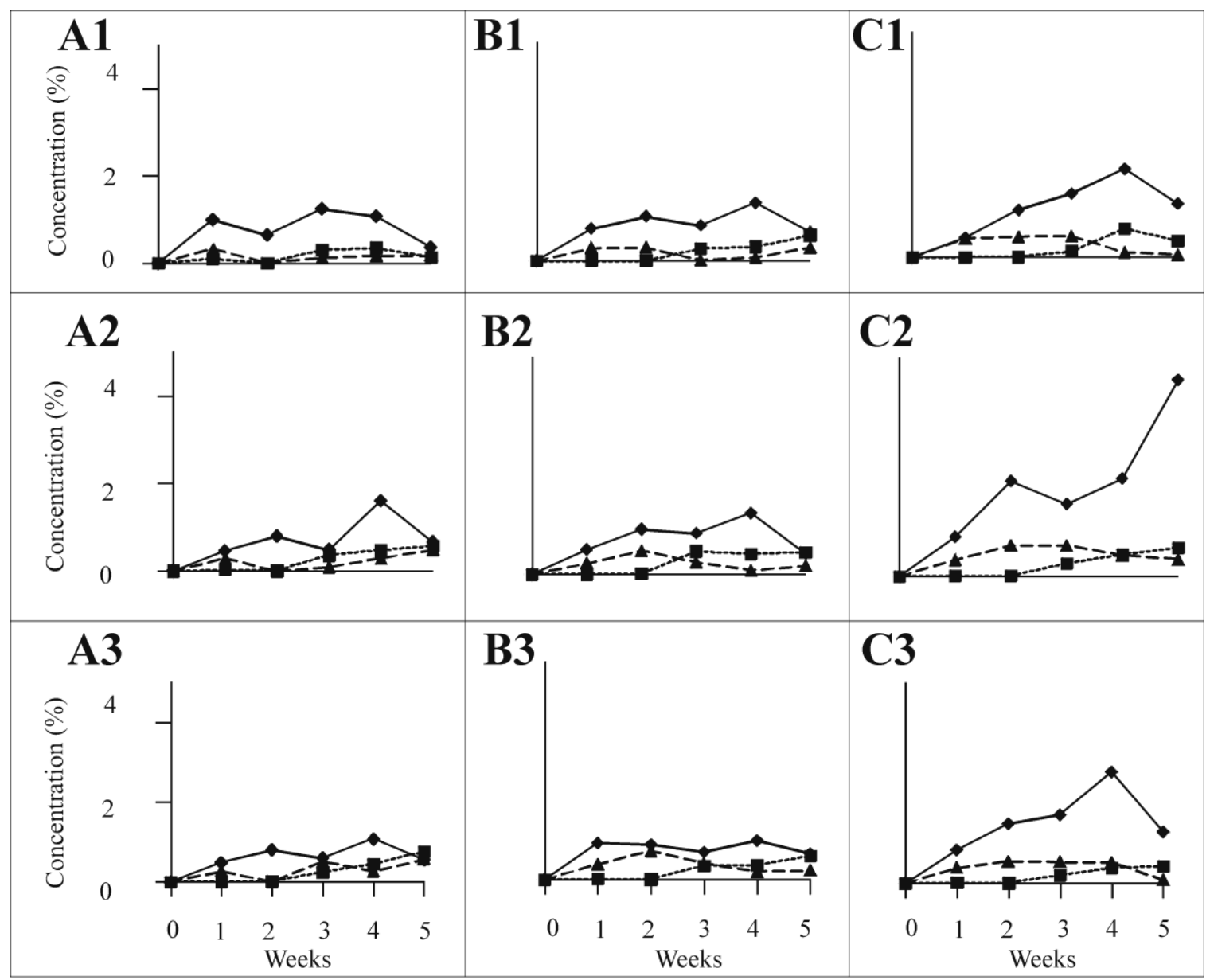

Figure 2.6. Evolution of: ethanol ( $\diamond$ ); acetic acid ( $\boldsymbol{\Delta})$; and butyric acid ( $\boldsymbol{\square})$ in all fermentors.

PS measured in the leachate in all fermentors decreased over time. In fermentors amended with $50 \%$ produce, PS started high and over a period of about one week decreased to values similar to those of the other produce treatments (Fig. 2.7A). PS in the leachate was lower when leachate was eliminated relative to that of recycling leachate treatments (Fig. 2.7B). Total PS in leachates was unaffected by recycling of the leachates stored under aerobic or anaerobic conditions. The increased PS value in the FLC 
materials amended with produce in the first week (Fig. 2.7A) is likely attributable to degradation of small molecular weight PSs and starch originating from produce, rather than cellulosic polymers from FLC.

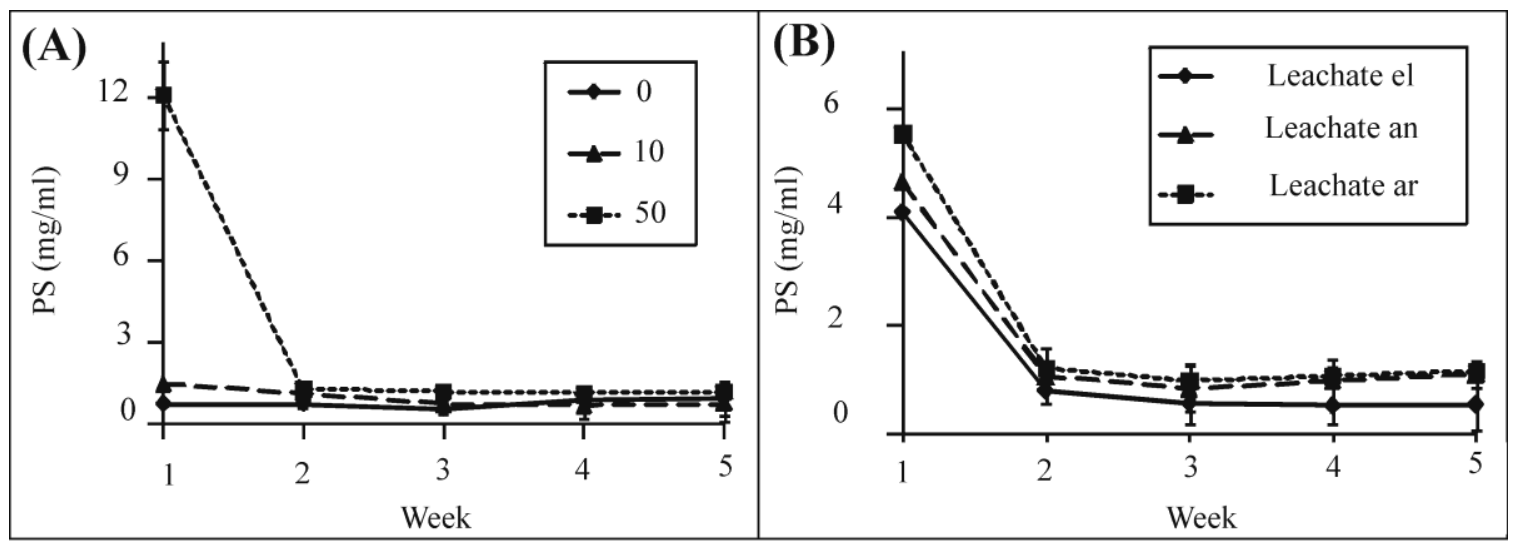

Figure 2.7. PS content in the leachate in relation to: A) produce amendment; and B) leachate treatment. The labels (Leachate el, Leachate an, and Leachate ar) are explained in Table 1.

In all untreated leachates, the BOD increased after the first week, and decreased progressively thereafter. Leachate BOD was negatively correlated with the amount of produce amended with FLC (Fig. 2.8A). The same overall trend was observed in leachate BOD for the various leachate treatments. In fermentors containing FLC amended with produce, no significant difference in leachate BOD was seen between leachate treatments (Fig. 2.8B). The BOD of the residue remained within the range of 0.1 and $0.2 \mathrm{mg} \mathrm{O}_{2} / \mathrm{L}$ throughout the course of the study. The absence of changes in BOD of FLC residues derived from the various treatments is consistent with the interpretation that MF of FLC was not initiated to measurable levels by the fifth week. In soil, all of the MF-processed residues led to EPF indices and PS values significantly higher than the un-amended control soil, but similar to un-fermented control FLC (Fig. 2.9). These 
results also support our interpretation that MF pre-processing of FLC does not accelerate its degradation.
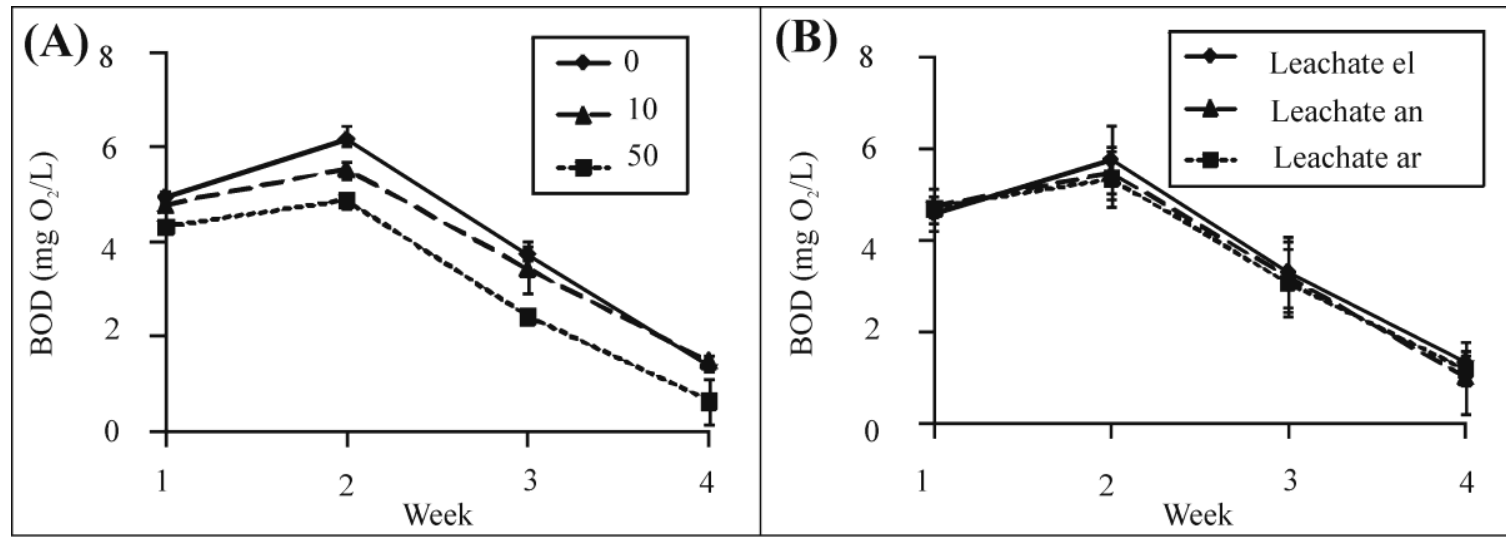

Figure 2.8. Evolution of BOD in leachate relative to: A) produce amendments; and B) leachate treatment.
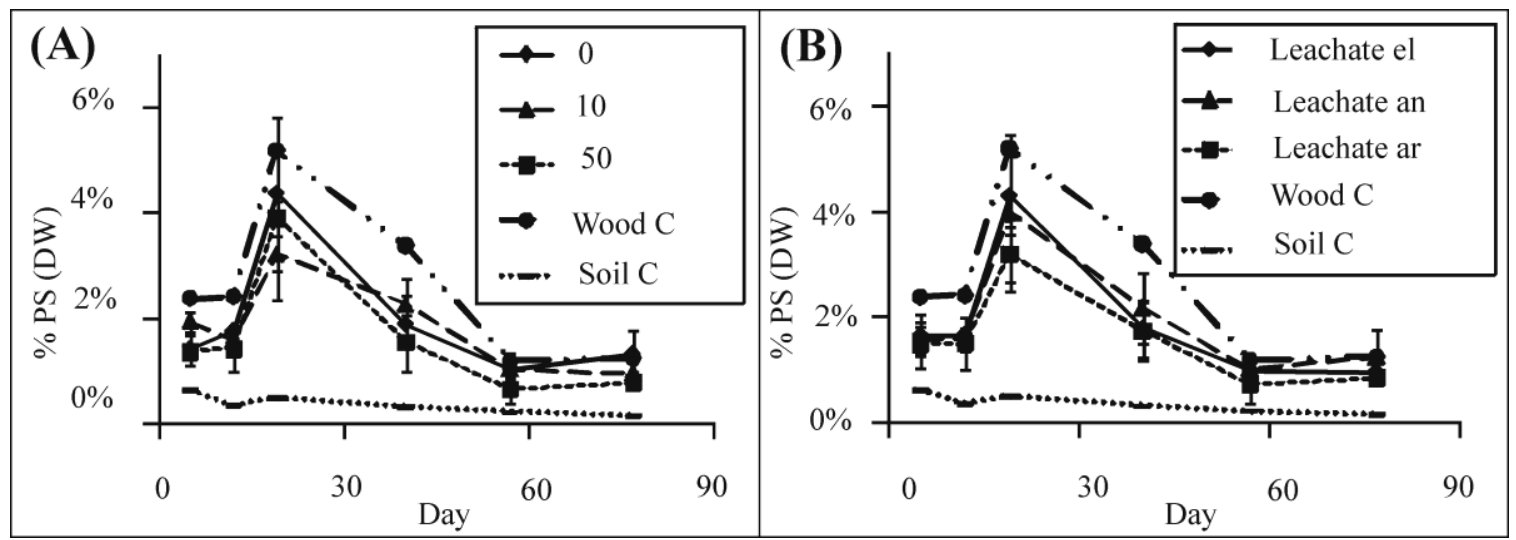

Figure 2.9. PS degradation in soil in relation to: A) produce amendment; and B) leachate treatment with FLC material relative to unfermented FLC material (Wood C) and control soil (Soil C). PS evolution in soil was similar in all treatments.

\section{Conclusions}

Previous studies have shown that pre-processing of vegetal and agricultural material by MF increases the availability of nutrients in soil by initiating the hydrolysis of polysaccharide polymers prior to their introduction into soil (Green and Popa, 2011; Yan and Xu, 2002; Hussain et al., 1995). The pre-processing by MF of FLC amended with 
produce for five weeks increased fermentation rates and decreased the BOD of the fermented residues. Draining leachate from the fermentor without returning it, increased acidification and decreased the free PS content of leachate subsequently recovered from fermentors. Gas production and BOD results indicate that mixing FLC with produce did not enhance the degradation of FLC. This appears to lead to a metabolic inhibition of the fermentation process, and biasing of microbial degradation towards small more easily digestible PS over the less accessible FLC materials. Produce amendment, or leachate treatments, did not influence the degradation of PS in soil amended with MF-processed materials relative to unfermented controls. Pre-processing FLC by MF therefore appears no more efficient than direct tilling of FLC into soil regarding its assimilation back into soil.

Our results demonstrate that 2-5 week MF pre-processing (when fermentation endpoints have been reached, with or without leachate recirculation or produce amendments) is not sufficient in advancing the degradation of FLC material for amending into soil. Efficiency of FLC pre-processing may be increased using longer MF processing, control of leachate $\mathrm{pH}$ and removal of organic acids, alcohols, and other metabolic inhibitors from leachate. 


\title{
Chapter 3:
}

\section{Treatment of MF leachate and fungal competition during processing}

\begin{abstract}
:
Experiments in chapter 2 showed that pre-processing of fibrous lignocellulosic (FLC) materials by microaerobic fermentation (MF) was insufficient and may require more thorough leachate treatment to increase polymer degradation. Leachate processing is often performed through microbial methods facilitated by various aeration regimes. This research compared these aeration methods with a novel larvae-based processing biotechnology. The evolution of biological oxygen demand (BOD), chemical oxygen demand (COD) and $\mathrm{pH}$ were monitored. Microbial treatments stabilized $\mathrm{pH}$ and decreased leachate's COD and BOD in about 2 months. Black Soldier fly larvae (BSFL) processing accelerated leachate treatment to within 2 - 7 days. Optimal processing occurred in treatments with the largest concentrations of BSFL $(0.5 \mathrm{~g} / \mathrm{ml}$ and $0.25 \mathrm{~g} / \mathrm{ml})$ followed by those with fewest larvae $(0 \mathrm{~g} / \mathrm{ml}$ and $0.005 \mathrm{~g} / \mathrm{ml})$. This suggests that low levels of BSFL can process leachate through a synergistic relationship with leachate microorganisms, while still producing valuable larval biomass. Finally, BSFL were shown to compete with naturally occurring leachate fungal species for essential nutrients. These data indicate that management of the leachate microbial community is needed to maintain optimal BSFL processing capacity in the Hermetia module of the integrated MF (IF) system.
\end{abstract}




\section{Introduction}

Experiments on pre-processing of FLC materials using MF (chapter 2) indicate that thorough leachate treatment may be essential for increased MF efficiency. Leachate is rich in organic acids and alcohols, organic nitrogen, small sugars and polysaccharides, and has a complex microbial community. MF residue and leachates host a suite of bacterial and fungal species. Bacterial species include microaerophilic and anaerobic bacteria, which are mainly Gram-positive organisms from the genus Clostridium $(\sim 60$ \%) (Green and Popa, 2011). Aerobic respiring microorganisms, such as Micrococcus sp. and Acetobacter sp., are present but are likely limited by low oxygen levels (Alattar unpublished, 2011). Low oxygen and highly acidic conditions within MF fermentors inhibit methanogens and methanogenesis (Qi et al., 2005; Bonartseva, 2003). The complex MF microbial communities may be essential in leachate treatment and likely affect larval growth in the BSFL IF treatment module. Therefore, it is important to understand the effects of leachate microorganisms on the processing of leachate and the processing capacity of BSFL.

Microbial treatments of leachate, especially those involving continuous aeration, are often used to detoxify large amounts of liquid (CED, 2010; Mehmood, 2009). Aerobic respiring microorganisms break down organic acids, alcohols and other small metabolites in the leachate, reducing its toxicity. Alternating leachate aeration with anaerobic storage has been shown to increase leachate treatment efficiency and decrease aeration costs (Fernandez et al., 2011; Hudnell et al., 2011). The alternation between aeration treatments may also promote a synergistic relationship between aerobic and 
anaerobic microorganisms. Some anaerobic microorganisms, such as Clostridium sp., produce exoenzymes that break down large polymers within the leachate (Zhang et al., 2010; Qi et al., 2005). Aerobic microorganisms can then remove acids, alcohols and other metabolites that are byproducts of the anaerobic processes (Yadav and Malanson, 2007). The effects of such microbial treatments on MF leachate processing were analyzed. Within this study it was predicated that increased processing would occur in the alternating aeration treatment.

Microbial treatments have been shown to be effective at leachate processing, but treatment may be accelerated using insect-based biotechnologies. In the IF system, BSFL process leachate synergistically with the indigenous microbial community. BSFL may be positively or negatively affected by the existing microorganisms. Increased microbial growth on compost material has been shown to increase BSFL growth and $\mathrm{pH}$ alteration rate (Yu, 2011). BSFL gut microflora have also been shown to vary depending on the characteristics of larval feedstock (Jeon, et al., 2011). On the other hand, fungal growth has been reported to inhibit the hatching and growth of young BSFL (Sheppard et al., 2002). Sheppard (2002) also reported that larval growth media incubated with BSFL often lacked large amounts of common fungal growth, suggesting a competitive or inhibitory interaction between fungi and BSFL. Similar observations were made when raising BSFL for these experiments.

Fungi can produce insecticides affecting dipteran species, while insects may produce fungicides as well. For example the soil fungus Beauveria bassiana is used in biological pest control because it produces the toxin beauvericin and causes white 
muscardine disease in adult house flies and mosquito larvae (Geisseler et al., 2010; Miller et al., 1983). Fungal insecticides are often insect specific and those affecting Hermetia have not yet been reported. Hermetia were shown to be susceptible to some synthetic pesticides including the pyrethroids, cyromazine and pyriproxifen (Tomberlin $e t$ al., 2002). BSFL have also been reported to directly reduce microbial numbers, especially those of human pathogens (Liu et al., 2008; Erickson et al., 2004). This reduction may occur due to direct ingestion by BSFL or chemical inhibition of microbial activity.

\section{Objectives}

The objectives of this section were to study processing efficiency, measuring $\mathrm{pH}$, chemical oxygen demand (COD) and biological oxygen demand (BOD) stabilization, of microbial and BSFL based leachate treatments. Also analyzed were the effects of fungal growth on BSFL and the effects of BSFL byproducts on growth of $E$. coli.

\section{Methods and Hypotheses}

\section{Microbial treatments of compost leachate}

Three microbial treatments were analyzed for efficiency of MF leachate processing. Treatments were promoted through various aeration regimes during incubation of 15 liters (L) of compost leachate in $20 \mathrm{~L}$ fermentors (Bokashicycle, NV). The first was an oxic treatment produced through continuous aeration of the leachate. In the second, leachate was aerated for 12 hours and left anoxic for 12 hours by connecting the air purger to a timer. In the control, the leachate was stored under anaerobic conditions in a 
closed fermentor for the entire experiment. Changes in $\mathrm{pH}, \mathrm{COD}$ and BOD were monitored in each treatment for a period of three months by sampling leachate through the fermentor's spigot.

BOD and $\mathrm{pH}$ were measured as described in chapter 1. COD was measured by adding $2 \mathrm{ml}$ of $10^{-3}$ dilution of leachate samples to $3 \mathrm{ml}$ of COD reagent (HACH, CO). The samples were run through a HACH COD cycler at $150{ }^{\circ} \mathrm{C}$ for 120 minutes. The samples were then read at $620 \mathrm{~nm}$ on a diode array spectrophotometer (8452A; Hewlett Packard). COD measurements were standardized using potassium hydrogen phthalate standards.

It was hypothesized that the 12 hour alternating treatment would lead to increased rates of $\mathrm{pH}$ stabilization, and COD and BOD decline.

\section{Larval treatment}

Larvae were incubated in 2 L plastic storage containers (Sistema, New Zealand) with air holes in the sides and openings in the lids, which were covered with a net. Each container contained $200 \mathrm{ml}$ of compost leachate and $0 \mathrm{~g}, 1 \mathrm{~g}(0.005 \mathrm{~g} / \mathrm{ml}), 10 \mathrm{~g}(0.05$ $\mathrm{g} / \mathrm{ml}), 50 \mathrm{~g}(0.25 \mathrm{~g} / \mathrm{ml})$, or $100 \mathrm{~g}(0.5 \mathrm{~g} / \mathrm{ml})$ of BSFL. The $\mathrm{pH}, \mathrm{COD}$ and BOD of each treatment were measured for 9 days as described above and in chapter 1 .

Organic acid and alcohol concentrations were measured by GC analysis (as described in chapter 2) of untreated MF leachate and leachate treated for 2 days with BSFL. There were impurities in the n-valeric acid standard used (Sigma), which showed 
two isoforms when analyzed with GC. These isoforms were also detected in the leachate samples though so in the results they were described as "n-valeric 1 " and "n-valeric 2".

It was hypothesized that a positive correlation would exist between larval: leachate ratio and the stabilization rate of $\mathrm{pH}, \mathrm{COD}$ and $\mathrm{BOD}$ and that organic acids and alcohols would decrease after BSFL processing.

Effects of BSFL byproducts on MF leachate inoculated with E. coli were also analyzed. BSFL excreta was collected by allowing larvae to grow in a container with leachate in one side as a growth medium and an incline leading to a drop-off in which larvae excreted and then moved back to the liquid food medium. Antibiograms using sterile disks of undiluted, filter sterilized BSFL excreta on trypticase soy agar (TSA) lawns of various microbial cultures were used to test for larval antibiotic production. The cultures used were E. coli, a putative Clostridium strain isolated from MF leachate and a mixed leachate microbial culture lawn.

Effects of larval excreta on $E$. coli growth was also measured using liquid cultures of $30 \mathrm{~g} / \mathrm{L}$ trypticase soy broth (TSB) with varying amounts of BSFL excreta or MF leachate $(0 \%, 25 \%, 50 \%, 75 \%$ and $100 \%)$. Growth was monitored using spectrophotometry at $600 \mathrm{~nm}$ (8452A; Hewlett Packard).

It was hypothesized that the BSFL excreta disk would produce a zone of inhibition on the E. coli lawn, but not the lawns of Clostridium or the mixed leachateculture and that in TSB cultures, increased BSFL excreta percentage would decrease $E$. coli growth. 


\section{Fungi-larvae interactions}

Effects of both fungal biomass (FB) and fungal leachate (FL) on BSFL growth and death rates were monitored. Fungal biomass and fungal leachate were obtained by incubating MF leachate at $30{ }^{\circ} \mathrm{C}$ in an open glass Pyrex baking pan $(13 \times 9 \times 2$ inches $)$ with a clear flat plastic sheet over part of it to decrease, but not inhibit, aeration. Naturally occurring leachate fungal strains covered the liquid in about two days and were incubated for about a week thereafter so fungal byproducts could accumulate in the leachate. Fungal biomass was then scraped off the top. Fungal leachate was collected from under the fungal mat. The control MF leachate had been stored anaerobically, and did not have significant accumulation of fungal species. Both types of leachate were centrifuged for 15 minutes at $14,000 \mathrm{rpm}$.

Using the titled tube set-up (described in chapter 4) larvae were incubated in either $10 \mathrm{ml}$ of fungal biomass or $10 \mathrm{ml}$ of fungal leachate and compared to those grown in $10 \mathrm{ml}$ of MF leachate that had been stored anaerobically. Larval growth and death were measured after two days of incubation.

It was hypothesized that both fungal biomass and fungal leachate would inhibit larval growth and increase death rates, suggesting chemical inhibition.

Experiments were conducted to determine if fungal inhibition of larval growth was due to nutrient competition or direct inhibition. Larvae were grown in titled tubes with fungal leachate $(5 \mathrm{ml})$ either amended with $5 \mathrm{ml}$ of nutrient supplement or a tap 
water control to determine if larval growth was restored. The nutrient supplement consisted of $1 \mathrm{~g} / 100 \mathrm{ml}$ yeast extract and $10 \mathrm{~g} / 100 \mathrm{ml}$ glucose.

It was hypothesized that nutrient supplements would not significantly increase larval growth rates suggesting direct fungal chemical inhibition.

\section{Results and Discussion}

\section{Microbial treatments}

Data on microbial treatments of leachate showed that in oxic and alternating aeration treatments the $\mathrm{pH}$ of leachate was neutralized from an initial value of 3.7 to between 8 and 10 in about 60 - 70 days (Fig 3.1A). As hypothesized, this $\mathrm{pH}$ neutralization occurred most quickly in the alternating treatment. Anoxic storage of the leachate did not alter the $\mathrm{pH}$ considerably over the three month period compared to the oxic treatment ( $\mathrm{p}$ value: $8.92 \mathrm{E}-08)$ (Fig 3.1A). The COD of leachates decreased from $1.5 \times 10^{5}$ to $5.0 \times 10^{4}$ $\mathrm{mg} \mathrm{O}_{2} / \mathrm{L}$ in about 36 days in all treatments, but the overall COD decreased at an accelerated rate in alternating and oxic treatments compared to the anoxic treatment (Fig 3.1B). BOD decreased at the most rapid rate in alternating and oxic treatments, but the BOD of the anoxic treatment did not decrease significantly over the duration of the experiment (Fig 3.1C). These results confirmed that alternating aeration may lead to more efficient microbial treatment of leachate, but the overall process still takes between about 2 - 3 months to bring the leachate mineralization and $\mathrm{pH}$ to endpoints. 

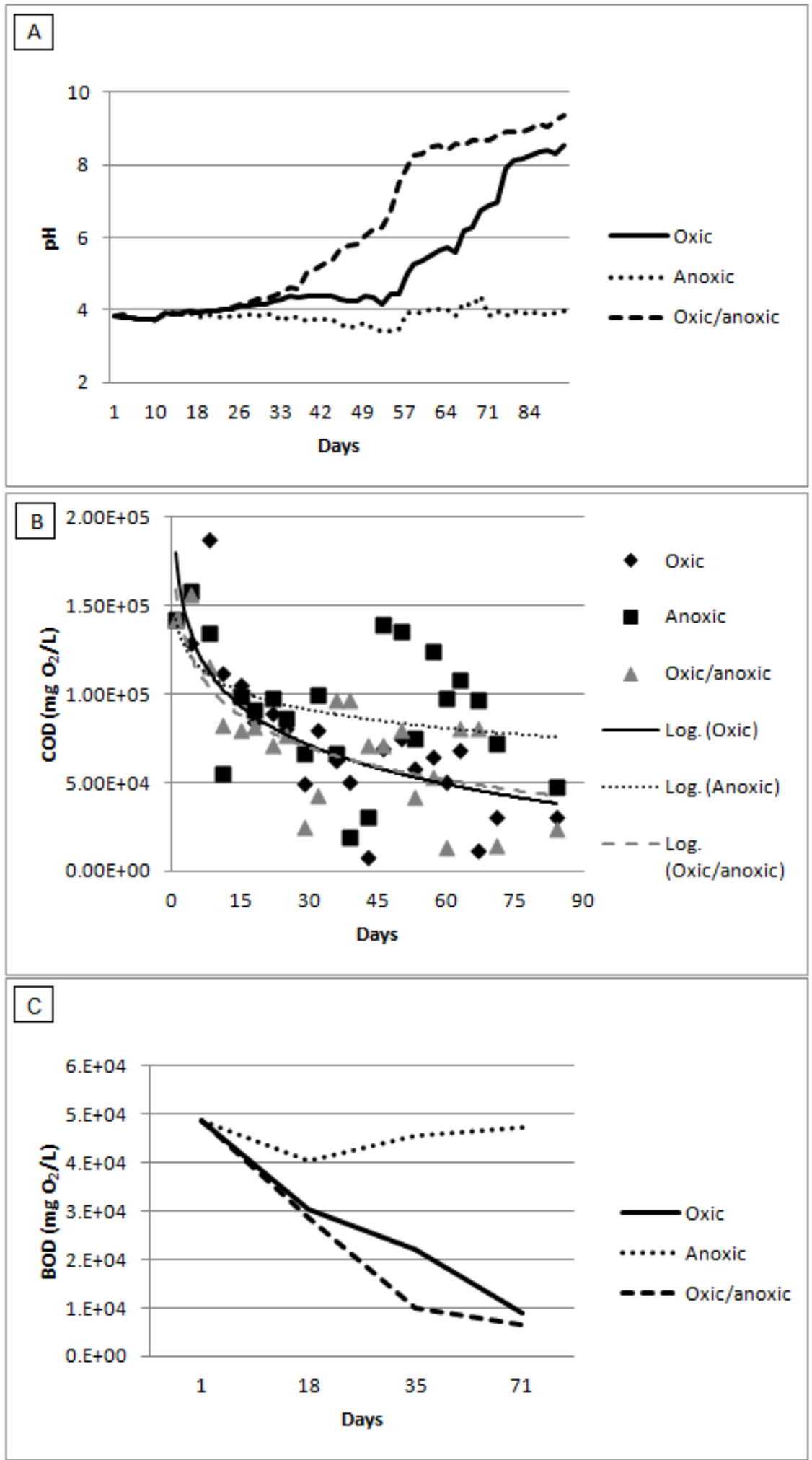

Figure 3.1. Evolution of $\mathrm{pH}(\mathrm{A}), \mathrm{COD}(\mathrm{B})$ and $\mathrm{BOD}(\mathrm{C})$ in oxic, anoxic and 12 hour alternate (oxic/anoxic) microbial treatments of MF leachate. 


\section{Larval treatments}

All leachate processed with larvae (Fig 3.2) exhibited a $\mathrm{pH}$ increase from 3.7 to $\mathrm{pH}$ of about 8 - 9 in about eight days, but the rates at which this occurred varied. The $\mathrm{pH}$ increased more quickly in treatments with higher larvae concentrations (Fig 3.3 A, treatments D and E) followed by treatments with the lowest larvae:leachate ratios $(0 \mathrm{~g} / \mathrm{ml}$ and $0.005 \mathrm{~g} / \mathrm{ml})($ Fig 3.3A, treatments A and B). The treatment with $10 \mathrm{~g}(0.05 \mathrm{~g} / \mathrm{ml})$ of BSFL, which was the medium concentration, had the slowest $\mathrm{pH}$ stabilization rate. Similarly BOD and COD decreased at the quickest rates in the treatments with most larvae $(0.5 \mathrm{~g} / \mathrm{ml})$. This indicates that optimal biomineralization and $\mathrm{pH}$ stabilization of leachate occurs with fewer $(<0.005 \mathrm{~g} / \mathrm{ml})$ or larger amounts of larvae $(>0.5 \mathrm{~g} / \mathrm{ml})$ in leachate. It is important to note that these trends were significant within a standard deviation of \pm 1 , but not within a $95 \%$ confidence t-test. Further experimentation should be done to verify these trends.

Larval processing results likely represent an interaction between larvae and bacteria in stabilization of $\mathrm{pH}, \mathrm{COD}$ and $\mathrm{BOD}$ in leachate. It is hypothesized that in treatments with low larval density $(0.005 \mathrm{~g} / \mathrm{ml})$, bacteria are prevalent and can quickly compensate for lack of larvae and in turn stabilize the $\mathrm{pH}$. Also, larger concentrations of larvae $(0.5 \mathrm{~g} / \mathrm{ml})$ can increase $\mathrm{pH}$ stabilization without significant support from the indigenous microbial community. Medium amounts of larvae $(0.05 \mathrm{~g} / \mathrm{ml})$, however, likely consume many bacteria, which leads in turn to decreased additive processing capacity and $\mathrm{pH}$ stabilization rate. These relationships may be understood in more detail in future research. This information is useful from a practical implementation standpoint, 
because it demonstrates that high concentrations of BSFL are not necessary for efficient leachate treatment. Rather, incubating MF leachate with $0.005 \mathrm{~g} / \mathrm{ml}$ of BSFL may be enough to treat leachate due to the supplemental assistance from indigenous leachate microflora.

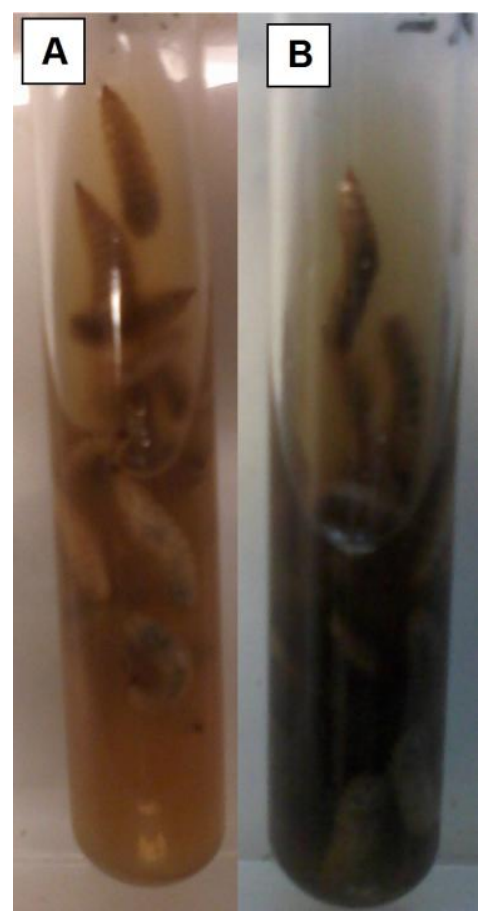

Figure 3.2. Compared to unprocessed MF leachate (A), BSFL treatment results in a darker, more thoroughly processed leachate $(\mathrm{B})$. (Aerial view).

BSFL were also shown to release frass (thin beaded materials composed of plant and other materials) into the liquid (Fig 3.4) which likely increases access of bacteria to materials that have been preprocessed by BSFL and are more difficult to degrade. 


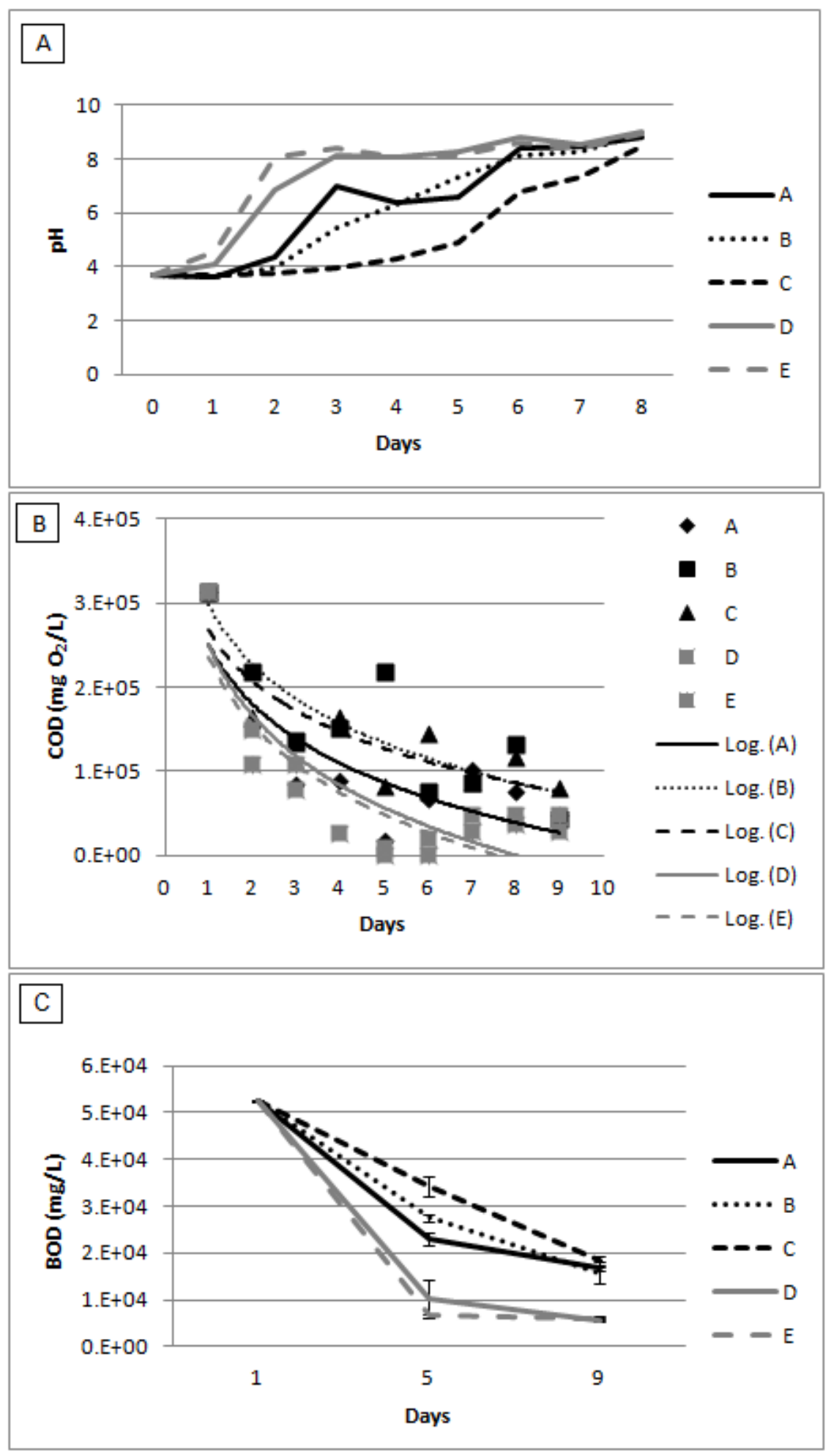

Figure 3.3. Evolution of $\mathrm{pH}(\mathrm{A}), \mathrm{COD}(\mathrm{B})$ and $\mathrm{BOD}(\mathrm{C})$ in relation to concentration of larvae in leachate treatments. (Treatments represented in legend had 0 larvae $(\mathbf{A}), 0.005 \mathrm{~g} / \mathrm{ml}(\mathbf{B}), 0.05 \mathrm{~g} / \mathrm{ml}(\mathbf{C}), 0.25 \mathrm{~g} / \mathrm{ml}(\mathbf{D})$, or $0.5 \mathrm{~g} / \mathrm{ml}$ (E) of larval concentrations.) 


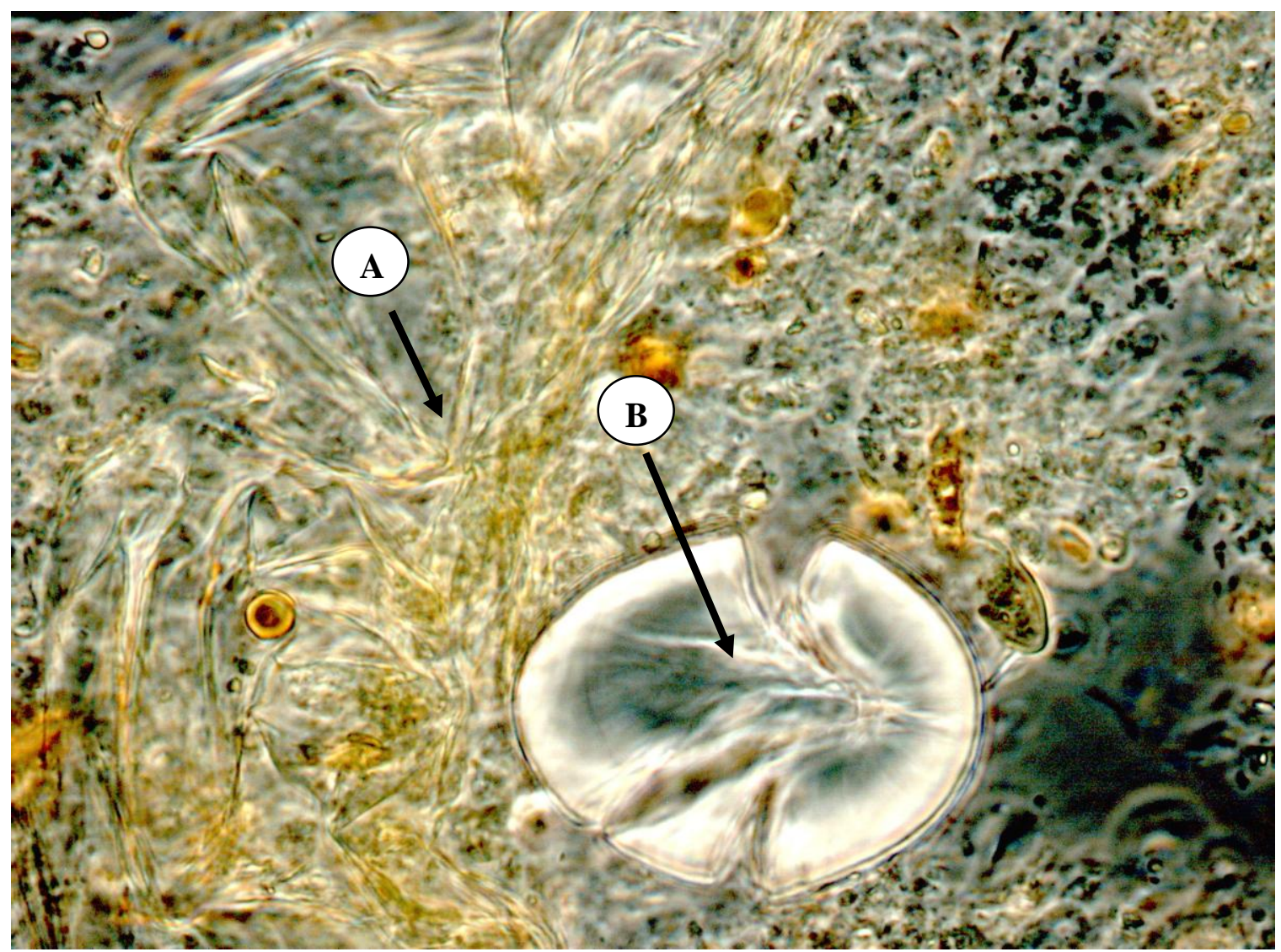

Figure 3.4. Larvae excrete partially digested plant waste (A; top left area) and compacted beaded materials (B, cracked ovoid object), or frass, into the leachate as they process it. (1000x magnification)

GC data on BSFL processed MF leachate indicates that organic acids and alcohols are quickly scrubbed from the liquid by BSFL. Only about $23 \%$ of the total organic acids and alcohols remained after 2 days of larval processing (Table 3.1). It is important to note that some of this loss was due to volatilization of VOAs. The capacity of BSFL to process organic acids and alcohols in MF leachate was further confirmed by other studies in our lab (Fig. 3.5). 


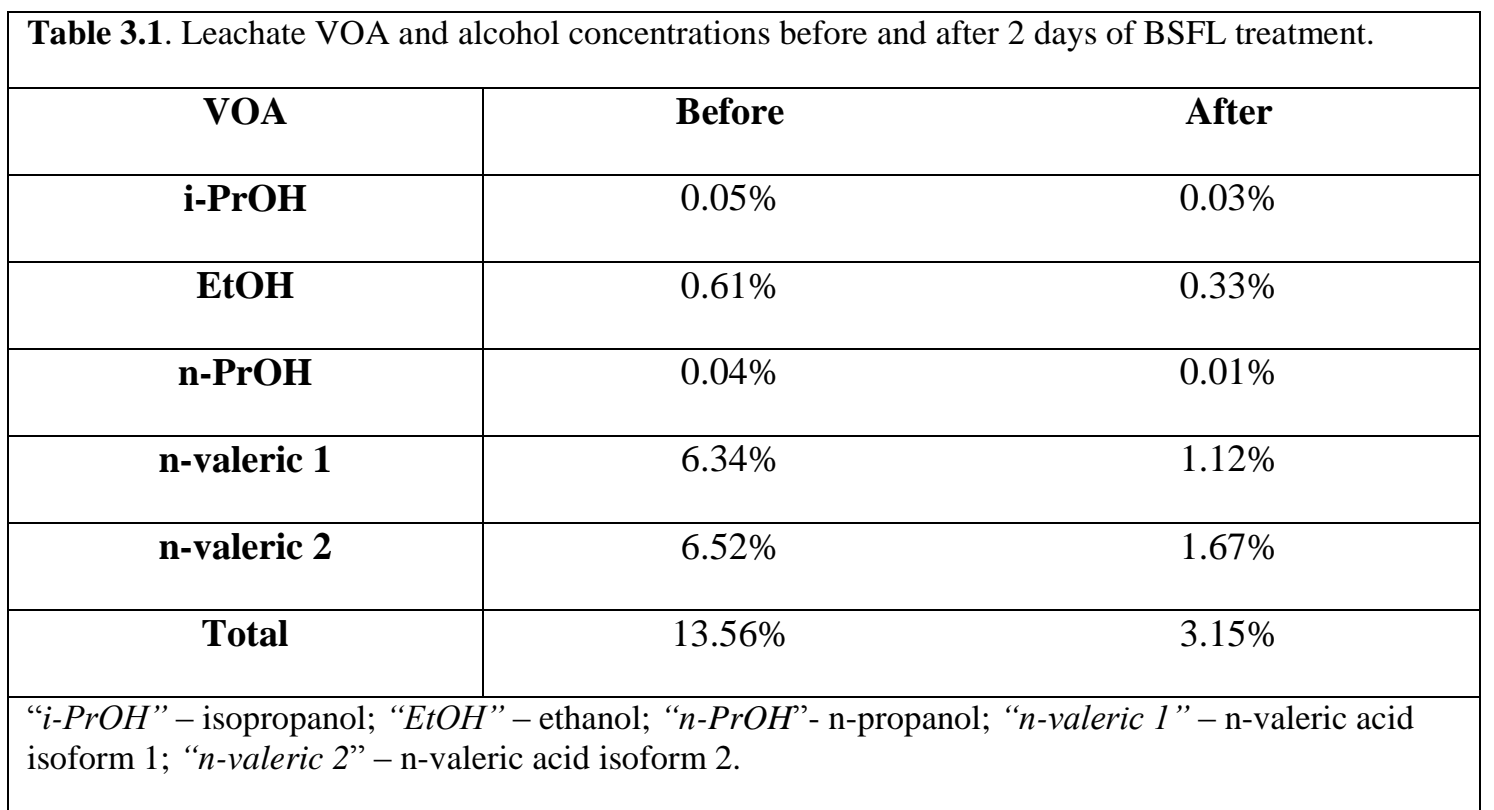

Concurrent studies in our lab confirmed that BSFL grown on leachate decreased free polysaccharides (PS), VOAs (Fig 3.5), organic N (Fig 3.6), and COD and increased $\mathrm{pH}$, bicarbonates and inorganic phosphate compared to untreated leachate (Popa and Green, 2012; Green, 2011 unpublished). Such changes may reduce overall phytotoxicity and possibly allow for processed leachate to be used as a liquid fertilizer. This idea will be revisited in chapter 5. Popa and Green (2012) also demonstrated that BSFL grown solely on MF leachate were able to grow and develop to sexual maturity and lay viable eggs as adults. This indicates further the suitability of BSFL for MF leachate treatment. 


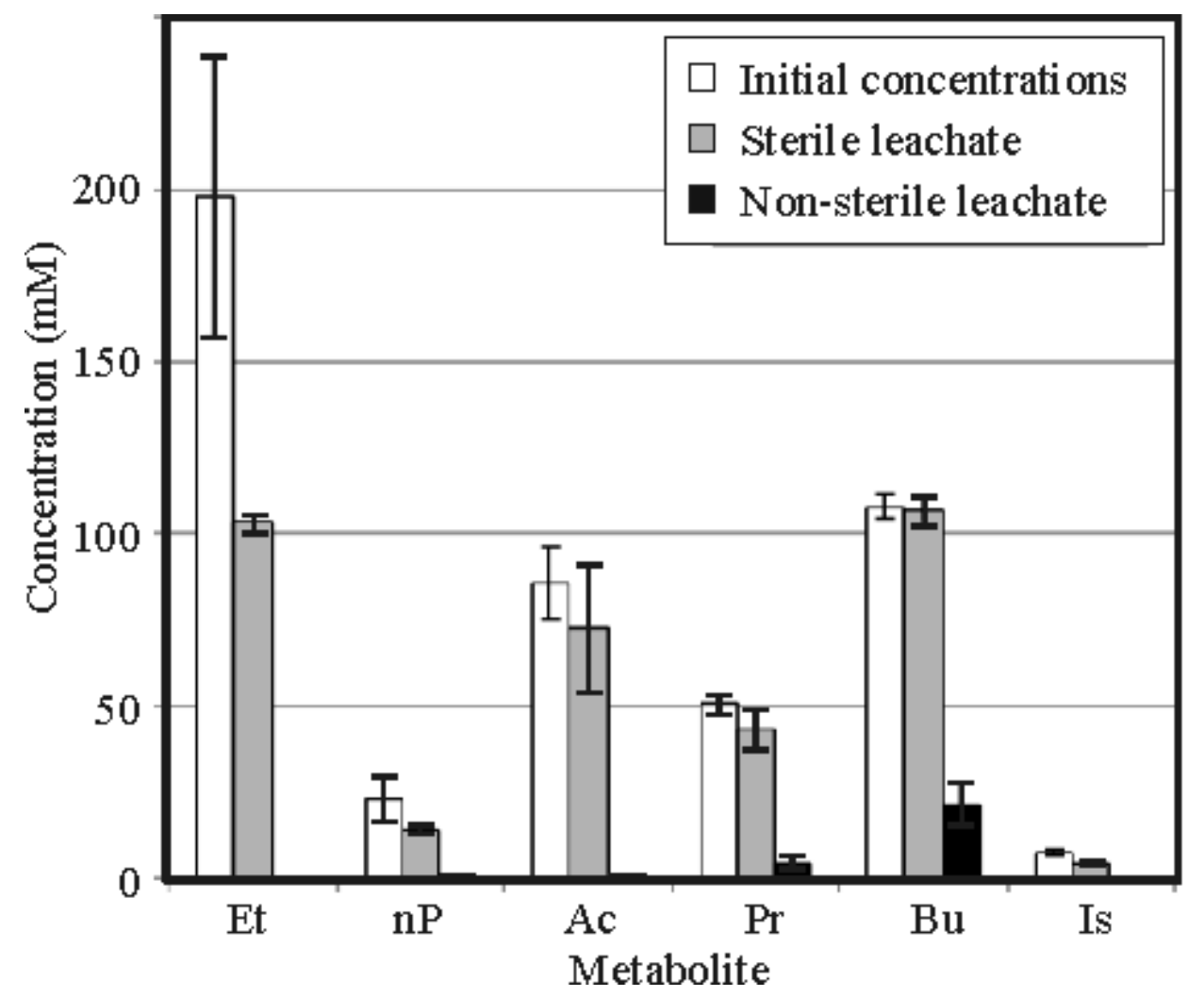

Figure 3.5. Acids and alcohols removed by BSFL. "Et" = ethanol; "nP"=n-Propanol; "Ac" = acetic acid; "Pr" = Propanoic acid; "Bu" = Butyric acid; "Is" = Isovaleric acid. (Popa and Green, 2012) 


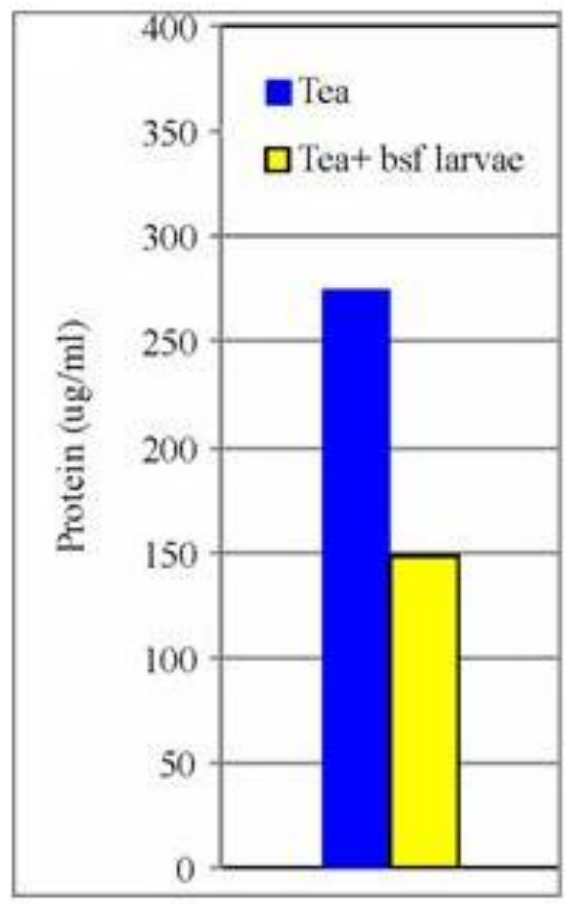

Figure 3.6. Changes in protein content in MF leachate due to larval processing. (Green, 2011 unpublished) Research showing that BSFL decrease human pathogen levels has not specifically focused on how this occurs, although direct ingestion has been suggested (Liu et al., 2008; Erickson et al., 2004). Antibiogram-based results supported this by showing no inhibition of $E$. coli by BSFL excreta. E. coli growth in TSB was also not affected by BSFL excreta (Fig 3.7). Further research is needed to determine the mechanisms for decreasing pathogens and other microbial communities by BSFL. 


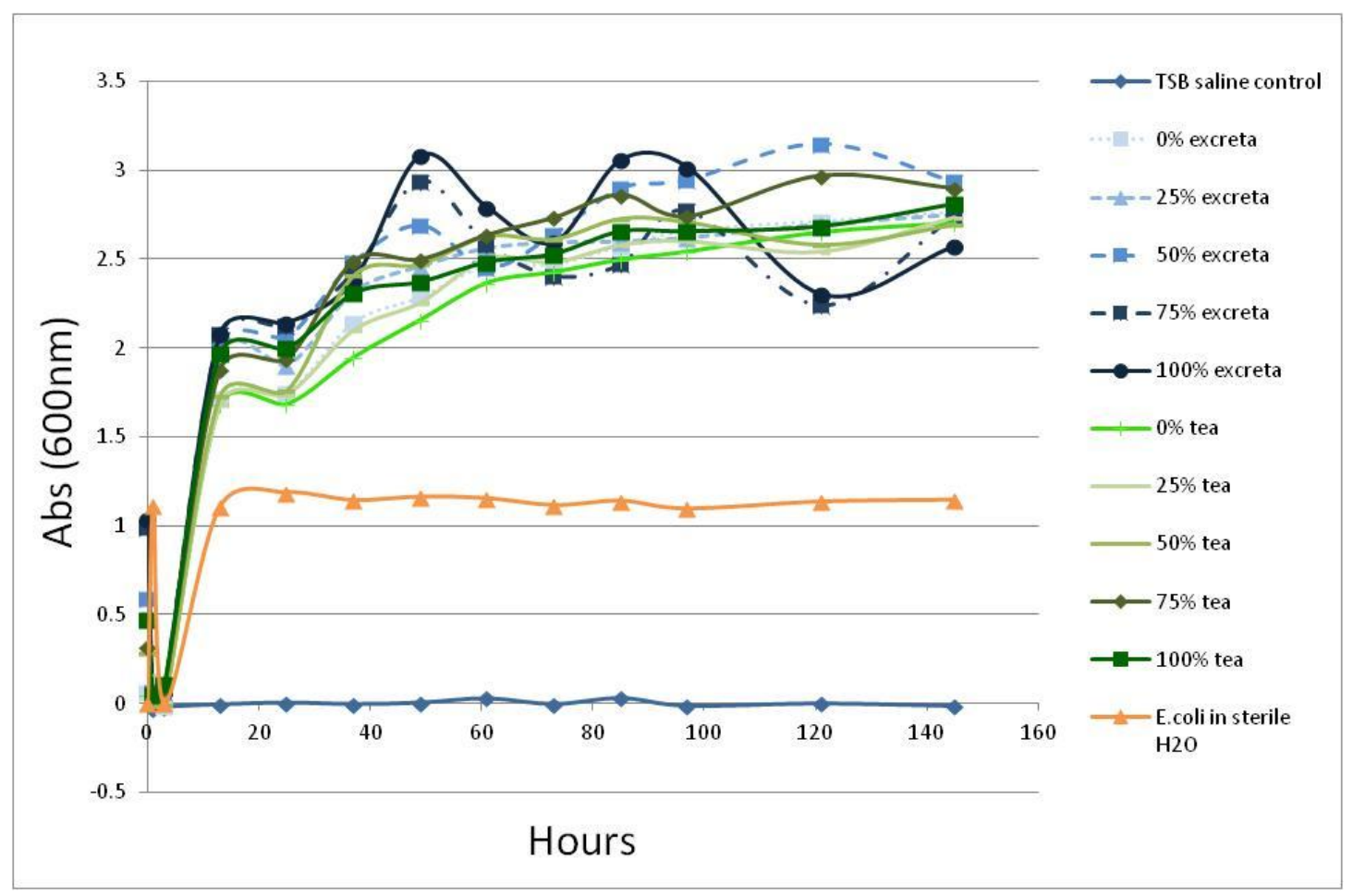

Figure 3.7: $E$. coli growth in various concentrations of BSFL excreta (in shades of blue) and MF leachate (in shades of green) compared to $E$. coli grown in sterile water $(\rightarrow)$ and a TSB/saline control $(\rightarrow-)$ ).

Fungi-larvae interactions

Initial results showed that BSFL exposed to $10 \mathrm{ml}$ of fungal biomass showed $7.6 \%$ increased growth rates over a control (MF leachate), whereas those exposed to $10 \mathrm{ml}$ of fungal leachate had $14.4 \%$ decreased growth compared to a control (p-value: 0.02) (Fig. 3.8). This suggests that larvae are able to eat fungal biomass directly, but are either in competition with the fungi for the nutrients within the leachate or are directly inhibited by the fungal byproducts. 


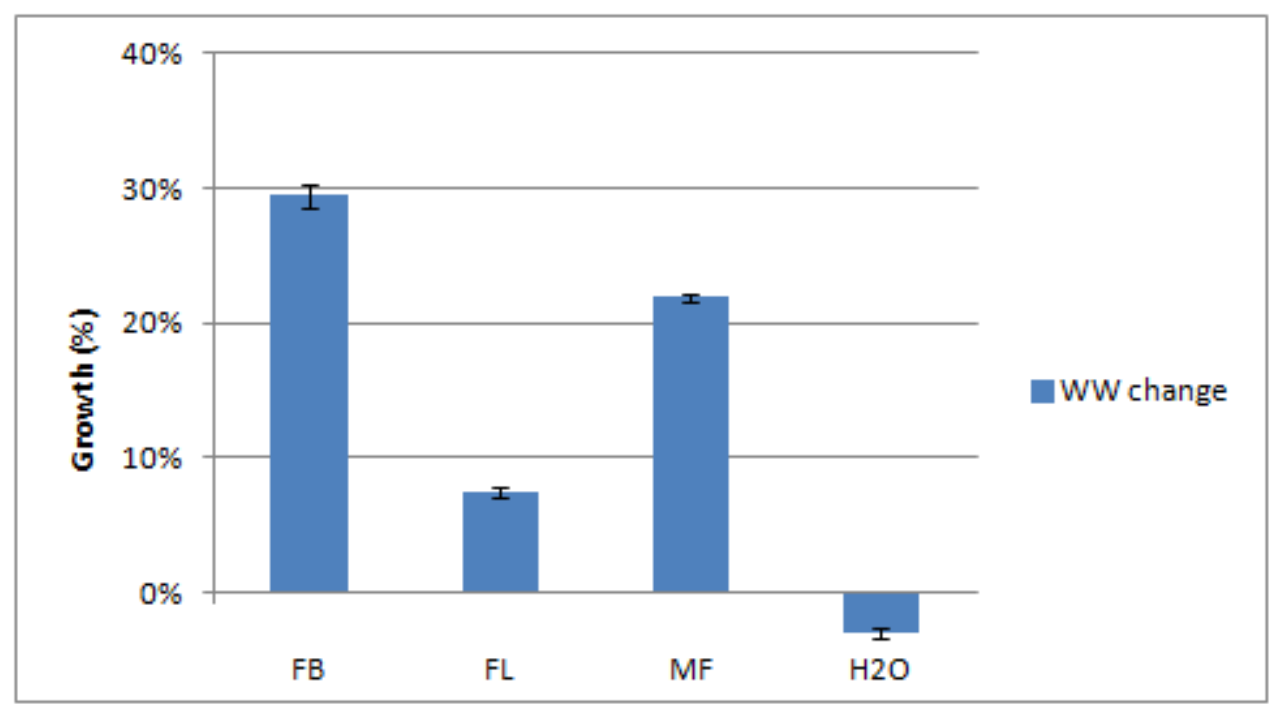

Figure 3.8. Effects of fungal biomass (FB) and fungal leachate (FL) on percent larval growth (change in wet weight (WW)) compared to controls with only MF leachate (MF) and water $\left(\mathbf{H}_{2} \mathbf{O}\right)$. Data significant within \pm 1 standard deviation.

Data on nutrient supplementation of fungal biomass and leachate was reviewed to determine whether decreased BSFL growth, shown in the FL treatment in Fig 3.8, was due to competition or inhibition. When larvae were grown in fungal leachate amended with nutrients they were able to regain growth levels comparable to an MF leachate control (Fig 3.9). The restoration of larval growth by nutrients suggests that larvae and fungi are in competition for the nutrients in the leachate, rather than fungal byproducts directly inhibiting larvae. Increased growth of larvae on fungal biomass, seen repetitively in experiments, also suggests that in a mixed culture larval ability to eat and grow off of fungal biomass may abate the adverse effects of nutrient competition on BSFL growth. 


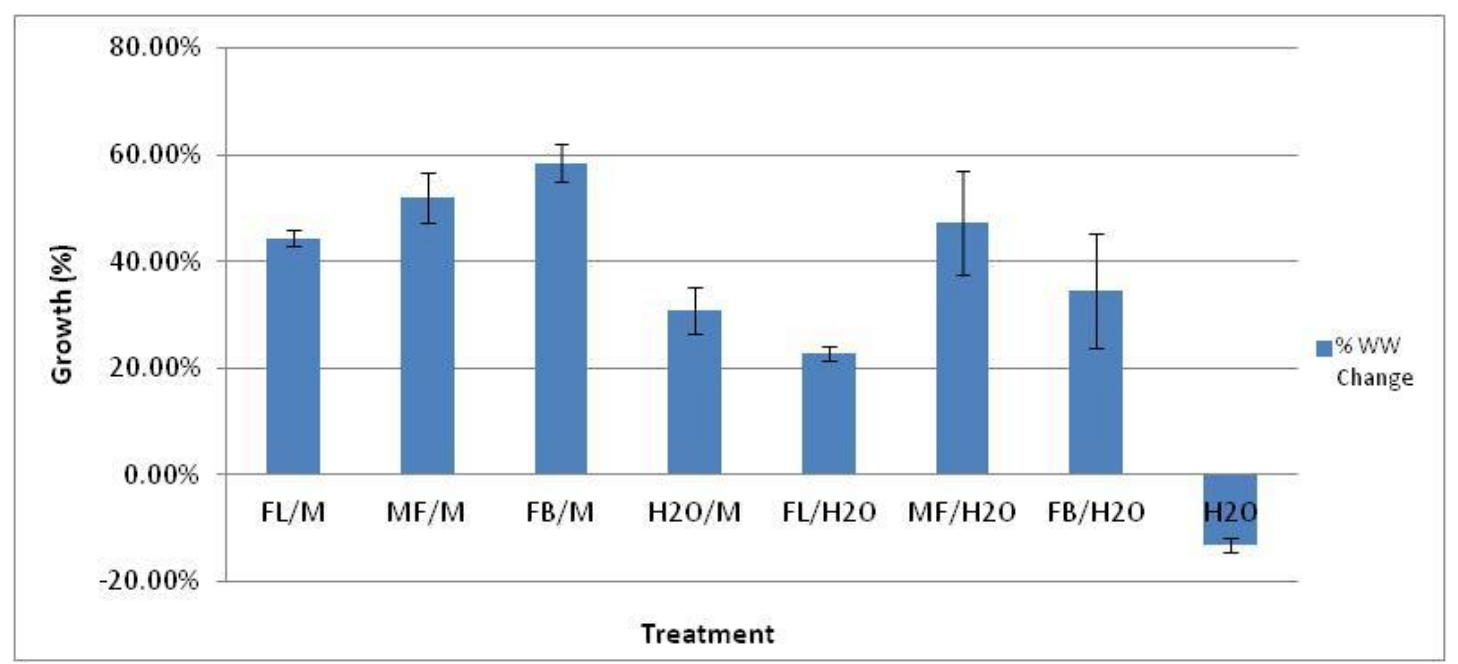

Figure 3.9: Effects of fungal leachate (FL), MF leachate (MF), or fungal biomass (FB) with either water (H2O) or nutrient media (M) on percent larval growth (change in wet weight (WW)).

\section{Conclusions}

The results presented in this chapter demonstrate a number of important concepts related to MF leachate treatment. First, optimal microbial treatment may be attained through alternating (oxic/anoxic) aeration regimes of leachate, which stabilized $\mathrm{pH}, \mathrm{COD}$ and BOD in about 2.5 months. Secondly, BSFL treatments on both high and low extremes $(0.5 \mathrm{~g} / \mathrm{ml}$ and $0.005 \mathrm{~g} / \mathrm{ml})$ of larval concentrations are able to decrease processing times of $\mathrm{pH}, \mathrm{COD}$ and BOD to about $2-7$ days. Finally, although larvae are able to eat fungal biomass, they are in competition with fungi for nutrients and resources. Therefore, during treatments that combine microbial and larval processing, fungal growth must be monitored. BSFL excreta did not inhibit the growth of E. coli. 


\title{
Chapter 4:
}

\section{Tolerance of BSFL (Hermetia illucens) to ethanol, acetic acid, $p H$ and temperature}

\begin{abstract}
Black Soldier fly larvae (BSFL), Hermetia illucens, are well-known for processing of solid organic materials and were recently shown by our lab to process phytotoxic liquid byproducts of fermenting organic waste (leachates) as well. Leachates are rich in metabolic inhibitors such as alcohols, carboxylic acids, and have an acidic $\mathrm{pH}$, but their effects on BSFL have not been previously described. Research on BSFL tolerance to such biological inhibitors is needed for optimizing BSFL-based leachate processing biotechnologies. This research analyzed the effects on larval growth and death rates of four of the most common stress agents present during BSFL leachate processing: ethanol, acetate, $\mathrm{pH}$ and temperature. Larvae were not affected by ethanol concentrations up to about $2.5 \%$ and acetate up to about $2.6 \%$. Growth was optimum around $0.9 \%$ acetate. The $50 \%$ lethal dose for larvae in 48 hours $\left(\mathrm{LD}_{50}\right)$ for ethanol was $42 \%$ for mature larvae and about $36 \%$ for younger larvae. For acetate the $\mathrm{LD}_{50}$ was $46 \%$ for more mature larvae and $16 \%$ for younger larvae. When grown in nutrient media with modified $\mathrm{pH}$, larvae were capable of tolerating a broad range of initial $\mathrm{pHs}$ ( $\mathrm{pH}$ 0.7-13.7). In nutrient media, acidic $\mathrm{LD}_{50}$ for initial $\mathrm{pH}$ was reached at about 0.7 and basic $\mathrm{LD}_{50}$ was reached at about 13.7. Larvae grew at temperatures between $7{ }^{\circ} \mathrm{C}$ and $37{ }^{\circ} \mathrm{C}$ (optimum 30 ${ }^{\circ} \mathrm{C}$ ), and showed $100 \%$ death at near $0{ }^{\circ} \mathrm{C}$ and at $50{ }^{\circ} \mathrm{C}$ and above. Temperature data is supported by findings in previously published literature.
\end{abstract}




\section{Introduction}

BSFL (Hermetia illucens) have been identified as instrumental insects in the degradation of organic waste in vermicompost-like practices (Morales and Wolff, 2010; Lui, 2008; Myers et al., 2008; Erickson et al., 2004; Sheppard et al., 2002). In fact, BSFL have been shown to decrease the dry weight of manure piles by $42-58 \%$, and decrease $\mathrm{N}$ by $30 \%-50 \%$ and phosphorous (P) by about $61 \%-70 \%$ after about 1 month of processing (Myers et al., 2008; Sheppard et al., 2002). Recently it was also shown that BSFL have the capacity to process and detoxify microaerobic fermentation (MF) leachate (Green and Popa, 2012). Natural degradation of and MF processing of fruits and other sugar-containing organic wastes may lead to ethanol levels between $2 \%$ and $12 \%$ in leachates, depending on the feedstock and waste recycling technology (David and Van Herrewege, 1983; Gibson et al., 1981). Bacteria such as Acetobacter and Clostridium convert ethanol into acetic acid, which lowers the $\mathrm{pH}$ of the solution (Kim et al., 2005; Peters, 1996). Because alcohols, carboxylic acids and acidity are metabolic inhibitors, it is important to understand their effects on BSFL within MF systems.

Most insect ethanol and acetic acid tolerance studies have been done on species of fruit flies (Drosophila), which often feed on rotting organic matter and are able to sense and tolerate levels of various organic alcohols and acids. Flies use olfactory senses to find food sources by sensing both increased ethanol and acetate concentrations (Eisses and Boer, 1995). Increased acetate also promotes oviposition in female D. melanogaster and D. simulans (Fluegel, 1981). 
Drosophila strains adapted to feed on fermenting organic matter are attracted to fruit with high ethanol and acetic acid concentrations and thrive in ethanol concentrations as high as $7 \%$ by using it as an energy source (Fry, 2001; Eisses and Boer, 1995; David and Van Herrewege 1983; Parsons and Spence, 1980). Strains with broader dietary options often have lower ethanol tolerance. For example $D$. immigrans can feed on a variety of food sources and can only tolerate up to $3 \%$ ethanol, whereas D. melanogaster feeds mainly on rotting fruit and can tolerate ethanol concentrations as high as $13 \%$ (Parsons and Spence, 1980). Some species, such as D. lebanonensis, have been shown to tolerate ethanol concentrations up to $28 \%$, based on lethal dose for $50 \%$ survival $\left(\mathrm{LD}_{50}\right)$ in 2 days (David and Van Herrewege, 1983). In Drosophila, ethanol tolerance is positively correlated with increased exposure over a lifespan or successive generations (Scholz et al., 2000; Pecsenye et al., 1997). This suggests that BSFL may have the capacity to adapt and increase tolerance to various leachate metabolic inhibitors over time as well.

Ethanol tolerance is achieved through a variety of methods. These include increased expression of alcohol dehydrogenase $(\mathrm{ADH})$, a temperature and $\mathrm{pH}$ tolerant enzyme, and structural modifications at the cellular level (Montooth et al, 2006; Peters 1996; Starmer et al., 1977). For example, upon ethanol exposure, structural changes occur in epithelial gut cells of D. melanogaster larvae (Montooth et al., 2006; Scholz et al., 2000; Hartman et al., 1993).

Due to the concurrent occurrence of ethanol and acetate in degrading organic waste, acetate tolerance occurs simultaneously with, and may even precede ethanol 
tolerance. Some strains such as $D$. simulans are able to tolerate acetate, but not ethanol (Omura et al., 2008; Elamrani and Idaomar, 2001; Chakir et al., 1996; Eisses and Boer, 1995). Like ethanol tolerance, acetate tolerance is partially dependant on ADH activity. Other mechanisms of acetate tolerance include the induction of fatty acid synthase, acetyl-coA synthetase, esterification of acetate with ethanol into ethylacetate, which buffers cells from toxic effects, and production of phospholipids that restore membrane fluidity (Montooth et al., 2006; Chakir et al., 1996; Eisses and Boer, 1995). It has been proposed though that many more genes and enzymes are likely involved (Montooth $e t$ al., 2006; Chakir et al., 1996; Eisses and Boer, 1995).

Zhong et al. (1998) reports induction of reversible heat shock transcription factor trimerization in Drosophila by low physiological $\mathrm{pH}(\mathrm{pH} \sim 6.5)$. Tolerance to $\mathrm{pH}$ variation is often studied in relation to aquatic arthropods as well. Bell and Nebeker (1969) tested 10 aquatic arthropod larvae for $\mathrm{pH}$ tolerance $\left(\mathrm{LD}_{50}\right.$ in $\left.96 \mathrm{hrs}\right)$ and found that larvae of the caddisfly (Brachycentrus americanus) were most tolerant, with an acidic $\mathrm{LD}_{50}$ of 1.5 in 96 hours. Least tolerant were larvae of the mayfly Ephemerella subvaria, with an acidic $\mathrm{LD}_{50}$ in 96 hours of $\mathrm{pH} 4.65$. Lechleitner (1985) reported that stonefly nymphs had acidic $\mathrm{LD}_{50}$ values in 96 hours of 2.8 to 3.3 and alkaline $\mathrm{LD}_{50}$ values from 10.3 to 12.1. Long-term $\mathrm{pH}$ tolerance of other arthropods has also been studied. The Funereal Duskywing butterfly (Erynnis funeralis) and nymphs of damselflies (Agrionidae) tolerate $\mathrm{pH} 4$ for 8 to 10 weeks (Standeven, 1988; Fiance, 1978). The alkali fly (Ephydra hians), the only insect that can inhabit the alkaline ( $\mathrm{pH} 9$ - 10) and saline (about 80-100 g/L) waters of Mono Lake in California, is known to have increased 
growth in alkaline conditions (Mono Lake Committee, 2012; Simeone, 2001; Herbst $e t$ al., 1988). Tolerance of BSFL to toxic metabolites from fermentation leachates has not yet been described

Many arthropods have been reported to tolerate extremely low temperature ranges, although metabolic activity is often very low when exposed to such temperatures. For example the mite Alaskozetes antarcticus, can survive in subfreezing temperatures, but loses locomotive abilities at about $-5.0^{\circ} \mathrm{C}$ to $-6.6^{\circ} \mathrm{C}$ (Block et al., 1990). Another species, the Antarctic mite (Nanorchestes antarcticus), retains locomotive abilities at temperatures as low as $-11^{\circ} \mathrm{C}$ (Block et al., 1990). Food consumption tends to decrease greatly when arthropods are cooled to between $5{ }^{\circ} \mathrm{C}$ and $0{ }^{\circ} \mathrm{C}$ as well (Block et al., 1990). On the other hand, species of ants (Ocymyrmex barbiger) known to scavenge insects that die from heat exposure were shown to have maximum scavenging temperatures as high as $52{ }^{\circ} \mathrm{C}$ (Marsh, 1985). Tomberlin et al. (2009) tested BSFL growth at $27{ }^{\circ} \mathrm{C}, 30^{\circ} \mathrm{C}$, and $36{ }^{\circ} \mathrm{C}$ and showed optimal survival and growth at $30^{\circ} \mathrm{C}$, but did not report tolerance extremes.

\section{Objectives}

The research presented in this chapter analyzes BSFL growth in and tolerance to four growth inhibitors common to compost and fermentation processes: ethanol, acetate, $\mathrm{pH}$ extremes, and temperature.

\section{Materials and Methods}

Tolerance to ethanol, acetate, $\mathrm{pH}$ and temperature were measured in triplicate using the slanted test tube set up (Fig. 4.1). In this experimental setup twenty BSFL are incubated 
in $10 \mathrm{ml}$ of a specific solution at $30^{\circ} \mathrm{C}$ at a $30^{\circ}$ angle for two days. The angle allows larvae to move in and out of the liquid to alternate between feeding and breathing. Therefore, although they weren't constantly submerged, they were consistently surrounded by the solution of interest within the tube. Solutions contained $30 \mathrm{~g} / \mathrm{L}$ Luria Broth (LB) broth (Becton, Dickinson and Company, DIFCO) and a specific concentration of ethanol or acetate, added in the form of sodium acetate $\mathrm{C}_{2} \mathrm{H}_{3} \mathrm{O}_{2} \mathrm{Na}$ (Sigma-Aldrich).

Larvae were exposed to nutrient solutions ( $30 \mathrm{~g} / \mathrm{L} \mathrm{LB}$ ) and water amended to $\mathrm{pHs}$ of 0.7 to 13.7 compared to an unamended control LB solution ( $\mathrm{pH}$ between 6.5 and 6.7). To test the effects of temperature on larvae, BSFL were exposed to temperatures of $0{ }^{\circ} \mathrm{C}$, $7{ }^{\circ} \mathrm{C}, 15{ }^{\circ} \mathrm{C}, 30{ }^{\circ} \mathrm{C}, 37^{\circ} \mathrm{C}, 50{ }^{\circ} \mathrm{C}, 60{ }^{\circ} \mathrm{C}$ and $70{ }^{\circ} \mathrm{C}$ for two days. Post-treatment weight, death and final $\mathrm{pH}$ of the solutions were collected. Growth rates, death rates and $\mathrm{LD}_{50}$ measurements for two days of exposure to a given condition were calculated based on results.

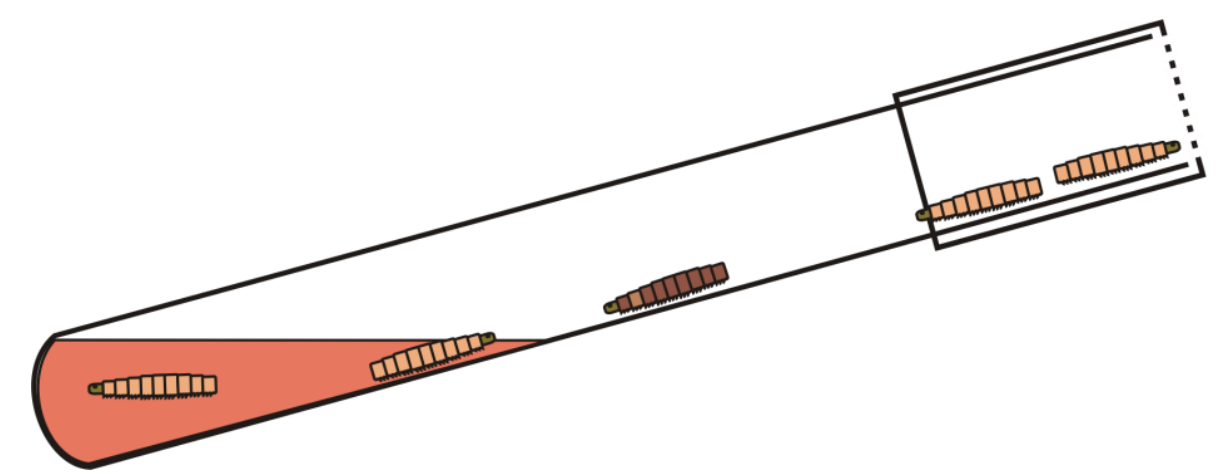

Figure 4.1. Tilted tube set-up exposes larvae to chemical or condition of interest as they feed on nutrients in the liquid, while allowing them to crawl in and out of the solution to breathe.

\section{Results and Discussion}

In ethanol tolerance experiments larval weight gain was negatively affected by ethanol levels above about $2.50 \%$ (Fig 4.2), but death rates did not increase until ethanol 
concentrations reached $40 \%$ (20\% death rate). The death rate increased to $87 \%$ in ethanol concentrations of $80 \% . \mathrm{LD}_{50}$ of two-day ethanol exposure was about $42 \%$ for mature larvae and about $36 \%$ for younger larvae. These values are higher than the largest $\mathrm{LD}_{50}$ levels reported for Drosophila, although Drosophila 48 hour $\mathrm{LD}_{50}$ levels were generally measured in adult flies rather than in larvae (David and Van Herrewege, 1983).

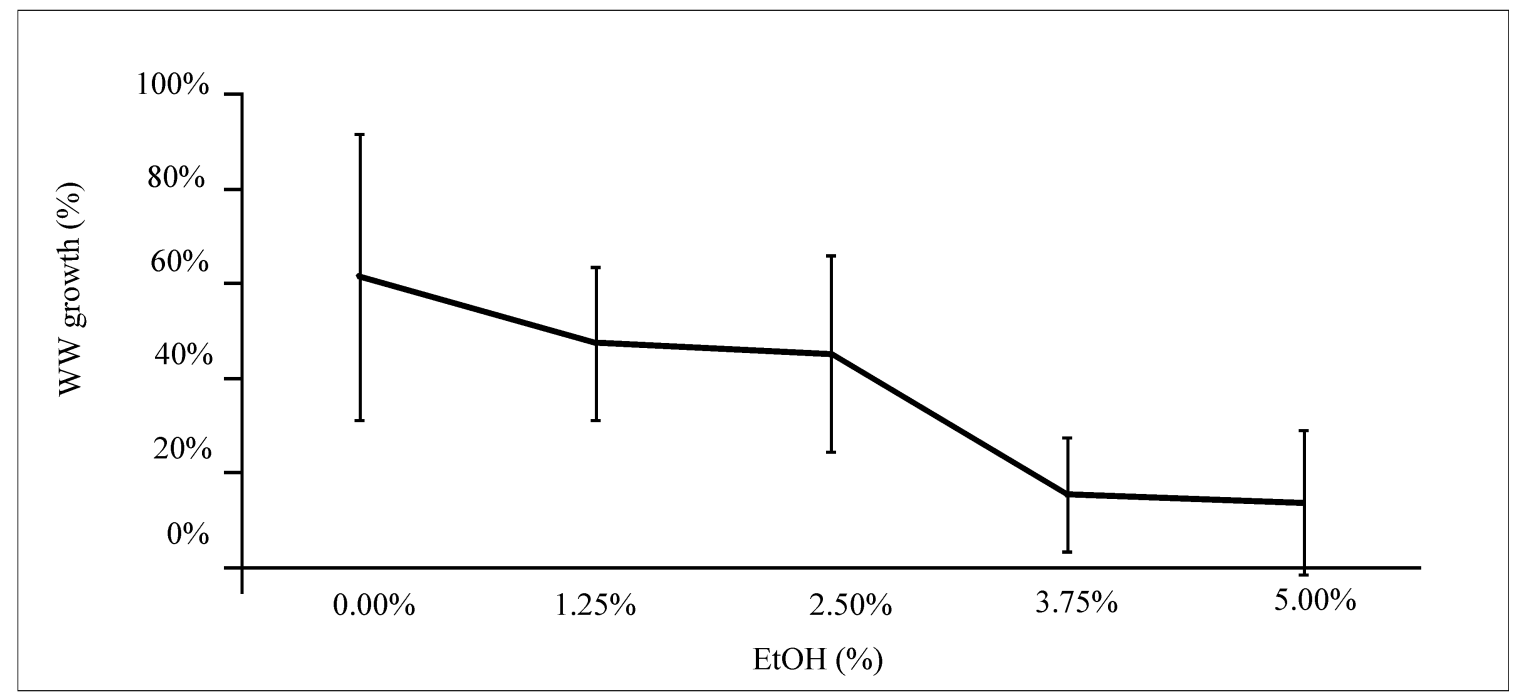

Figure 4.2: Percent larval wet weight (WW) growth after two days of incubation in up to $5 \%$ ethanol. WW growth is not significantly affected until $3.75 \%$. Error bars represent \pm 1 standard deviation.

In acetate inhibition experiments the $\mathrm{pH}$ was initially maintained at 3.7 (i.e. the $\mathrm{pH}$ of compost leachate), but larvae changed the $\mathrm{pH}$ to 7.8 - 8.9 in all treatments within one to two days. We explored using a phosphate buffer to stabilize the $\mathrm{pH}$, but larval growth was negatively affected by the buffer and they were still able to alter the $\mathrm{pH}$ to about $7.80-8.05$ in the presence of up to $200 \mathrm{mM}$ of buffer. Therefore, further experiments were conducted without buffer.

BSFL were shown to tolerate acetate up to about $2.6 \%$ without visible effects on growth (Fig. 4.3). A slight increase in growth was consistently measured at acetate 
concentrations of about $0.9 \%$ (Fig. 4.3). This suggests that larvae are benefiting from low levels of acetate, either directly or indirectly. This was supported by research from the previous chapter which indicated that BSFL are able to ingest VOAs (Popa and Green, 2012). Treatments with $3.5 \%$ acetate led to significant decrease in weight as acetate concentrations increase (Fig. 4.3). Finally, the $\mathrm{LD}_{50}$ for acetate for two days was calculated to be about $46 \%$ for mature larvae and about $16 \%$ for younger larvae. Data indicate that younger larvae are more sensitive to acetate and ethanol than more mature larvae.

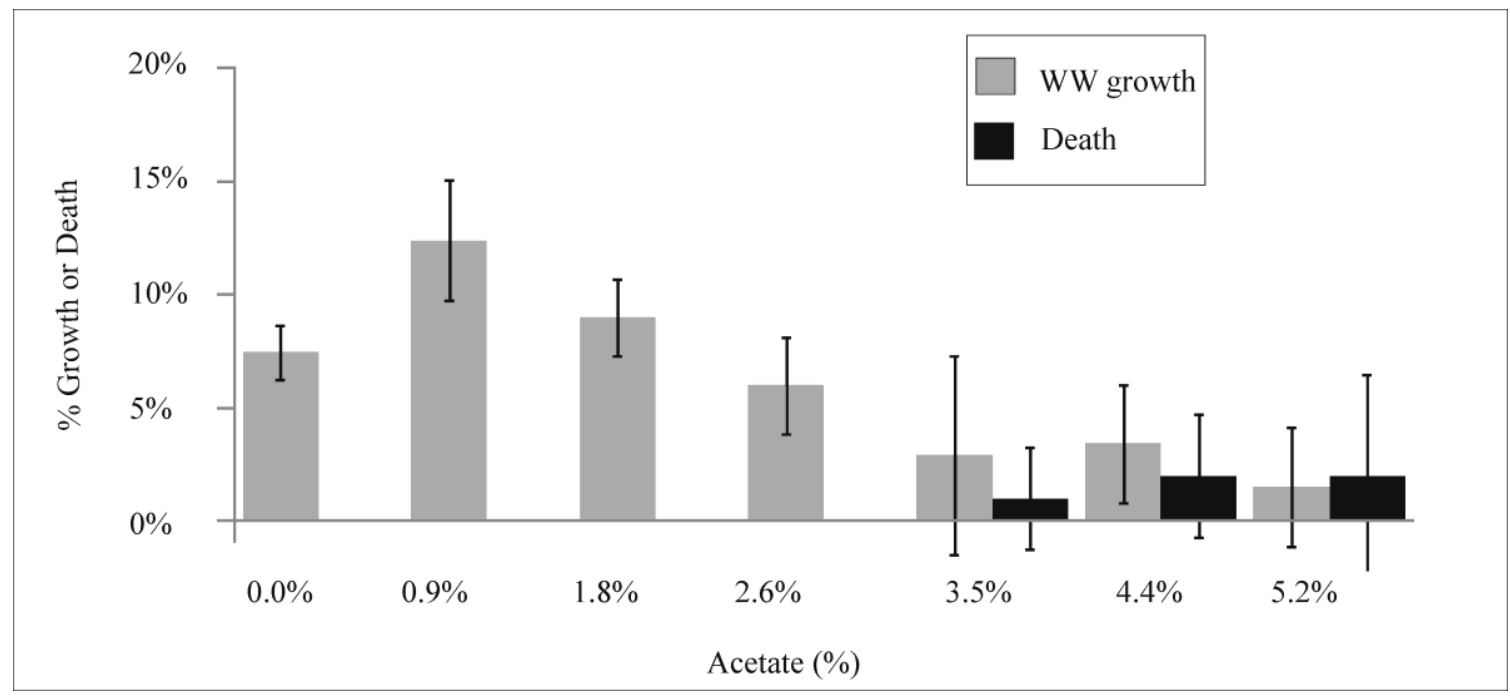

Figure 4.3: Larval growth and death rates after two days of incubation in solutions of varying acetate concentrations.

Larvae were able to tolerate both nutrient and water solutions with initial $\mathrm{pHs}$ from 1.7-12.7 without significant increases in death rate above the control (Fig 4.4). When exposed to initial pHs between 2.7 and 12.7, larvae altered the $\mathrm{pH}$ of the solution to $7.8-8.9$ within a two-day period. When exposed to a nutrient solution with a $\mathrm{pH}$ of 1.7 the larvae increased the $\mathrm{pH}$ to between 2.4 and 2.7 within two days, but without measurable increased death rates relative to the controls. Growth rates decreased and 
death rates increased significantly at $\mathrm{pHs}$ of 0.7 and 13.7 in nutrient solutions (Fig. 4.4). In water solutions, $0 \%$ of larvae survived a $\mathrm{pH}$ of 0.7 , and $90 \%$ survived a $\mathrm{pH}$ of 13.7. These results show that both younger and older larvae are able to tolerate a wide range of pHs including acidic and alkaline extremes. These extremes are lower than previously reported for other arthropods, but this may be due to the short-term nature of the study as some caddisflies have been shown to tolerate pHs of 1.5 for up to 96 hours (based on $\mathrm{LD}_{50}$ values) (Standeven, 1988).

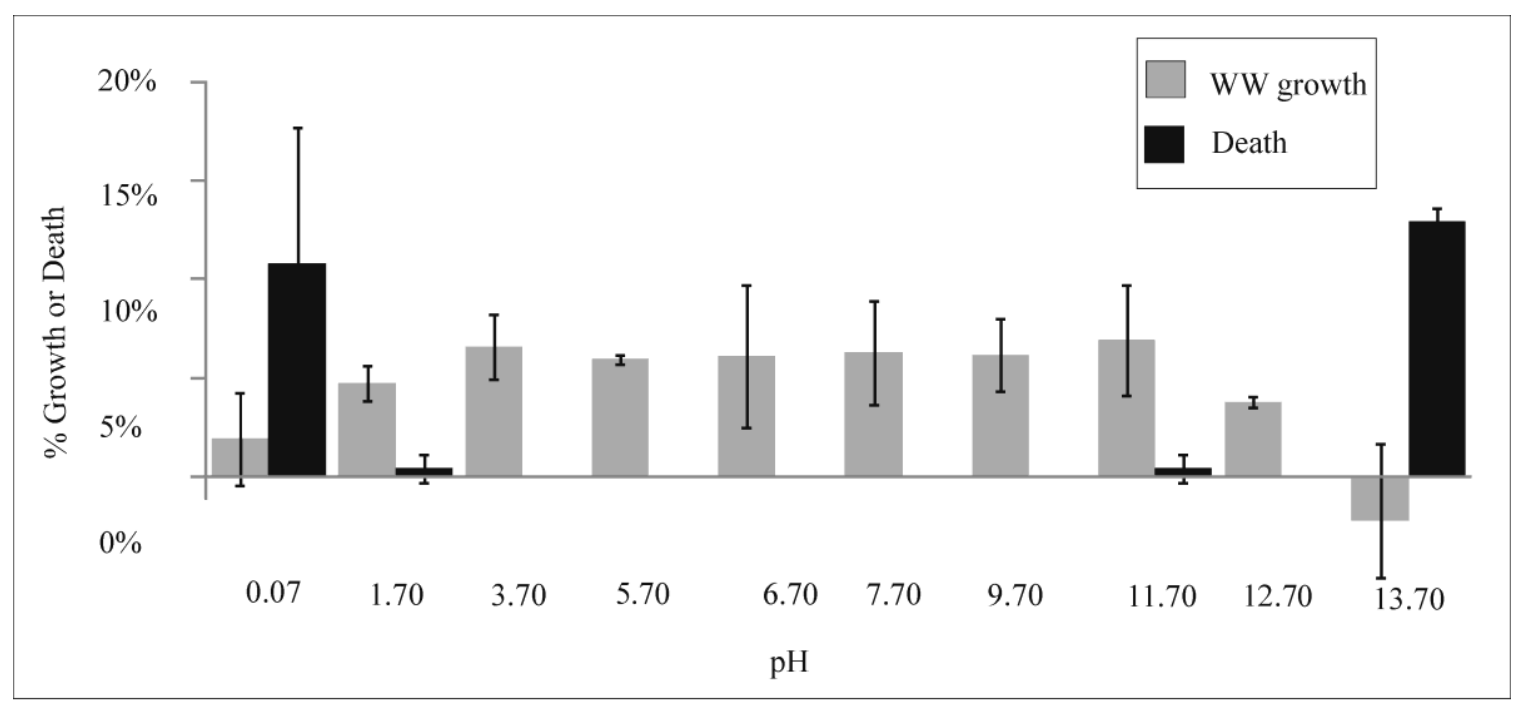

Figure 4.4: Larval growth and death rates after two days of incubation in solutions of LB with amended pHs.

Analysis of combined effects of $\mathrm{pH}$ and acetate on larval growth and death was attempted. But, due to the larval tendency to alter $\mathrm{pH}$ and the negative effects of buffers on growth, no conclusions were reached in terms of combined affects.

BSFL grew within a temperature range between $7{ }^{\circ} \mathrm{C}$ and $37{ }^{\circ} \mathrm{C}$ with optimal growth at $30{ }^{\circ} \mathrm{C}$ (Fig. 4.5). This temperature optimal is consistent with previously reported data by Tomberlin et al. (2009). BSFL had $100 \%$ death rates at temperatures of near $0{ }^{\circ} \mathrm{C}$ and at or above $50{ }^{\circ} \mathrm{C}$. 


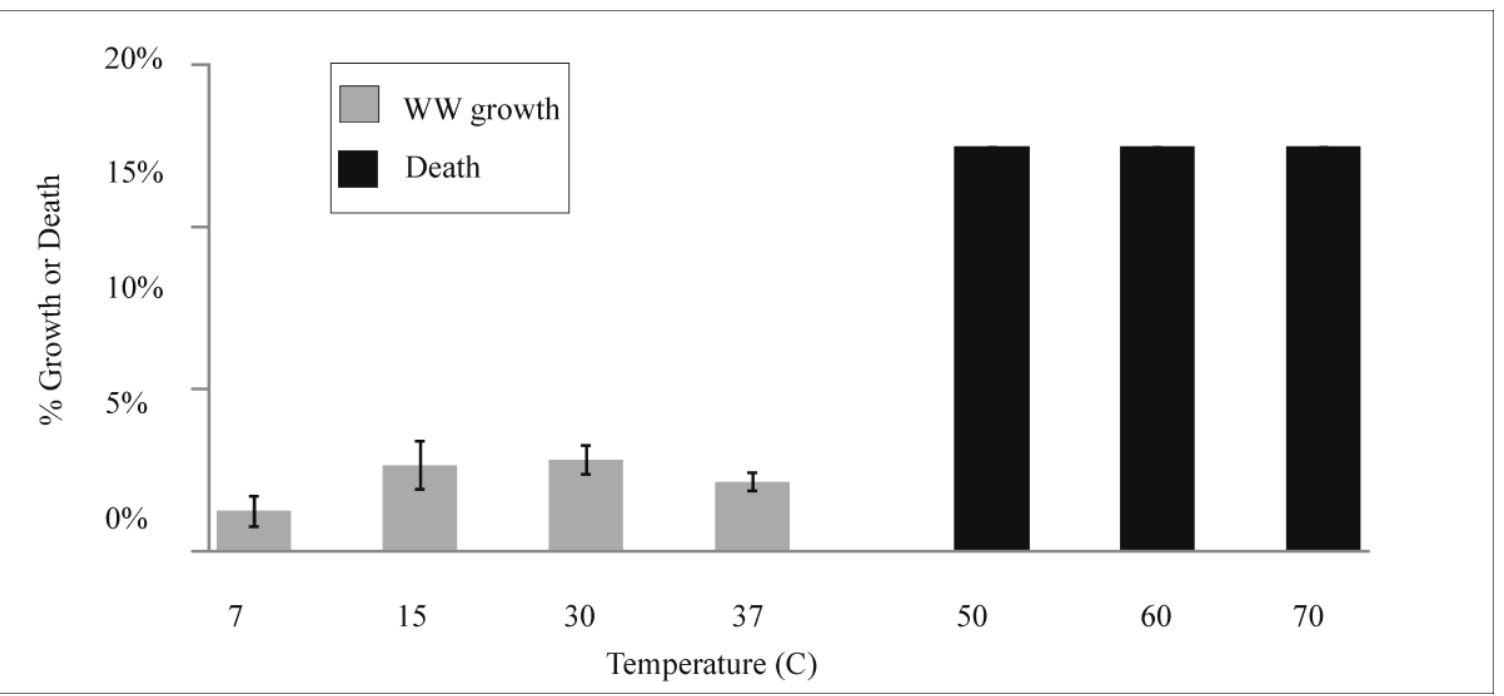

Figure 4.5: Larval growth and death rates after two days of incubation at various temperatures.

It is important to note that initial results were taken on mid-sized ( 23 to $25 \mathrm{~mm}$ ) white/gray larvae that still had not entered the final instar of development. It was observed that control larvae would increase or decrease in weight with no apparent explanation. Therefore, an experiment was conducted on larvae of various colors, and densities representing different developmental stages. Results showed that white-grey larvae were not all in similar developmental stages (Fig. 4.6). In fact, they could be differentiated by density. Those with densities higher than water were close to the final instar of development and were no longer gaining weight. This explained data in which decreased growth was observed. Those large white/grey larvae lighter than water were still growing and developing. Small white larvae (about 8 to $18 \mathrm{~mm}$ ) had a density lower than water and consistently grew in all experiments. Therefore, after the initial set of experiments with large white larvae ("mature"), results were verified with small white larvae (“younger") as well, which supported previous results. 

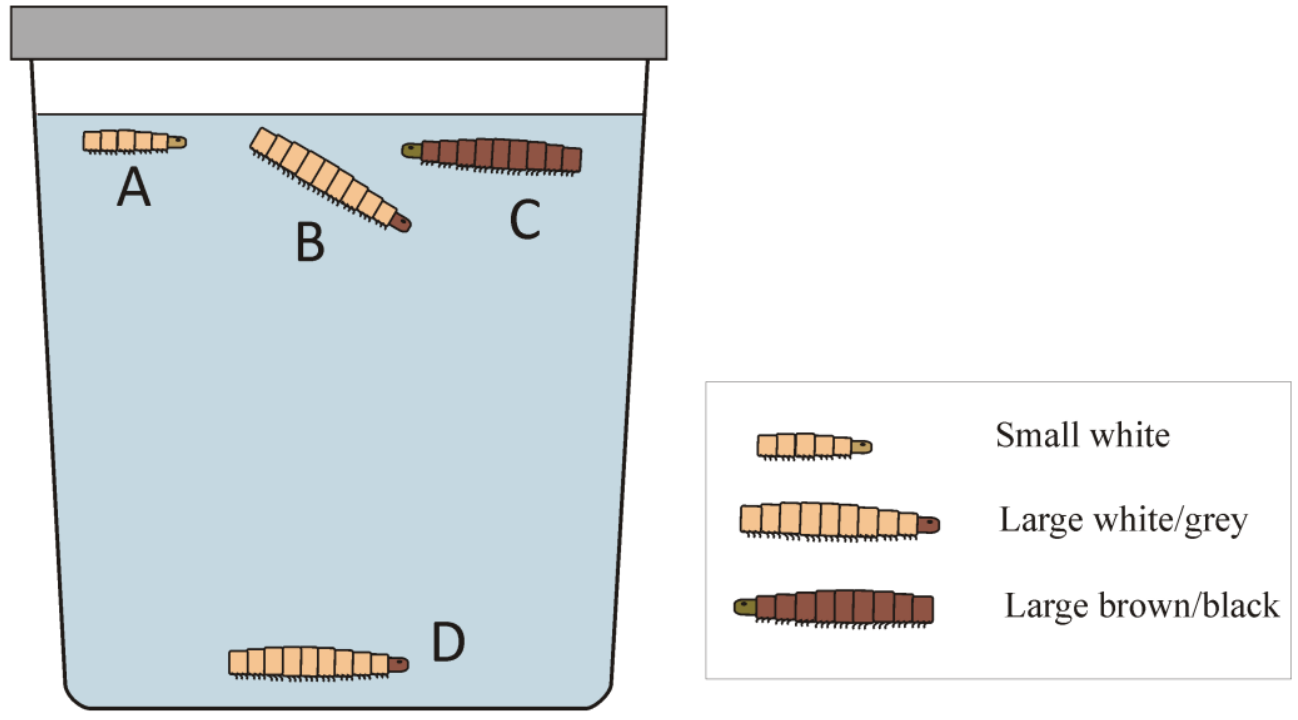

Figure 4.6: Larval developmental categories based on color and density relative to water. Small (A; 8-18 $\mathrm{mm})$ and large (B;20-25 mm) white/grey floaters developed and grew, but brown floaters (C) and white/grey sinkers (D) were near pupating stage and no longer grew.

\section{Conclusions}

The results indicate that growth of BSFL is unaffected by ethanol up to about $2.5 \%$ and acetate up to about $2.6 \%$. In fact, larvae have increased growth at about $0.9 \%$ acetate. They are also tolerant to initial $\mathrm{pH}$ levels ranging from 0.7 to 13.7 and are able to amend initial pHs of 2.7 to 12.7 to between 7.8 and 8.9 within one to two days. BSFL were also shown to grow in temperatures between $7{ }^{\circ} \mathrm{C}$ and $37^{\circ} \mathrm{C}$, but optimal growth occurred at about $30^{\circ} \mathrm{C}$. This resilience to alcohols, acids and $\mathrm{pH}$ make BSFL suitable for use in leachate processing biotechnologies. 


\title{
Chapter 5:
}

Effects of various compost residues and leachates on growth of corn and winter wheat Additional author

Fetheya Alattar (Co-primary investigator; to present project at Intel NW Science Expo)

\begin{abstract}
The positive short and long term effects of aerated compost and earthworm vermicompst on soil quality and plant growth are well documented. Soil amendments from these processes lead to increased carbon $(\mathrm{C})$ and nitrogen $(\mathrm{N})$ content, biodiversity of soil microbiota, and crop yields and decreased soil density and plant pathogens. Yet, relatively little is known about the effects of microaerobic fermentation (MF) and Black Soldier fly larvae (BSFL) processing products, both liquid and solid, on soil quality and plant growth. This study compared growth of corn plants in soil amended with MF, BSFL, and aerated compost solid residues. The effects of MF and BSFL leachate on the growth of winter wheat were also analyzed. Corn plants showed increased height and leaf growth when grown in soil amended with aerated compost and MF residues, but showed stunted growth in soils amended with BSFL solid residue. This suggests that BSFL solid residue is phytotoxic when amended into soil in a ratio of one part residue to two parts dirt. MF leachate decreased winter wheat growth by about $93 \%$ when undiluted and unprocessed, but BSFL processed leachate enhanced plant growth by $11 \%$ to $30 \%$ at concentrations of 1 and $10^{-1}$ respectively. This indicates that MF solid residues are beneficial soil amendments and that diluting MF leachate or treating it with BSFL makes it suitable as a liquid fertilizer.
\end{abstract}




\section{Introduction}

The process of composting produces organic material rich in fiber, $\mathrm{N}$ and phosphorous (P), which can be used as an agricultural fertilizer or soil amendment. Fertilizing efficiency of compost product depends on feedstock materials and specifics of the process used. Aerated composting has many variations, but essentially encourages the thermopilic breakdown of organic material through respiration by introducing air into the organic waste pile (BioCycle, 2008). Vermicomposting, another compost method, allows for processing of materials by worms (often Red Wrigglers and other earthworms) and bacterial communities under non-thermophilic conditions (Theunissen, 2010). BSFL are also used for degradation of organic matter, especially manure (Liu et al., 2008; Myers et al., 2008), but little is known about the effects of BSFL solid residues on plant growth. MF is another process for controlled degradation and recycling of organic waste and is described in detail in chapter 1.

Optimal proportions of compost amendment depend on the type of compost and the crop being grown. Recommended amendment proportions range from $8 \%$ to $75 \%$ (Kalantari et al., 2011; Herrera et al., 2008; Atiyeh et al., 2000; Hicklenton, 2001). For example, Herrera et al. (2008) reports optimal growth of tomato seedlings in soil amended with $30 \%$ municipal solid waste (MSW) aerated compost. Kalantari et al. (2011) reported optimal growth in corn plants grown in soil amended with $3 \%$ vermicompost (yard leaf and manure origin) and even higher growth when Fe sulfate supplements were added. Atiyeh et al. (2000) reported increased growth of tomato plants grown in $10 \%$ and $20 \%$ pig manure vermicompost, or $10 \%$ vermicomposted food 
waste, but no significant increased growth in raspberry plants amended with similar vermicompost types and proportions.

Even though amendment proportions vary, research consistently shows extensive short and long term affects on soil quality and plant growth. Long-term effects include increased sequestration of organic $\mathrm{C}$, increased $\mathrm{N}$ content, increased soil microbial biodiversity, decreased bulk density and increased crop quality and yields (Diacono et al. 2010; Ingham, 2008; Ros et al., 2006; Meier-Ploeger et al., 1989; Marchesini et al. 1988). Some studies have shown that use of compost fertilizers instead of inorganic fertilizers can decrease the amount of fertilizer needed from $400 \mathrm{~kg} / \mathrm{ha}$ inorganic fertilizer to $4 \mathrm{~kg} / \mathrm{ha}$ compost material, which could decrease the price of agricultural fertilizing by $50 \%$ or more (Blenkinsop, 2012; EPA, 2011; USDA, 2011; Ingham, 2008).

Composts and compost teas, liquid mixtures of compost residues and nutrients, have also been shown to decrease the prevalence of certain plant pathogens in soil (Dukare et al., 2011; Kone et al., 2010; Ingham, 2008; Szczech and Smolinska, 2001). In some cases these effects have been more significant than those demonstrated with chemical control methods (Dukare et al., 2011). On the other hand, the effects of MF leachate on plant growth are not well documented.

Furthermore, BSFL processing of liquid is a completely novel biotechnology and has not been studied prior to the research done in our lab. Preliminary data suggest that MF leachate is phytotoxic due to its high concentration of organic acids and alcohols and low $\mathrm{pH}$. But, BSFL processing has been shown to decrease concentrations of organic 
acids and alcohols and neutralize pH (Fig. 3.2 and 3.3). Therefore, resulting leachate may be suitable for use as a liquid fertilizer.

\section{Objectives}

The research presented in this chapter had two objectives: 1) to compare effects of residue produced from aerated composting, earthworm vermicomposting, MF and BSFL processed residues on corn plant (Zea mays) growth. 2) To compare the effects of BSFL processed and unprocessed MF leachate on winter wheat (Triticum hybernum) growth.

\section{Methods and Hypotheses}

Effects of solid residue on corn plant growth

All organic materials for corn plant experiments originated from kitchen scraps. These included waste from fruits, vegetables, breads, coffee grounds, rice and grains, and some eggs and dairy products (only in BSFL and MF bins). Organic material was collected in a mixed bin and distributed between the composting units: a Garden Plus 115 gallon aerobic compost bin (Fig. 5.1A), a cylindrical 5 gallon drinking thermos (Rubbermaid) which served as an MF fermentor (Fig. 5.1B), and separate units made from plastic $68 \mathrm{~L}$ containers with air-holes drilled into the sides, lid and bottom (Rubbermaid, Roughneck) for BSFL and earthworm processing (Fig. 5.1C).

A bag made from DuPont 100' x 4' WeedFreePro Fabric filled with rocks was laid on the bottom of both the MF fermentor and vermicomposting units. In the MF fermentor the bag functioned as a filter of particular matter to avoid clogging when leachate was drained from the spigot, and in the vermicompost units it allowed for simultaneous aeration of larvae/worms and insulation of the container from the bottom. 
The earthworm vermicompost was terminated about a month into the experiment, because it was difficult to get the worms to remain in the bin and process the materials. Rotting organics resulting from the lack of worm processing eventually led to earthworm death as well.

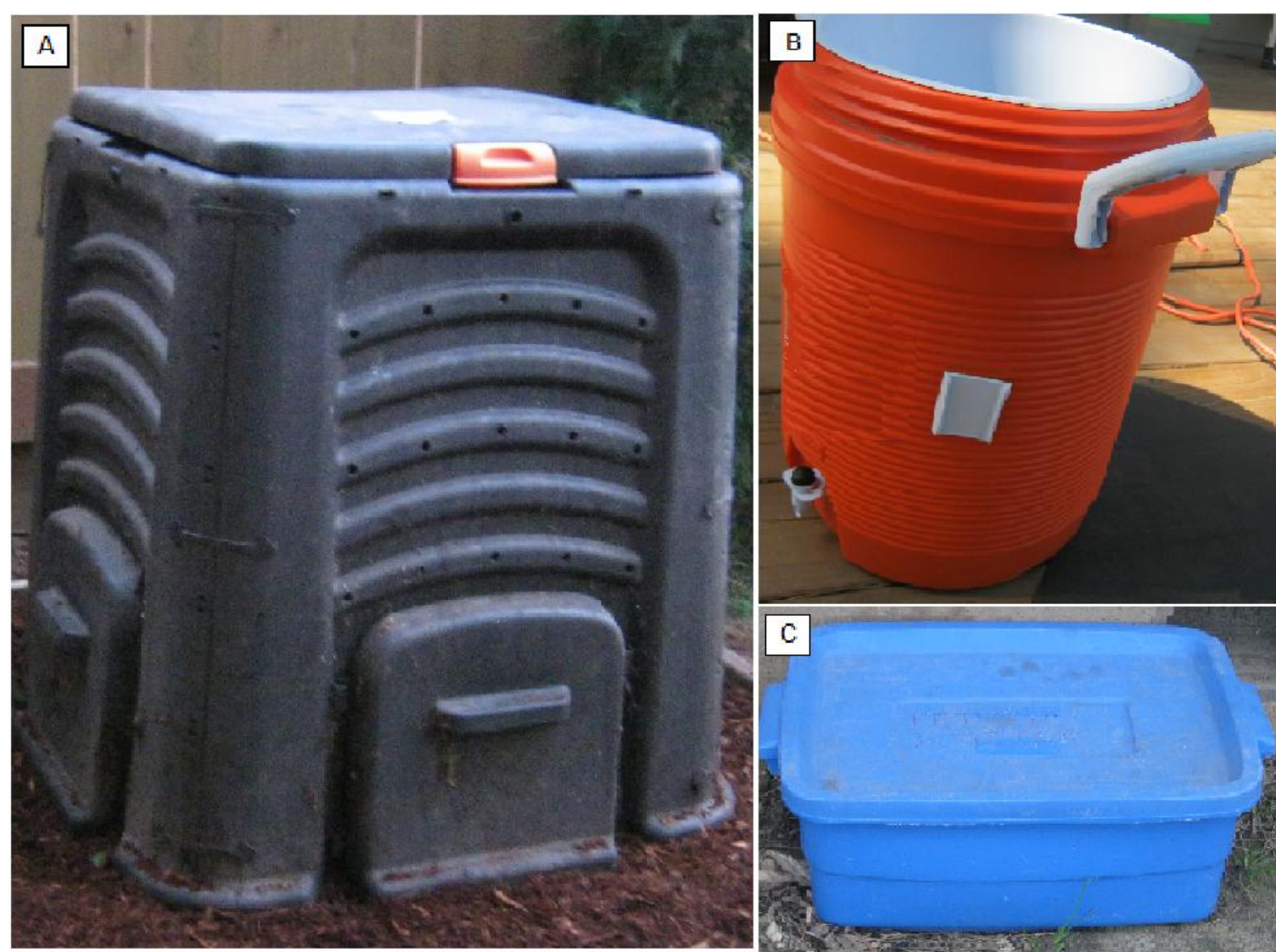

Figure 5.1: Aerobic compost bin (A), MF fermentor (B), BSFL processing bin (same container type used for earthworm vermicompost) (C).

Organics were collected and processed for 3 months for aerated and MF units and 1.5 months for the BSFL unit (due to increased processing efficiency). Compost stability for aerated and BSFL processed materials were determined through visual and olfactory characteristics. Material was collected from the bottom of the aerated compost bin when 
it resembled soil visually and in odor and its origin could not be recognized. Some lignocellulosic material, small twigs and straw, were still recognizable in the material though. BSFL residue stabilization was identified with similar visual methods, but was also collected from areas with little larval activity, which indicates lack of nutrients and complete degradation of that area. MF materials were considered completely processed, because they were incubated for 3 months, which is significantly longer than the 2-5 week processing common for MF. Materials were collected from the bottom of the MF and leachate was lightly squeezed out before mixing into soil.

Processed materials were mixed into soil in a ratio of one part compost to two parts dirt (volume/volume). The dirt used for mixing (and as a control) was collected from a yard area that had not recently been fertilized and did not have significant plant or grass growth. BSFL and aerated composts were mixed thoroughly through the soil, whereas MF residues were laid over about $2-5 \mathrm{~cm}$ of soil on the bottom of the pot and then covered with about $15 \mathrm{~cm}$ of soil on top. Since MF is generally used as an underground or buried fertilizer this method was consistent with the common practical application of MF materials (Bokashicycle, 2010). The mixtures were allowed to set and stabilize for three days before planting. Each treatment was tested in triplicate using three separate pots with one corn plant in each. Two controls were used in the experiment: an unamended dirt control and a store-bought aerated compost control (Cedar Grove, WA). Both controls were mixed in the same ratios as the compost treatments and allowed to stabilize for the same period of time. 
About one hundred Sweet Corn plants (Ed Hume Seeds, WA) were started in 3oz (89 ml) paper cups (Dixie, GA), from seed, using seedling soil mix (Black Gold, WA). After one week, fifteen similar sized seedlings were chosen for experimentation and randomly assigned to a treatment.

Plants were transferred to $2.6 \mathrm{~L}$ pots $(\mathrm{ProCal}, \mathrm{OH})$ with a specific compost treatment for the duration of the experiment. Their location in the experimental plot was randomized each week for the first six weeks. After this point, randomization was stopped because of increased risk of damaging the large plants. All plants were watered for 15 minutes one to two times daily using an automatic sprinkling system. The height and number of leaves for each plant were collected weekly. After ten weeks the plants were removed from their pots. Roots and leaves checked for deformities, abrasions or evidence of illness.

Ammonium content of unmixed compost, initial compost/soil mixtures and final compost/soil mixtures were measured using the Nessler ammonium assay (Jenkins, 1967) and $\mathrm{pH}$ was measured on aqueous slurries.

Effects of BSFL and MF leachate on winter wheat growth

Effects of MF and BSFL leachate on winter wheat growth was studied by growing approximately 200 seeds (about $8.89 \mathrm{~g}$ ) of winter wheat in $20 \mathrm{oz}(590 \mathrm{ml})$ plastic containers with varying exposure levels and duplicates of each treatment. Winter wheat is harvested in the early spring, but is planted in the late fall or early winter so that it can take root. Therefore, methods for quickly increasing root biomass and structure before overwintering are important for its practical use in agricultural settings. The plants were 
watered twice weekly with $40 \mathrm{ml}$ of tap water, a vitamin and nutrient mixture, or $1,10^{-1}$,

$10^{-2}, 10^{-3}, 10^{-4}$ dilutions of MF or BSFL processed leachate. The vitamin nutrient media contained $1 \mathrm{mM}$ ammonium bicarbonate $\left(\mathrm{NH}_{4} \mathrm{HCO}_{3}\right), 1 \mathrm{mM}$ potassium phosphate $\left(\mathrm{K}_{3} \mathrm{PO}_{4}\right)$, and $1 \%$ of a culturing mixture including 67.2 uM, $\mathrm{Na}_{2}$ EDTA, $56.6 \mathrm{uM}$ boric acid $\left(\mathrm{H}_{3} \mathrm{BO}_{3}\right), 10 \mathrm{uM}$ sodium chloride $(\mathrm{NaCl}), 5.4 \mathrm{uM}$ ferrous sulfate $\left(\mathrm{FeSO}_{4}\right), 5 \mathrm{uM}$ cobalt dichloride $\left(\mathrm{CoCl}_{2}\right), 5.0 \mathrm{uM}$ nickel sulfate $\left(\mathrm{NiSO}_{4}\right), 3.87 \mathrm{uM}$ sodium molybdate $\left(\mathrm{Na}_{2} \mathrm{MoO}_{4}\right), 1.5 \mathrm{uM} \mathrm{NaSeO} 4,1.26 \mathrm{uM}$ manganese chloride $\left(\mathrm{MnCl}_{2}\right), 1.04 \mathrm{uM}$ zinc chloride $\left(\mathrm{ZnCl}_{2}\right)$, and $0.2 \mathrm{uM}$ copper chloride $\left(\mathrm{CuCl}_{2}\right)$.

For all other days of the week, plants were watered with tap water alone. Plant growth was monitored through photography for two weeks and then final leaf and root mass were measured at the end of the experiment. Experiments on leachates' effects on winter wheat were done twice, once in rich fertilized garden soil and once in nutrientpoor dirt.

\section{Results and Discussion}

\section{Effects of solid residue on corn plant growth}

Product of aerated compost resembled soil or dirt with some twigs and straw evident in the mix. MF processed materials resembled pickled organics. BSFL solid reside was dense, grey in color and the consistency of thick, moist clay. Once mixed with dirt, mixtures had more uniform characteristics, although mixtures from the BSFL residue was slightly more moist and grey in color and mixture from the Cedar Grove control was drier and more dark brown in color than others. 
Plant height and leaf number varied greatly between treatments. Aerated and MF residue amendments led to the largest increase in height and leaf number compared to controls (MF, p-value: 0.005 and aerobic, p-value: 0.006) (Fig 5.2 and 5.3). BSFL solid residues stunted plant growth (Fig 5.2 and 5.3). This suggests that the components of BSFL residues are phytotoxic at a concentration of one part compost to two parts dirt. These effects were hypothesized to be due to high ammonium concentrations characteristic of BSFL residues or lack of residue porosity. 

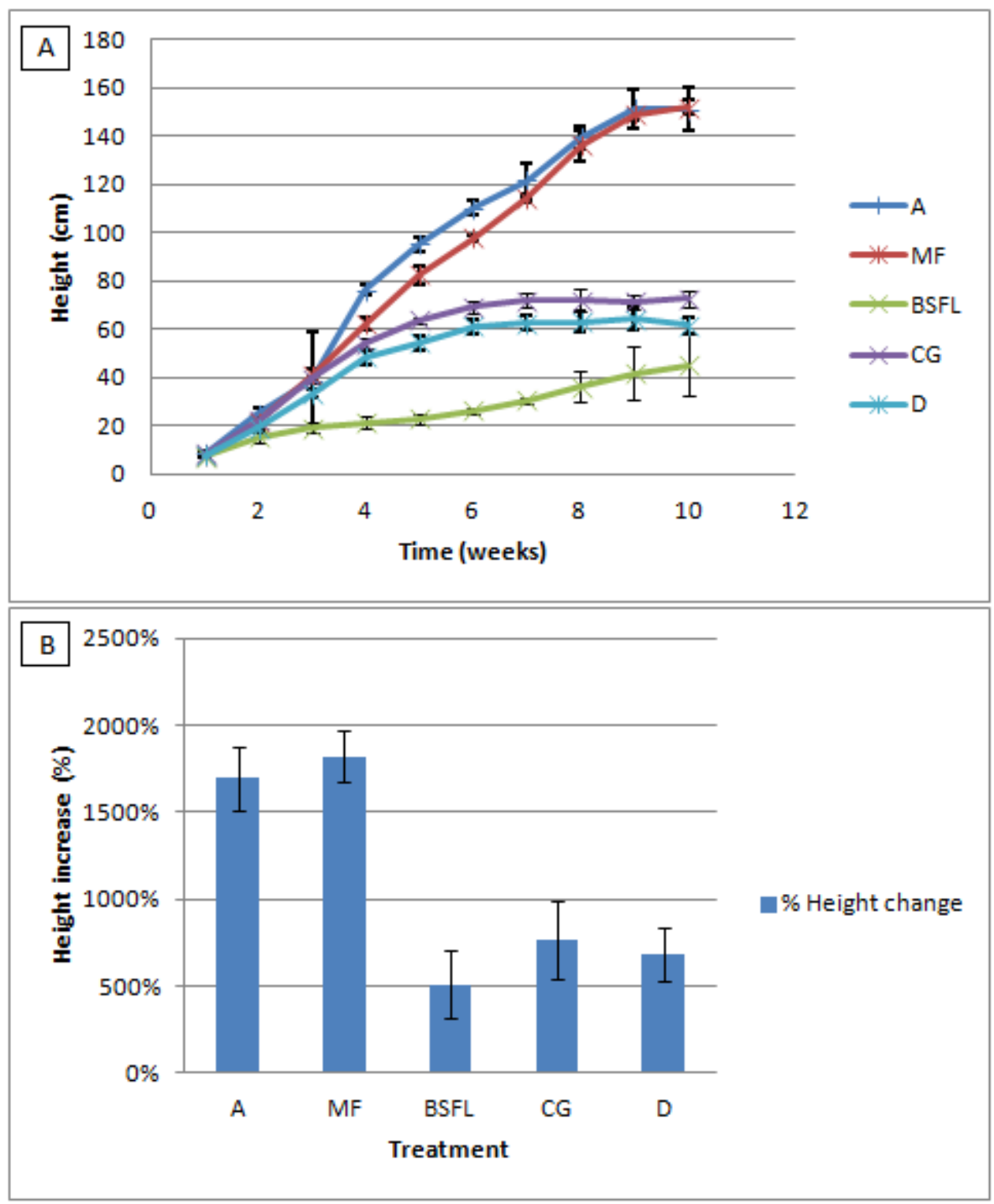

Figure 5.2: Evolution of growth of height over time (A) and as a percentage over the duration of the experiment (B) in compost treatments: Aerobic (A), MF and BSFL residue (BSFL) compared to control dirt (D) and Cedar Grove compost (CG). 

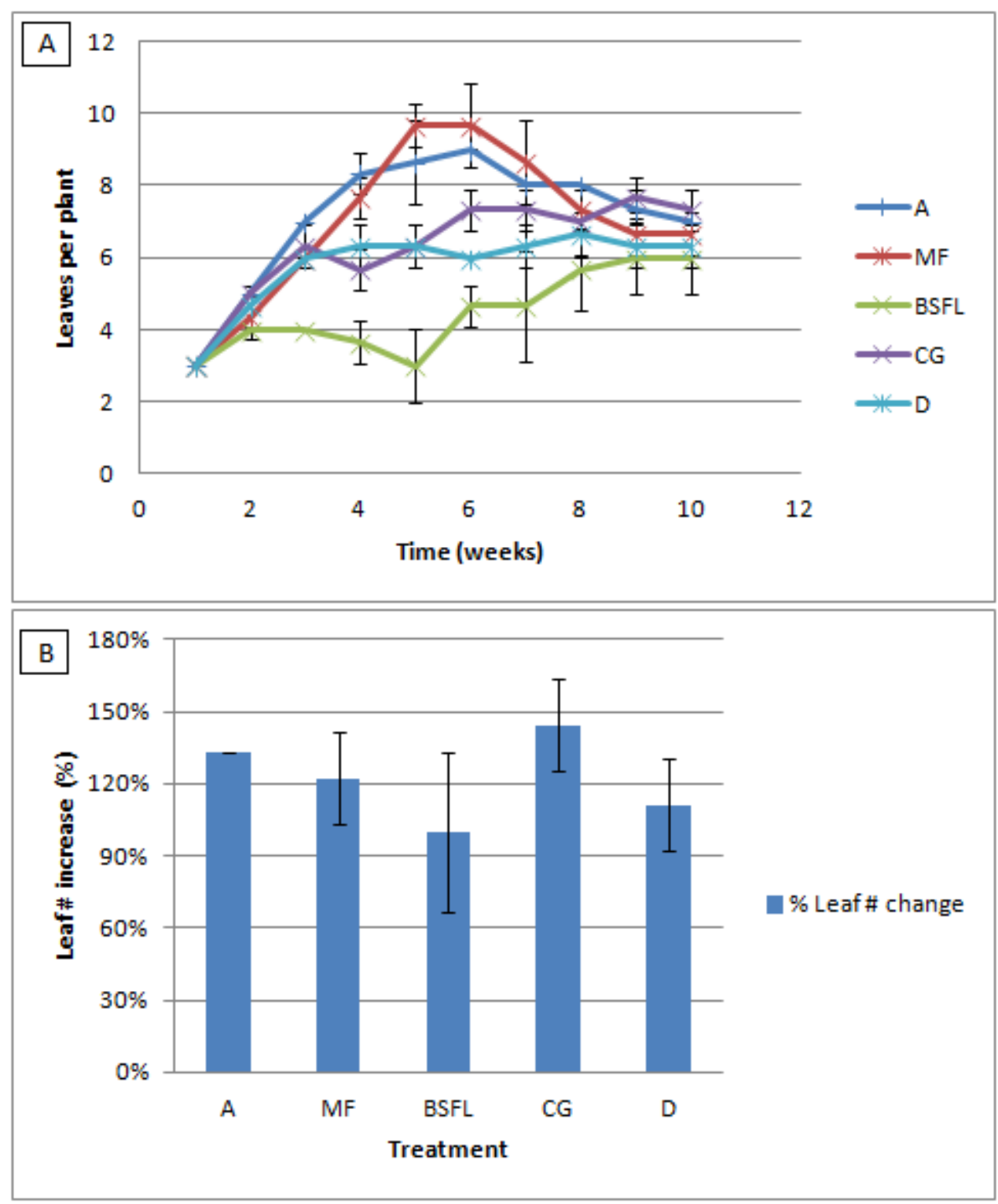

Figure 5.3: Evolution of leaf growth (A) and percent overall growth of leaves (B) over the duration of the experiment in compost treatments: Aerobic (A), MF and BSFL residue (BSFL) compared to control dirt (D) and Cedar Grove compost (CG).

Ammonium concentrations in the various residues and dirt/residue mixtures were tested to determine if high ammonium concentration explained stunted growth in BSFL residue treatments. Although ammonium was present in the unmixed BSFL residue, once it was mixed with the soil very little ammonium was detectable (Fig. 5.4). MF residue actually had higher concentration of ammonium both before (about $5233 \mathrm{mM}$ 
ammonium) and after (about $10 \mathrm{mM}$ ammonium) mixture with dirt. Initial data was not available for aerobic treatments (Fig. 5.4). These data suggest that ammonium is not the direct cause of stunted plant growth in plants grown in soil amended with BSFL residue. Further research is required to fully understand the reason for BSFL residue stunting of corn plant growth.

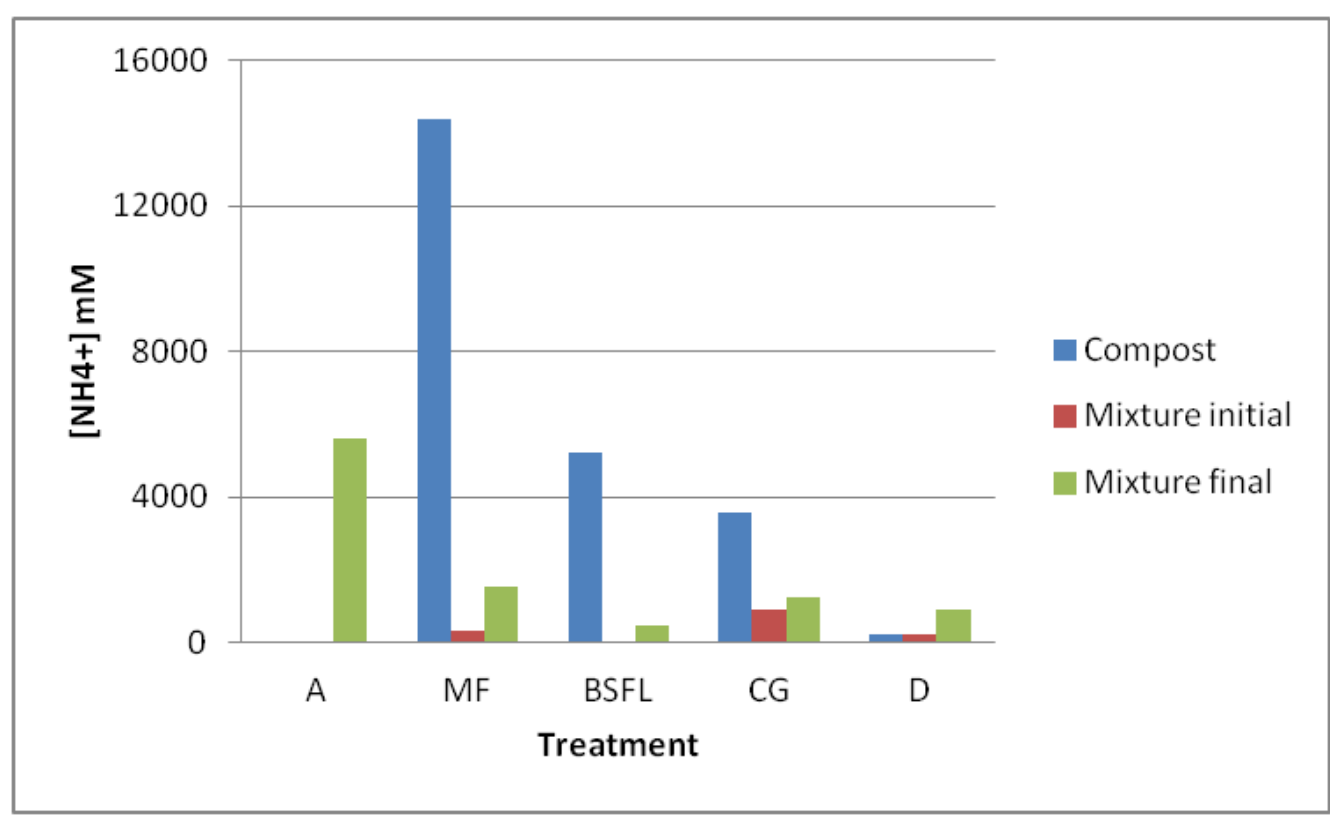

Figure 5.4: Ammonium concentrations in unmixed compost (compost), initial compost/dirt mixtures (Mixture initial) and final compost/dirt mixtures (Mixture final) from different treatments and controls: Aerobic (A), MF and BSFL residue (BSFL) compared to control dirt (D) and Cedar Grove compost (CG).

\section{Effects of BSFL and MF leachate on winter wheat growth}

BSFL processed leachate, when undiluted or diluted 10 fold, led to about $11 \%$ to $30 \%$ increased winter wheat growth compared to water control (BSF 1x, p-value: 0.05 and BSF 10x, p-value: 0.04), but lead to growth similar to controls when diluted further (Fig. 5.5). Undiluted, untreated MF leachate, however, showed $93 \%$ decrease in winter wheat growth when compared to water control (p-value: 0.003 ). When diluted 10 to 10,000 fold growth was similar to controls (Fig. 5.6). Trends were evident in both leaf and root 
growth data. Although BSFL processed leachate significantly increase plant growth, it is important to note that its practical use as a liquid fertilizer will likely be hampered by its unpleasant smell and the need to concentrate it before use for it to reach beneficial concentrations when mixed with irrigation water. This should be considered in further research.

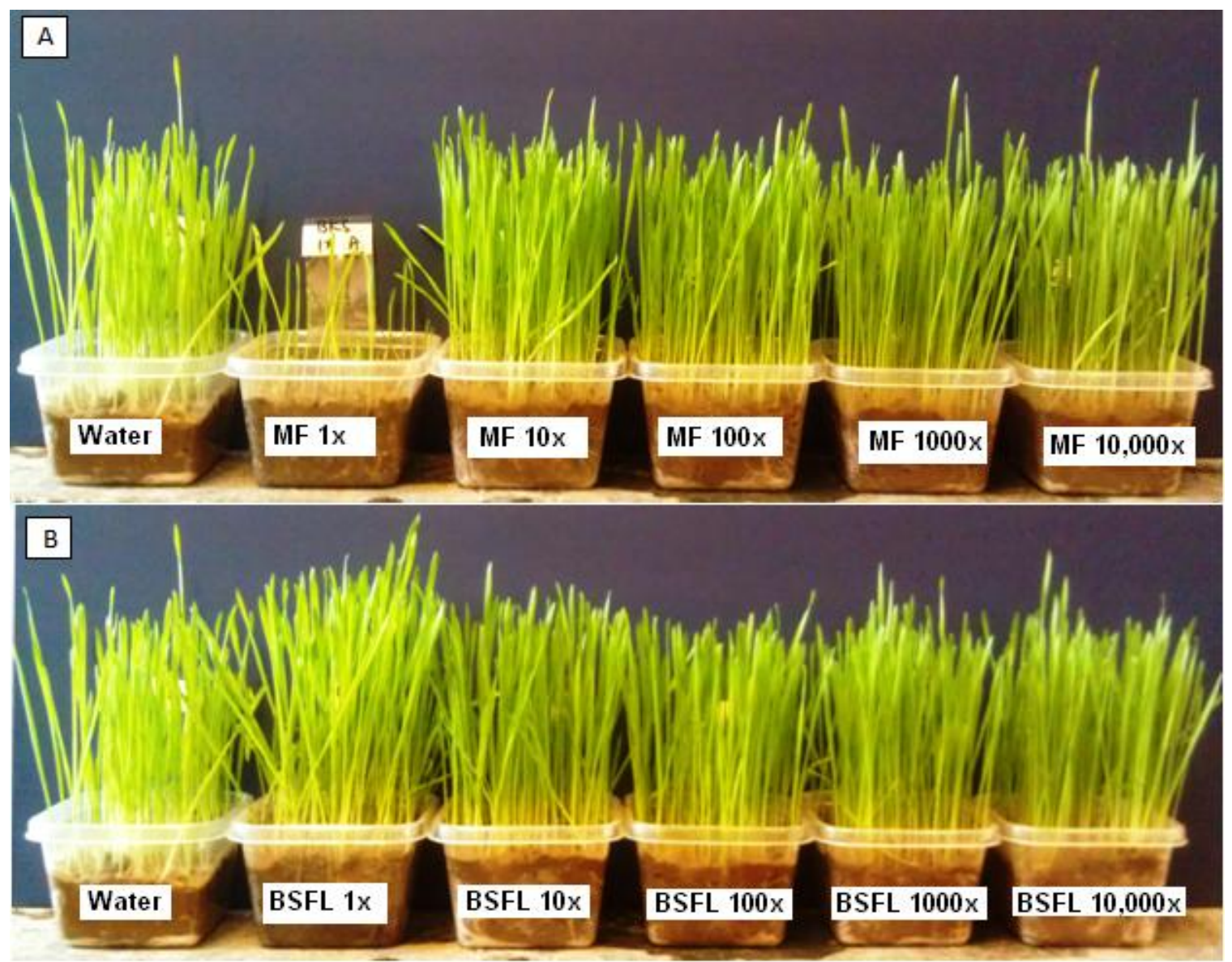

Figure 5.5: Winter wheat growth in water controls compared to dilution series of MF leachate (A) and dilution series of BSFL processed leachate (B) (Photo by Terrence Green, 2012). 


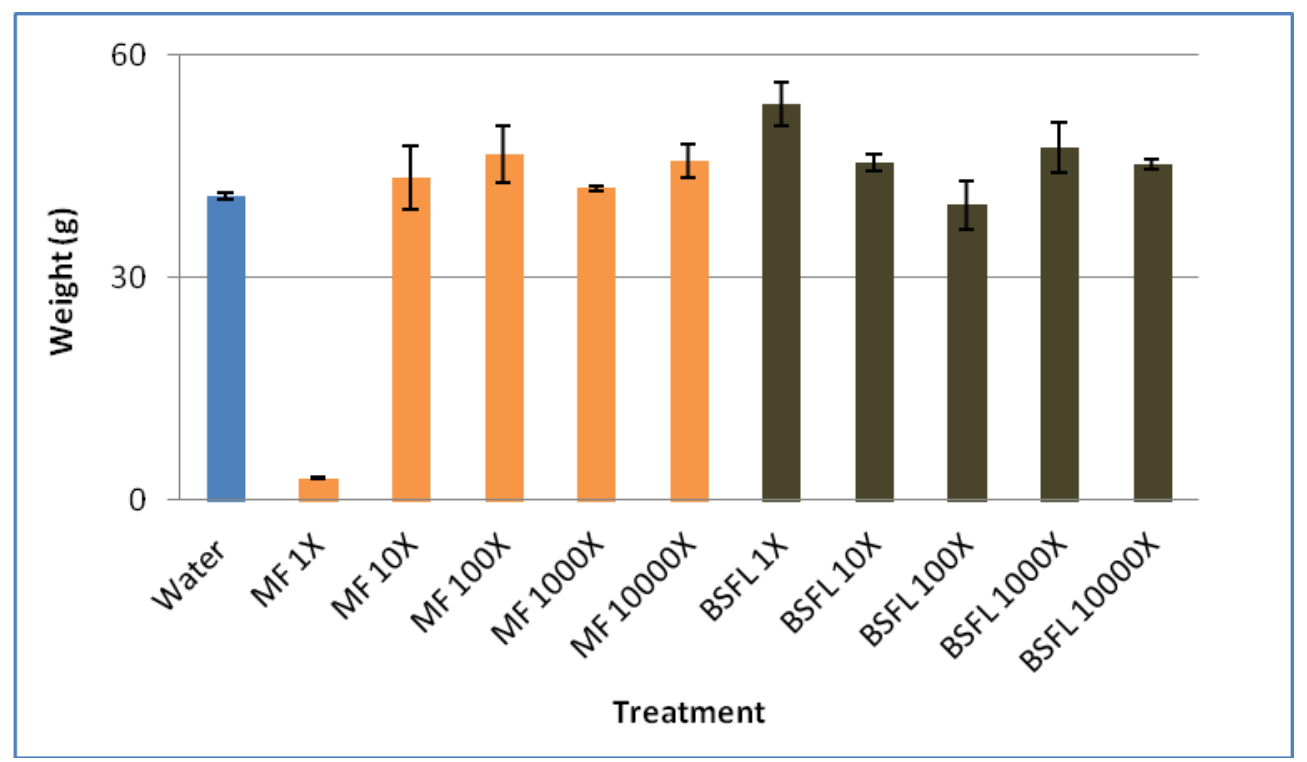

Figure 5.6: Average total winter wheat plant weight in relation to leachate treatment. (Bars are color-coded by the color of the original liquid used for fertilizing: water - blue; MF leachate - tan; BSFL leachate - dark brown.)

\section{Conclusions}

The data indicate that different types of processed organic materials have varying effects on plant growth. Aerated compost and MF solid residues increased corn plant growth, but BSFL residues stunted growth. Although it was hypothesized that stunted growth may have been the result of toxic ammonium levels in the BSFL residue, this was not supported by ammonium content measurements which were actually lower in BSFL residues than in other residues. Therefore, MF solid residues are suitable for amendments with soil at about $30 \%$ amendment, but BSFL residues are not.

MF leachate decreased leaf and root growth of winter wheat plants when added directly to soil, but when diluted 10-10,000 fold showed no phytotoxic effects. BSFL leachate increased plant growth over controls when undiluted or diluted 10 fold. This indicates that BSFL processing eliminates leachate phytotoxicity and makes it a suitable plant fertilizer. 


\section{Chapter 6:}

\section{Overall conclusions}

Microaerobic fermentation (MF) is a method of controlled organic waste degradation in which materials are processed in enclosed, microaerobic fermentors. When processing vegetal materials, endpoints are reached in 2-5 weeks. Products of MF include a solid residue which can be used for soil amendment and a leachate with high concentrations of acids and alcohols and low $\mathrm{pH}$, all strong inhibitors of microbial activity. This research analyzed the efficiency of MF pre-processing of fibrous lignocellulosic (FLC) materials, potential MF leachate treatment methods, and effects of MF and Black Soldier fly larvae (BSFL) solid and liquid processing products on plant growth.

- Data indicate that the traditional 2 - 5 week MF incubation interval is insufficient for preprocessing of FLC materials even with increased produce amendment and various leachate treatments. Although fermentation endpoints were reached within expected time period, once materials were reintroduced into the soil, polysaccharide degradation rates were similar to non-fermented control wood.

Microbial and insect-based technologies were analyzed for efficiency of MF leachate processing with the goal of prolonging MF processing and increasing overall organic degradation efficiency. Sufficient microbial processing treatment could be achieved in 2-3 months through 12 hour alternation between aeration and anaerobic storage or constant aeration, but lengthy processing time makes recirculation of processed leachate impractical. Insect-based leachate treatment using BSFL increased the 
stabilization rate of $\mathrm{pH}$, chemical oxygen demand (COD) and biological oxygen demand (BOD) to $2-7$ days with optimal BSFL concentrations of $0.5 \mathrm{~g} / \mathrm{ml}$ or $0.005 \mathrm{~g} / \mathrm{ml}$.

BSFL have optimal growth in leachate incubated at $30^{\circ} \mathrm{C}$ with controlled fungal growth, as they compete for nutrients within the leachate. They are also able to tolerate a number of biological inhibitors common in MF leachate including ethanol up to about 42 $\%$ for mature larvae and about $36 \%$ for younger larvae, acetate up to about $46 \%$ for mature larvae and about $16 \%$ for younger larvae, initial $\mathrm{pH}$ between 0.7 and 13.7 and temperatures from $7{ }^{\circ} \mathrm{C}$ and $37^{\circ} \mathrm{C}$. The ability of BSFL to withstand such inhibitors makes BSFL suitable for MF leachate processing.

The effects of solid and liquid residues of MF and BSFL processing methods on plant growth were also analyzed. MF solid residues greatly increased corn plant height and leaf growth, but BSFL solid residues stunted overall corn growth compared to controls. This indicates that while MF residues are suitable for soil amendment and plant fertilization, BSFL residue is phytotoxic and must be processed before using as a soil amendment. Although MF leachate inhibits winter wheat growth if undiluted, dilution (10 to 10,000 times) or BSFL processing of leachate significantly decrease phytotoxicity. BSFL processed leachate increase growth of winter wheat $11 \%$ to $30 \%$ over unfertilized controls.

In conclusion, although 2-5 week MF is not suitable for processing of FLC materials, MF processing of vegetal waste does produce a solid residue beneficial for soil amendment and plant growth. MF leachate untreated is phytotoxic, but BSFL processing removes phytotoxicity and the resulting fluid is beneficial as a liquid fertilizer. Research 
is needed to determine if efficiency of FLC pre-processing by MF can be increased by treating leachate using BSFL and recycling it into fermentors for the duration of the process. Finally, research on practical implementation of BSFL leachate processing on a large-scale is essential for application of such biotechnology. 


\section{References}

Aiba, S., Shoda, M., \& Nagatani, M. (2000). Kinetics of product inhibition in alcohol fermentation. Biotechnology and Bioengineering, 67(6), 671-690.

Albers, D., Schaefer, M., \& Scheu, S. (2006). Incorporation of Plant Carbon into the Soil Animal Food Web of an Arable System. Ecology, 87, 235-245.

Atiyeh, R. M., Subler, S., Edwards, C. A., Bachman, G., Metzger, J. D., \& Shuster, W. (2000). Effects of vermicomposts and composts on plant growth in horticultural container media and soil. Pedobiologia, 44(5), 579-590.

Beckemeyer, R. J. (2008). Phylogeny of the Insecta.

Bell, H. L., \& Nebeker, A. V. (1969). Preliminary Studies on the Tolerance of Aquatic Insects to Low pH. Journal of the Kansas Entomological Society, 42(2), 230-236.

Bhattarai, S., Bhudhathoki, K., \& Sherchan, D. P. (2006). Organic Farming, Its Role in Soil Fertility, Effect on Crop Production, Constraints and Future Strategy (pp. 131137). Presented at the National Workshop on Organic Farming, Kirtipur, Kathmandu, Nepal.

BioCycle. (2008). Food Composting Infrastructure $::$ BioCycle, Advancing Composting, Organics Recycling \& Renewable Energy.

Blanco-Canqui, H., \& Lal, R. (2004). Mechanisms of Carbon Sequestration in Soil Aggregates. Critical Reviews in Plant Sciences, 23(6), 481-504.

Blenkinsop, S. (2012, February 1). Compost experiment.

Block, W., Baust, J. G., Franks, F., Johnston, I. A., \& Bale, J. (1990). Cold Tolerance of Insects and Other Arthropods [and Discussion]. Philosophical Transactions of the Royal Society of London. B, Biological Sciences, 326(1237), 613 -633.

Bokashicycle, LLC. (n.d.). Bokashi Composting Supplies, Bins and Fermenting Systems - Green Garbage to Great Soil.

Bonartseva, G. A., Myshkina, V. L., Nikolaeva, D. A., Kevbrina, M. V., Kallistova, A. Y., Gerasin, V. A., Iordanskii, A. L., et al. (2003). Aerobic and Anaerobic Microbial Degradation of Poly- $\beta$-Hydroxybutyrate Produced by Azotobacter chroococcum. Applied Biochemistry and Biotechnology, 109(1-3), 285-302.

Bradley, S. W., \& Sheppard, D. C. (1984). House fly oviposition inhibition by larvae ofHermetia illucens, the black soldier fly. Journal of Chemical Ecology, 10(6), 853859.

Breitenbeck, G. A., \& Schellinger, D. (2004). Calculating the reduction in material mass and volume during composting. Compost science \& utilization, 12(4), 365-371.

Brown, S., Angle, J. S., \& Jacobs, L. (1998). Beneficial co-utilization of agricultural, municipal, and industrial by-products. Springer.

Butterly, C. R., Kaudal, B. B., Baldock, J. A., \& Tang, C. (2011). Contribution of soluble and insoluble fractions of agricultural residues to short-term $\mathrm{pH}$ changes RID G1362-2010. European Journal of Soil Science, 62(5), 718-727.

Campiglia, E., Mancinelli, R., \& Radicetti, E. (2011). Influence of no-tillage and organic mulching on tomato (Solanum Lycopersicum L.) production and nitrogen use in the mediterranean environment of central Italy. Scientia Horticulturae, 130(3), 588598. 
CED. (2010). Solid Waste and Waste Water Management. Thiruvananthapuram, India: Centre for Environment and Development.

Chakir, M., Capy, P., Genermont, J., Pla, E., \& David, J. R. (1996). Adaptation to Fermenting Resources in Drosophila melanogaster: Ethanol and Acetic Acid Tolerances Share a Common Genetic Basis. Evolution, 50, 767.

Cumar, S. K. M., \& Nagaraja, B. (2010). Environmental impact of leachate characteristics on water quality. Environmental Monitoring and Assessment, 178(14), 499-505.

David, J. R., \& Van Herrewege, J. (1983). Adaptation to alcoholic fermentation in Drosophila species: Relationship between alcohol tolerance and larval habitat. Comparative Biochemistry and Physiology Part A: Physiology, 74(2), 283-288.

Diacono, M., \& Montemurro, F. (2010). Long-term effects of organic amendments on soil fertility. A review. Agronomy for Sustainable Development, 30(2), 401-422.

Diclaro, J., \& Kaufman, P. (2009). EENY 461/IN830: Black soldier fly Hermetia illucens Linnaeus (Insecta: Diptera: Stratiomyidae) ( No. EENY 461). University of Florida (UF) Insitute of Food and Agricultural Sciences (IFAS) Extension.

DuBois, M., Gilles, K. A., Hamilton, J. K., Rebers, P. A., \& Smith, F. (1956). Colorimetric Method for Determination of Sugars and Related Substances. Analytical Chemistry, 28(3), 350-356.

Dukare, A. S., Prasanna, R., Chandra Dubey, S., Nain, L., Chaudhary, V., Singh, R., \& Saxena, A. K. (2011). Evaluating novel microbe amended composts as biocontrol agents in tomato. Crop Protection, 30(4), 436-442.

EcoSystem Corp. (2009, March 17). EcoSystem Unveils MAGFUEL ${ }^{\mathrm{TM}}$ Feedstock for Biodiesel | Business Wire.

Eisses, K., \& Boer, A. A. (1995). Acetic acid tolerance in Drosophila is a prerequisite for ethanol tolerance. Journal of Evolutionary Biology, 8(4), 481-491.

Eitzer, B. D. (1995). Emissions of Volatile Organic Chemicals from Municipal Solid Waste Composting Facilities. Environ. Sci. Technol., 29(4), 896-902.

Elamrani, A., \& Idaomar, M. (2001). Changes in enzymatic activity and behavioural responses during Drosophila melanogaster development: effects of environmental ethanol and acetic acid. Invertebrate Reproduction and Development, 40(2-3), 171180.

Erickson M.C., Islam M., Sheppard C., Liao J., \& Doyle M.P. (2004). Reduction of Escherichia coli O157:H7 and Salmonella enterica Serovar Enteritidis in Chicken Manure by Larvae of the Black Soldier Fly. Journal of Food Protection, 67(4), 685690.

Fernandez, F. J., Castro, M. C., Rodrigo, M. A., \& Canizares, P. (2011). Reduction of aeration costs by tuning a multi-set point on/off controller: A case study. Control Engineering Practice, 19(10), 1231-1237.

Fiance, S. B. (1978). Effects of $\mathrm{pH}$ on the Biology and Distribution of Ephemerella Funeralis (Ephemeroptera). Oikos, 31(3), 332-339.

Fluegel, W. (1981). Oviposition rhythm in Drosophila melanogaster is influenced by acetic acid. Journal of Insect Physiology, 27(10), 705-710. 
Fry, J. (2001). Direct and correlated responses to selection for larval ethanol tolerance in Drosophila melanogaster. Journal of Evolutionary Biology, 14(2), 296-309.

Geisseler, D., Horwath, W. R., Joergensen, R. G., \& Ludwig, B. (2010). Pathways of nitrogen utilization by soil microorganisms â€" A review. Soil Biology and Biochemistry, 42(12), 2058-2067.

Gibson, J. B., May, T. W., \& Wilks, A. V. (1981). Genetic variation at the alcohol dehydrogenase locus in Drosophila melanogaster in relation to environmental variation: Ethanol levels in breeding sites and allozyme frequencies. Oecologia, 51(2), 191-198.

Green, G., \& United States.;Oregon State University. (1982). Soil survey of Washington County, Oregon. [Washington D.C.]: U.S. Dept. of Agriculture Soil Conservation Service.

Green, T., \& Popa, R. (2010). A Simple Assay for Monitoring Cellulose in Paper-Spiked Soil. Journal of Polymers and the Environment, 18(4), 634-637.

Green, T., \& Popa, R. (2011). Endpoint Fragmentation Index: A Method for Monitoring the Evolution of Microbial Degradation of Polysaccharide Feedstocks. Applied Biochemistry and Biotechnology, 163(4), 519-527.

Hall, D., Gerhardt, R., Mullen, G., \& Durden, L. (2002). Flies (Diptera). Medical and veterinary entomology (pp. 127-161). Amsterdam ;;Boston: Academic Press.

Hartman, J. R., Dybas, L. K., \& Geer, B. W. (1993). At high dietary levels ethanol alters the structure of mid- and hindgut epithelial cells of Drosophila melanogaster larvae. Journal of Experimental Zoology, 267(4), 365-376.

Hellmann, B. (1997). Emission of Climate-Relevant Trace Gases and Succession of Microbial Communities during Open-Windrow Composting. Applied and environmental microbiology, 63(3), 1011-8.

Herbst, D. B., Conte, F. P., \& Brookes, V. J. (1988). Osmoregulation in an alkaline salt lake insect, Ephydra (Hydropyrus) hians Say (Diptera: Ephydridae) in relation to water chemistry. Journal of Insect Physiology, 34(10), 903-909.

Herrera, F., Castillo, J. E., Chica, A. F., \& Lapez Bellido, L. (2008). Use of municipal solid waste compost (MSWC) as a growing medium in the nursery production of tomato plants. Bioresource Technology, 99(2), 287-296.

Hicklenton, P. R., Rodd, V., \& Warman, P. R. (2001). The effectiveness and consistency of source-separated municipal solid waste and bark composts as components of container growing media. Scientia Horticulturae, 91(3-4), 365-378.

Ingham, E. (2008). How to grow crops that resist pest attacks? (2008).

Hoyle, F. C., \& Murphy, D. V. (2011). Influence of organic residues and soil incorporation on temporal measures of microbial biomass and plant available nitrogen. Plant and Soil, 347, 53-64.

Hubbe, M. A., Nazhad, M., \& Sanchez, C. (2010). Composting as a way to convert cellulosic biomass and organic waste into high-value soil amendments: A review. Bioresources, 5(4), 2808-2854.

Hudnell, H. K., Green, D., Vien, R., Butler, S., Rahe, G., Richards, B. A., \& Bleth, J. (2011). Improving wastewater mixing and oxygenation efficiency with solar- 
powered circulation. Clean Technologies and Environmental Policy, 13(5), 731742.

Hussain, T., Jilani, T., \& Tahir, S. H. (1995). Nature farming with EM technology for sustainable crops production in Pakistan (pp. 71-78). Presented at the Fourth international conference on Kyusei nature farming, France.

Jenkins, D. (1967). The differentiation, analysis and preservation of nitrogen and 262 phosphorus forms in natural waters. Adv. Chem. Ser., (73), 265-280.

Jeon, H., Park, S., Choi, J., Jeong, G., Lee, S.-B., Choi, Y., \& Lee, S.-J. (2011). The Intestinal Bacterial Community in the Food Waste-Reducing Larvae of Hermetia illucens. Current Microbiology, 62(5), 1390-1399.

Kalantari, S., Ardalan, M. M., Alikhani, H. A., \& Shorafa, M. (2011). Comparison of Compost and Vermicompost of Yard Leaf Manure and Inorganic Fertilizer on Yield of Corn. Communications in Soil Science \& Plant Analysis, 42(2), 123-131.

Kim, J.-N., Choo, J.-S., Wee, Y.-J., Yun, J.-S., \& Ryu, H.-W. (2005). Culture Medium Optimization for Acetic Acid Production by a Persimmon Vinegar-Derived Bacterium. Applied Biochemistry and Biotechnology, 123(1-3), 0861-0870.

Kone, S. B., Dionne, A., Tweddell, R. J., Antoun, H., \& Avis, T. J. (2010). Suppressive effect of non-aerated compost teas on foliar fungal pathogens of tomato. Biological Control, 52(2), 167-173.

Kumar, V., Brainard, D. C., Bellinder, R. R., \& Hahn, R. R. (2011). Buckwheat Residue Effects on Emergence and Growth of Weeds in Winter-Wheat (Triticum aestivum) Cropping Systems. Weed Science, 59, 567-573.

Lechleitner, R. A., Cherry, D. S., Cairns, J., \& Stetler, D. A. (1985). Ionoregulatory and toxicological responses of stonefly nymphs (Plecoptera) to acidic and alkaline $\mathrm{pH}$. Archives of Environmental Contamination and Toxicology, 14(2), 179-185.

Lee, C., Erickson, P., Lazarus, M., \& Smith, G. (2010). Greenhouse gas and air pollutant emissions of alternatives for woody biomass residues. Stockholm Environment Institute: Olympic Region Clean Air Agency (ORCAA).

Li, Q., Zheng, L., Cai, H., Garza, E., Yu, Z., \& Zhou, S. (2011). From organic waste to biodiesel: Black soldier fly, Hermetia illucens, makes it feasible. Fuel, 90(4), 15451548.

Liu, Q., Tomberlin, J. K., Brady, J. A., Sanford, M. R., \& Yu, Z. (2008). Black Soldier Fly (Diptera: Stratiomyidae) Larvae Reduce Escherichia coli in Dairy Manure. Environmental Entomology, 37(6), 1525-1530.

Maddox, I. (2000). The cause of "acid crash" and "acidogenic fermentation" during the batch acetone-butanol-ethanol (ABE-) fermentation process, 74(1), 3.

Marchesini, A., Allievi, L., Comotti, E., \& Ferrari, A. (1988). Long-term effects of quality-compost treatment on soil. Plant and Soil, 106, 253-261.

Maso, M. A., \& Blasi, A. B. (2008). Evaluation of composting as a strategy for managing organic wastes from a municipal market in Nicaragua. Bioresource Technology, 99(11), 5120-5124.

Mata-Alvarez, J., Mace, S., \& Llabres, P. (2000). Anaerobic digestion of organic solid wastes. An overview of research achievements and perspectives. Bioresource Technology, 74(1), 3-16. 
Mayer, J., Scheid, S., Widmer, F., Fliessbach, A., \& Oberholzer, H.-R. (2010). How effective are "Effective microorganisms (R) (EM)"? Results from a field study in temperate climate. Applied Soil Ecology, 46(2), 230-239.

Mehmood, M. K., Adetutu, E., Nedwell, D. B., \& Ball, A. S. (2009). In situ microbial treatment of landfill leachate using aerated lagoons. Bioresource Technology, 100(10), 2741-2744.

Meier-Ploeger, A., Duden, R., \& Vogtmann, H. (1989). Quality of food plants grown with compost from biogenic waste. Agriculture, Ecosystems \& Environment, 27(14), 483-491.

Miller, L. K., Lingg, A. J., \& Bulla, L. A. (1983). Bacterial, Viral, and Fungal Insecticides. Science, 219(4585), $715-721$.

Mono Lake Committee. (2012). About Mono Lake: Chemistry.

Montooth, K. L. (2006). Membrane lipid physiology and toxin catabolism underlie ethanol and acetic acid tolerance in Drosophila melanogaster. Journal of Experimental Biology, 209, 3837-3850.

Morales, G., \& Wolff, M. (2010). Insects associated with the composting process of solid urban waste separated at the source. Revista Brasileira De Entomologia, 54(4), 645653.

Myers, H. M., Tomberlin, J. K., Lambert, B. D., \& Kattes, D. (2008). Development of black soldier fly (Diptera : Stratiomyidae) larvae fed dairy manure. Environmental Entomo, 37(1), 11-15.

Najafpour, G., \& Lim, J. (2002). Evaluation and Isolation of Ethanol Producer Strain SMP-6. Presented at the Regional Symposium on Chemical Engineering.

Newton, L., Sheppard, C., Watson, D., Burtle, G., \& Dove, R. (2005). Using the black soldier fly, Hermetia illucens, as a value-added tool for the management of swine manure. Waste Management.

Nishio, M. (1996a). Microbial Fertilizers in Japan. Japan: National Institute of AgroEnvironmental Sciences.

Nishio, M. (1996b). Microbial Fertilizers in Japan. Japan: National Institute of AgroEnvironmental Sciences.

Omura, H., Honda, K., Asaoka, K., \& Inoue, T. A. (2008). Tolerance to fermentation products in sugar reception: gustatory adaptation of adult butterfly proboscis for feeding on rotting foods. Journal of Comparative Physiology A, 194(6), 545-555.

Osman, Y. A., \& Ingram, L. O. (1985). Mechanism of ethanol inhibition of fermentation in Zymomonas mobilis CP4. Journal of Bacteriology, 164(1), 173 -180.

Parsons, P., \& Spence, G. (1980). Larval Responses to Environmental Ethanol in Three Drosophila Species: an Indicator of Habitat Selection. Aust. J. Zool., 28(4), 543546.

Pecsenye, K., Bokor, K., Lefkovitch, L., Giles, B., \& Saura, A. (1997). Enzymatic responses of Drosophila melanogaster to long- and short-term exposures to ethanol. Molecular and General Genetics, 255(3), 258-268.

Perez, A., Céspedes, C., \& Núnez, P. (2008). Physical, chemical and biological characterization of applied organic amendments in crop production in Dominican Republic. Revista de la ciencia del suelo y nutrición vegetal, 8(3), 10-29. 
Peters, T. (1996). Alcohol Tolerance in Drosophila and You.

Pontin, G., Daly, M., \& Duggan, C. (n.d.). Disposal of Organic Kitchen Food Waste in the Canterbury/Christchurch Region of New Zealand with an EM-Bokashi Composting System. Garden City Composting.

Popa, R., \& Green, T. (2012). Using Black Soldier Fly Larvae (Hermetia illucens) for Processing Organic Leachates. Journal of Economic Entomology.

Qi, B. C., Aldrich, C., Lorenzen, L., \& Wolfaardt, G. W. (2005). Acidogenic fermentation of lignocellulosic substrate with activated sludge. Chemical Engineering Communications, 192(9), 1221-1242.

Rezende, A. M. F. A., Tomita, C. K., \& Uesugi, C. H. (2008). Cupric fungicides, benzalconium chlorides and liquid bioactive compost (Bokashi): phytotoxicity and control of guava bacterial blight caused by Erwinia psidii. Tropical Plant Pathology, 33(4), 288-294.

Ros, M., Klammer, S., Knapp, B., Aichberger, K., \& Insam, H. (2006). Long-term effects of compost amendment of soil on functional and structural diversity and microbial activity. Soil Use \& Management, 22(2), 209-218.

Safarik, I., \& Santruckova, H. (1992). Direct determination of total soil carbohydrate content. Plant and Soil, 143(1), 109-114.

Sans, C., Mata-Alvarez, J., Cecchi, F., Pavan, P., \& Bassetti, A. (1995). Volatile fatty acids production by mesophilic fermentation of mechanically-sorted urban organic wastes in a plug-flow reactor. Bioresource Technology, 51(1), 89-96.

Savard, T., Beaulieu, C., Gardner, N. J., \& Champagne, C. P. (2002). Characterization of spoilage yeasts isolated from fermented vegetables and Inhibition by lactic, acetic and propionic acids. Food Microbiology, 19(4), 363-373.

Scholz, H., Ramond, J., Singh, C. M., \& Heberlein, U. (2000). Functional Ethanol Tolerance in Drosophila. Neuron, 28(1), 261-271.

Sealey, W. M., Gaylord, T. G., Barrows, F. T., Tomberlin, J. K., McGuire, M. A., Ross, C., \& St-Hilaire, S. (2011). Sensory Analysis of Rainbow Trout, Oncorhynchus mykiss, Fed Enriched Black Soldier Fly Prepupae, Hermetia illucens. Journal of the World Aquaculture Society, 42(1), 34-45.

Sheppard, C. D., Tomberlin, J. K., Joyce, J. A., Kiser, B. C., \& Sumner, S. M. (2002). Rearing Methods for the Black Soldier Fly (Diptera: Stratiomyidae). Journal of Medical Entomology, 39(4), 695-698.

Simeone, M. (2001). The Biogeography of Mono Lake alkali fly (Ephydra hians). San Francisco State University Department of Geography.

Standeven, A. M. (1988). The Effect of Low pH and Elevated Aluminum Ion Concentration on the Growth and Mortality Rates of Damselfly Nymphs. Bios, 59(3/4), 72-78.

St-Hilaire, S., Sheppard, C., Tomberlin, J. K., Irving, S., Newton, L., McGuire, M. A., Mosley, E. E., et al. (2007). Fly Prepupae as a Feedstuff for Rainbow Trout, Oncorhynchus mykiss. Journal of the World Aquaculture Society, 38(1), 59-67.

Szczech, M., \& Smolinska, U. (2001). Comparison of Suppressiveness of Vermicomposts Produced from Animal Manures and Sewage Sludge against Phytophthora 
nicotianae Breda de Haan var. nicotianae. Journal of Phytopathology, 149(2), 7782.

Theunissen, J., Ndakidemi, P., \& Laubscher, C. (2010). Potential of vermicompost produced from plant waste on the growth and nutrient status in vegetable production. International Journal of the Physical Sciences, 5(13), 1964-1973.

Tomberlin, J. K., Adler, P. H., \& Myers, H. M. (2009). Development of the Black Soldier Fly (Diptera: Stratiomyidae) in Relation to Temperature. Environmental Entomology, 38(3), 930-934.

Tomberlin, J. K., \& Sheppard, D. (2002). Factors influencing mating and oviposition of black soldier flies (Diptera : stratiomyidae) in a colony. Journal of Entomological Science, 37(4), 345-352.

Tomberlin, J. K., Sheppard, D. C., \& Joyce, J. A. (2002). Susceptibility of Black Soldier Fly (Diptera: Stratiomyidae) Larvae and Adults to Four Insecticides. Journal of Economic Entomology, 95, 598-602.

Tyree, M. C., Seiler, J. R., \& Maier, C. A. (2011). Short-term impacts of soil amendments on belowground $\mathrm{C}$ cycling and soil nutrition in two contrasting Pinus taeda L. genotypes. Forest Ecology and Management, 262(8), 1473-1482.

US EPA, O. (2011). Organic Materials. Collections \& Lists.

US EPA, O. (n.d.). Basic Information | Composting. Overviews \& Factsheets.

USDA. (2011). USDA-NRCS Energy Consumption Awareness Tool: Tillage.

Yadav, V., \& Malanson, G. (2007). Progress in soil organic matter research: litter decomposition, modelling, monitoring and sequestration. Progress in Physical Geography, 31(2), 131-154.

Yan, P., \& Xu, H. (2002). Influence of EM bokashi on nodulation, physiological characters and yield of peanut in nature farming fields. Journal of Sustainable Agriculture, 19(4), 105-112.

Yu, G., Cheng, P., Chen, Y., Li, Y., Yang, Z., Chen, Y., \& Tomberlin, J. K. (2011). Inoculating Poultry Manure with Companion Bacteria Influences Growth and Development of Black Soldier Fly (Diptera: Stratiomyidae) Larvae. Environmental Entomology, 40(1), 30-35.

Zanon, M. J., Font, M. I., \& Jordá, C. (2011). Use of tomato crop residues into soil for control of bacterial wilt caused by Ralstonia solanacearum. Crop Protection, 30(9), $1138-1143$.

Zhang, W., Wang, H., Zhang, R., Yu, X.-Z., Qian, P.-Y., \& Wong, M. H. (2010). Bacterial communities in PAH contaminated soils at an electronic-waste processing center in China. Ecotoxicology, 19(1), 96-104.

Zhong, M., Kim, S.-J., \& Wu, C. (1999). Sensitivity of Drosophila Heat Shock Transcription Factor to Low pH. Journal of Biological Chemistry, 274(5), 3135 3140 . 